\title{
Estudo comparativo das respostas ergoespirométricas em esteira de solo versus subaquática
}

Tese apresentada à Faculdade de Medicina da Universidade de São Paulo para obtenção do titulo de Doutor em Ciência

Programa de Fisiopatologia Experimental

Orientador: Prof. Dr. Eduardo Massad 


\section{Estudo comparativo das respostas ergoespirométricas em esteira de solo versus subaquática}

Tese apresentada à Faculdade de Medicina da Universidade de São Paulo para obtenção do titulo de Doutor em Ciência

Programa de Fisiopatologia Experimental

Orientador: Prof. Dr. Eduardo Massad 
Dados Internacionais de Catalogação na Publicação (CIP)

Preparada pela Biblioteca da

Faculdade de Medicina da Universidade de São Paulo

CCreprodução autorizada pelo autor

\section{Garcia, Mauricio Koprowski}

Estudo comparativo das respostas ergoespirométricas em esteira de solo versus subaquática / Mauricio Koprowski Garcia. -- São Paulo, 2016.

Tese(doutorado)--Faculdade de Medicina da Universidade de São Paulo. Programa de Fisiopatologia Experimental.

Orientador: Eduardo Massad.

Descritores: 1.Teste de esforço 2.Imersão 3.Testes de função cardiaca 4.Testes de função respiratória 5.Doença das coronárias 6.Ergometria 7.Estudo comparativo

USP/FM/DBD-046/16 


\section{DEDICATÓRIA}

Aos meus queridos filhos, esposa, amigos e aos meus pais. 


\section{AGRADECIMENTOS}

A Maria Marcia, minha querida esposa, pelos cuidados com a família, pelo amor, apoio e por acreditar em minhas idéias e objetivos. Obrigada pela, compreensão, ajuda, carinho, orientação e pelo apoio em todas as horas. Aos meus filhos, que pacientemente toleraram as desculpas de eu não dispor de tempo para brincar e passear. Obrigada pelo amor incondicional. Aos meus pais, que me ensinaram que os maiores bens que se pode deixar para um filho são a educação, a cultura e o estudo.

Ao Prof. Dr. Eduardo Massad, pesquisador exemplar, por confiar na idéia, incansável apoio e orientação. A Profa. Dra. Linamara Rizzo Battistella, entusiasta incentivadora de inúmeros projetos de pesquisa, por seu comprometimento com o ensino, a assistência e a pesquisa, pelos preciosos ensinamentos e grandiosa contribuição. Ao Prof, Dr. Paulo Yasbek Junior valioso apoio técnico científico e parceria no campo experimental. Aos Diretores Chefes e colegas do Instituto de Medicina Física e Reabilitação IMREA, pela compreensão, pelo apoio, confiança e parceria. À equipe de enfermagem e auxiliares de enfermagem do IMREA Tatiana da Costa Oliveira, José Marcos da Silva e Ailton dos Santos Pereira, pala prontidão e ajuda incondicional na preparação dos pacientes e acompanhamento nos testes. A equipe de terapeutas do setor de reabilitação em piscina do IMREA unidade Vila Mariana: Fabíola Jomar da Silva, Denise Matheus, Daniela Montans, Andrea Capusso e em especial Daniela Mityio Odagiri Utyiama pela dedicação e empenho neste projeto. Aos instrutores Halliwick da Unidade Lapa, em especial a Edenilson Cordeiro Joares que, por seus esforços, permitiu minha concentração neste projeto. Aos voluntários do estudo, pela disposição, paciência e confiança. Sem vocês este estudo não se realizaria. Aos colegas e Professores do Curso de Pós-Graduação, pelos bons momentos, ensinamentos, alegria e amizade.

Ao Professor Sido Otto Koprowski por suas reflexões e orientações no campo educacional, pelo incentivo e equilíbrio. 
Aos meus amigos Clovis Menezes e Zdenko Herbet Kirsner pela constante motivação e aos colegas José Augusto Lopes e Gustavo Gorozo pela troca de idéias, questionamentos e conhecimentos.

A Deus, por todos os dias, por todas as horas, pelas pessoas que embarcam nas nossas vidas. 
SUMÁRIO

AGRADECIMENTOS

LISTAS DE ABREVIATURAS

LISTAS DE FIGURAS

LISTAS DE QUADROS

LISTA DE TABELAS

RESUMO

ABSTRACT

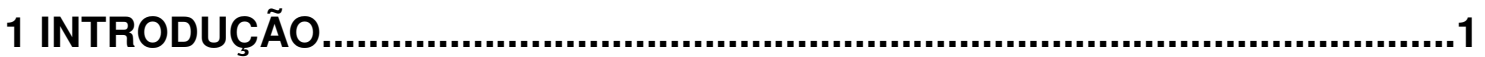

2 OBJETIVO

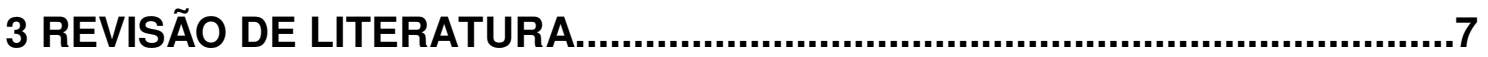

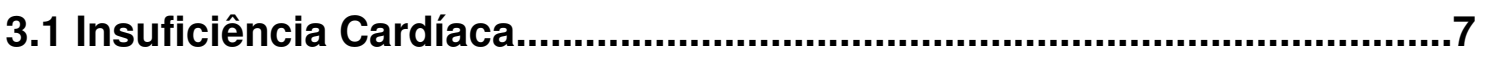

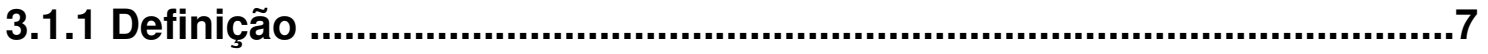

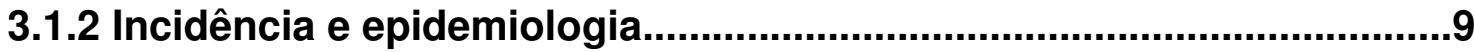

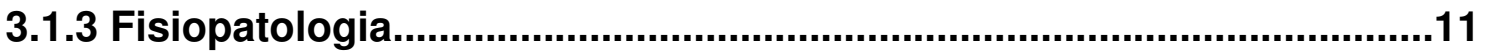

3.2 Testes Ergoespirométricos.....................................................................14

3. 2.1 Definição..................................................................................................14

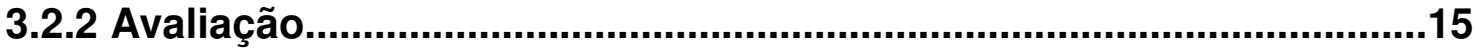

3.2.3 Indicações e Contra-indicações .........................................................16

3.2.3.1 Indicação

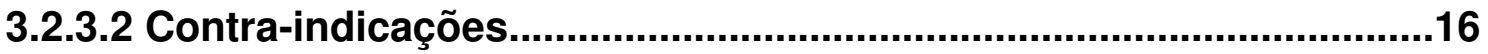

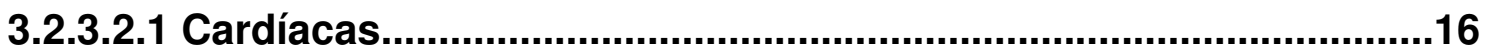

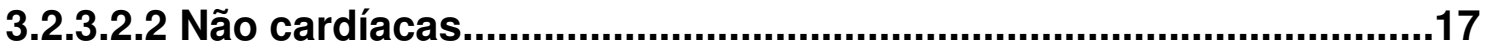


3.2.4 Critérios para suspensão do teste....................................................18

3.3 Ambiente para realização do exame no solo e na piscina.....................19

3.4 Equipamentos para realização do teste no solo e na água....................21

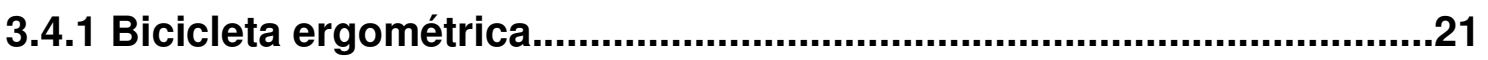

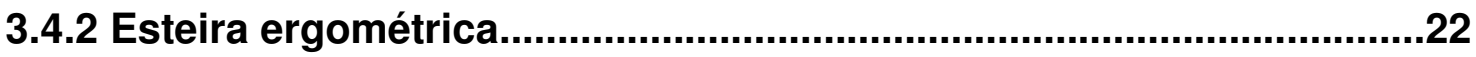

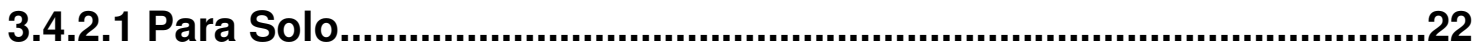

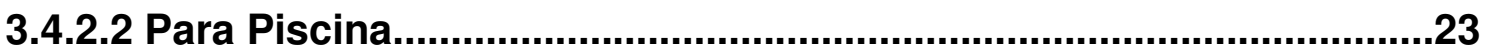

3.5 Aparelho para medida da ventilação....................................................25

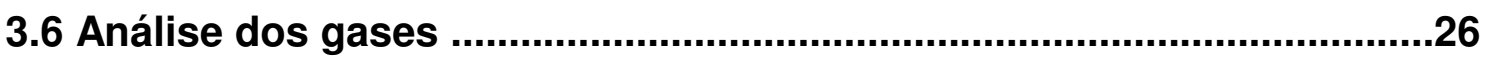

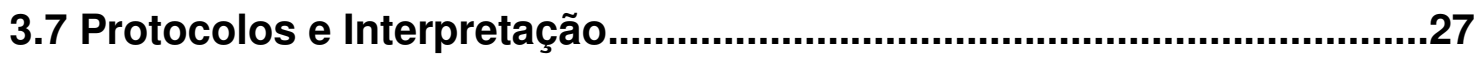

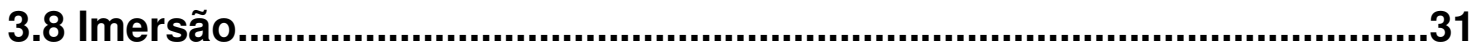

3.8.1 Propriedades físicas da água................................................................32

3.8.1.1 Propriedades estáticas da água (hidrostática).................................32

3.8.1.2 Propriedades dinâmicas da água (hidrodinâmicas).........................37

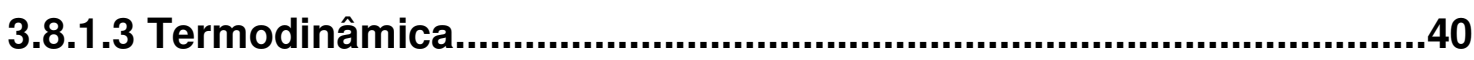

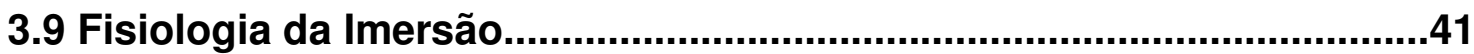

3.9.1 Efeitos no sistema pulmonar.............................................................

3.9.2 Efeitos nos sistemas renal e endócrino................................................42

3.9.3 Efeitos no sistema músculo-esquelético.............................................44

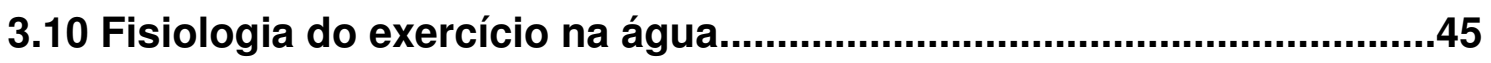

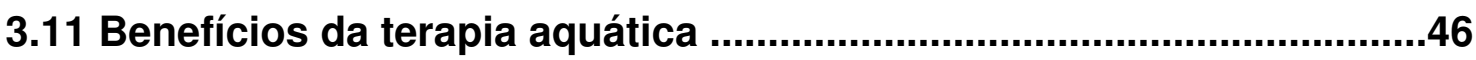

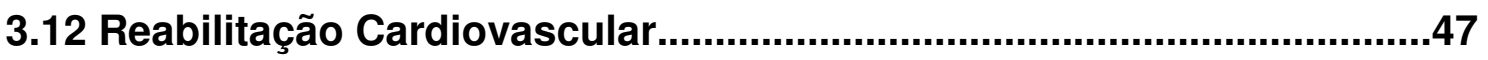

3.12.1 Recomendações para treinamento físico .........................................51

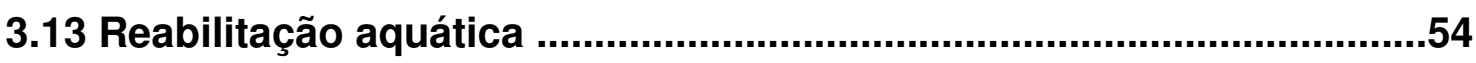

3.13.1 Condição Clínica...........................................................................54 


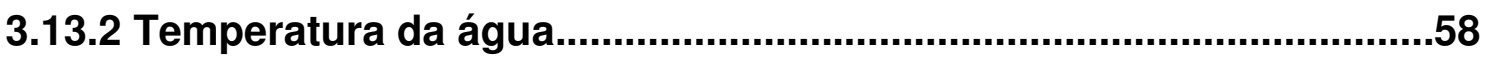

3.13.3 Nível de Imersão e Posicionamento...................................................61

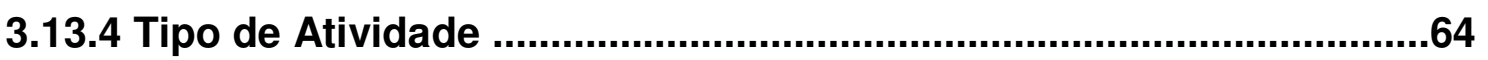

3.13.5 Duração da imersão e adaptação.......................................................66

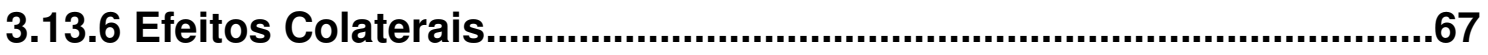

3.13.6.1 Edema pulmonar induzido por natação.........................................67

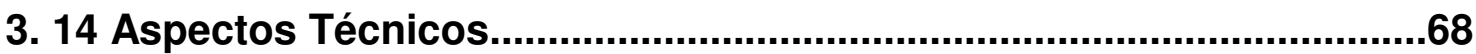

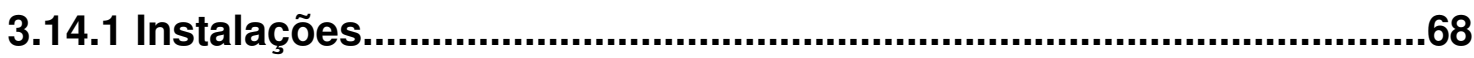

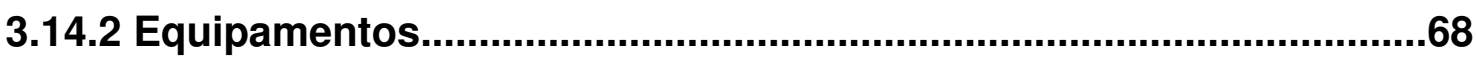

3.15 Técnicas empregadas em programas de terapias em piscina.............68

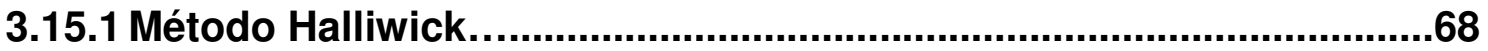

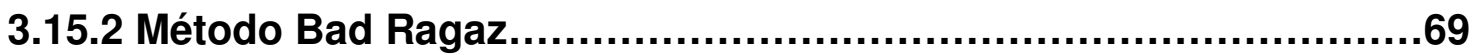

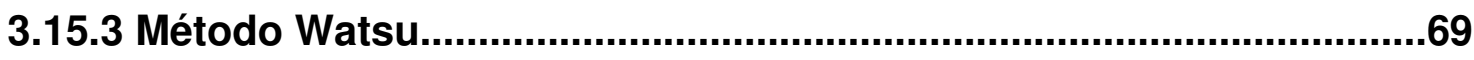

3.15.4 Hold / Relax - Prende / Solta.......................................................69

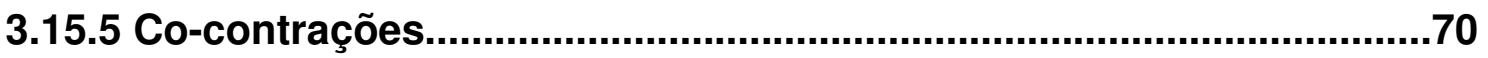

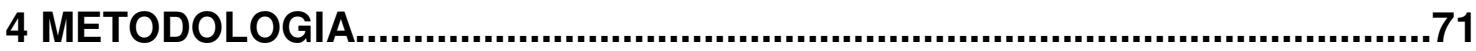

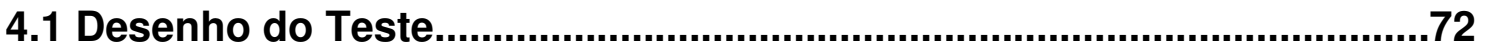

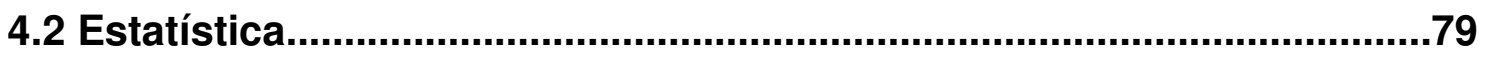

4.2.1 Analise de variância.......................................................................79

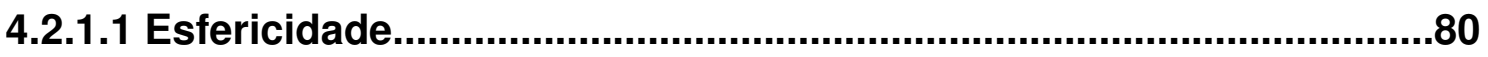

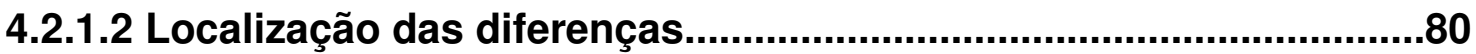

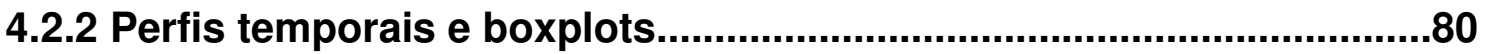

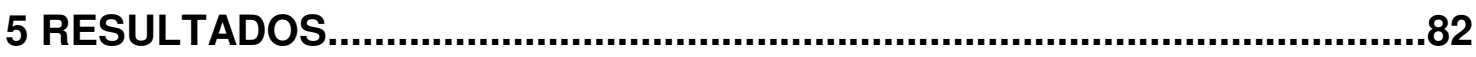

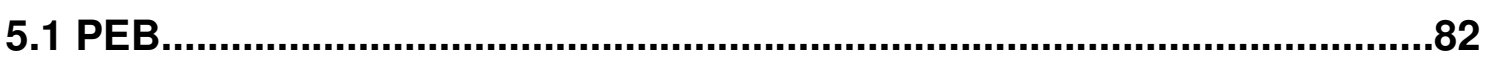

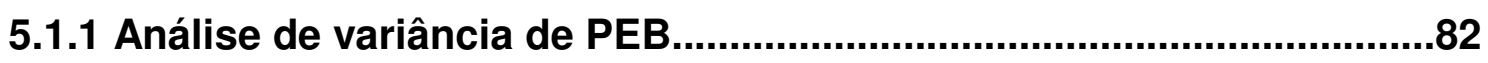


5.1.2 Teste de esfericidade de Mauchly para PEB......................................82

5.1.3 Correções de esfericidade para PEB...............................................83

5.1.4 Perfis e boxplots de PEB................................................................84

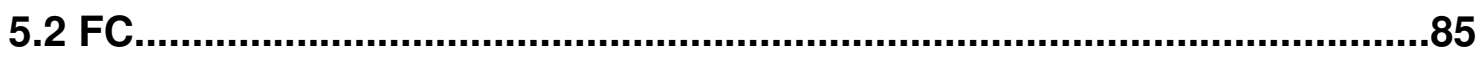

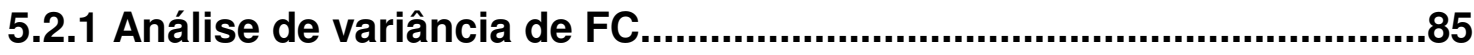

5.2.2 Teste de esfericidade de Mauchly para FC........................................86

5.2.3 Correções de esfericidade para FC.............................................87

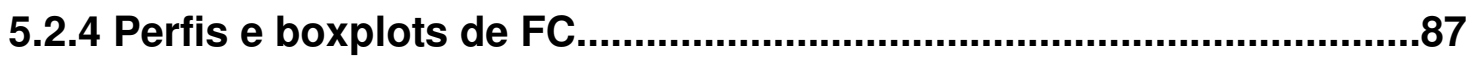

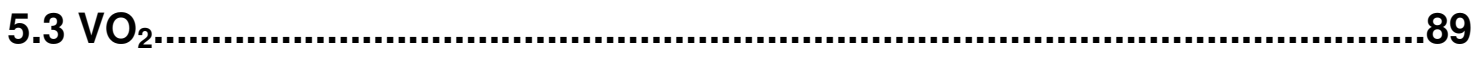

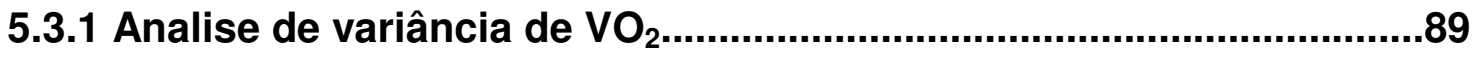

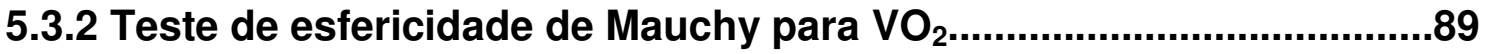

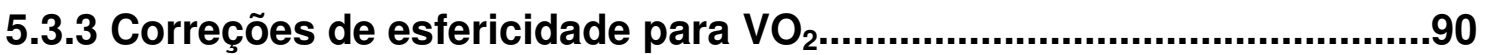

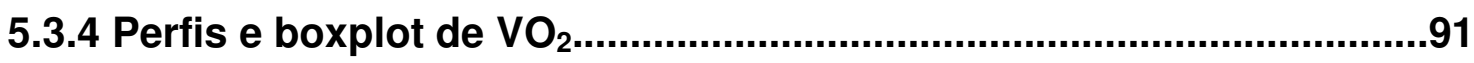

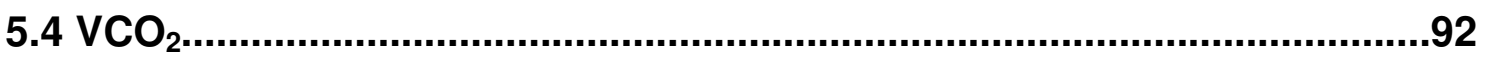

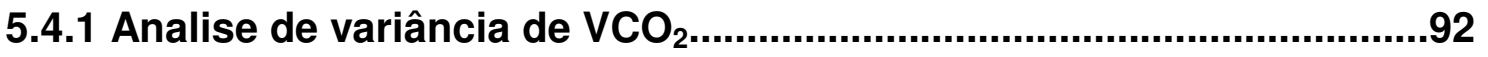

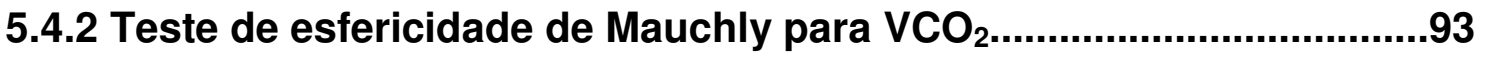

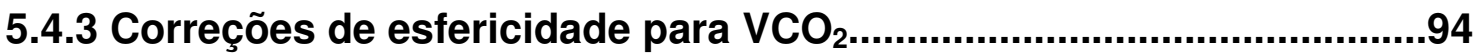

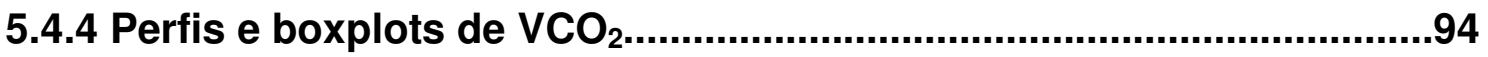

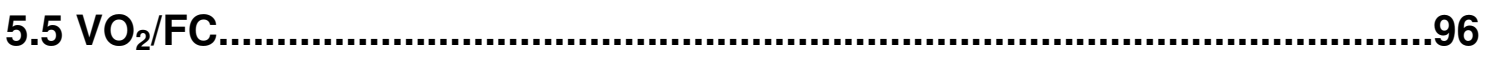

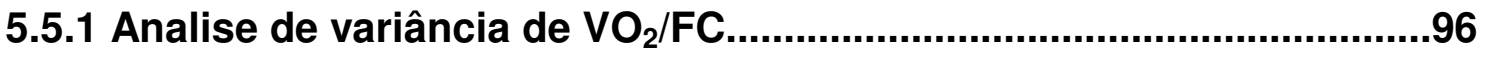

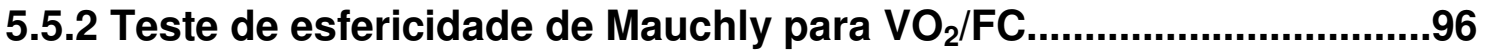

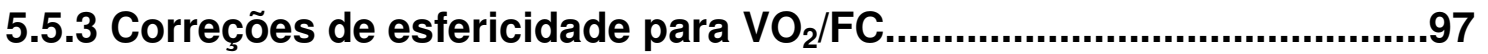

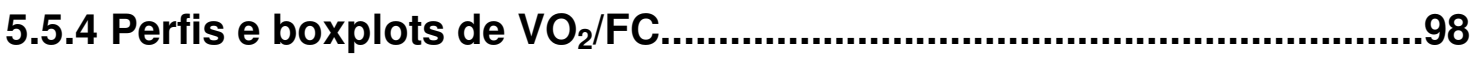

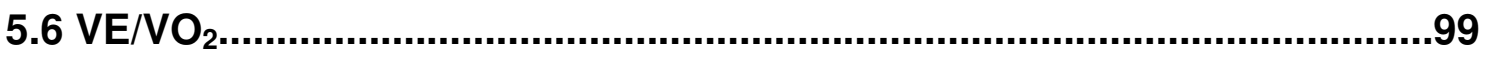

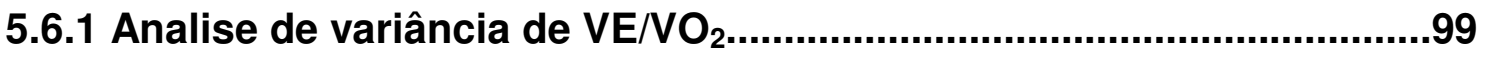




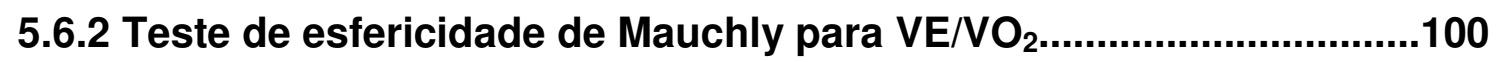

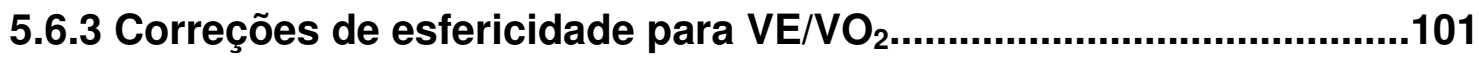

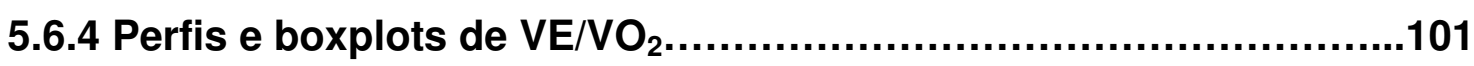

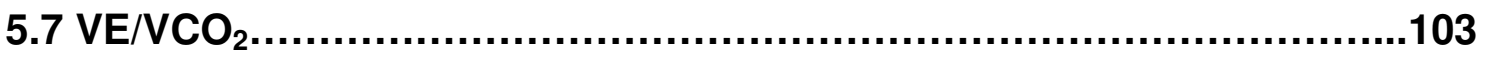

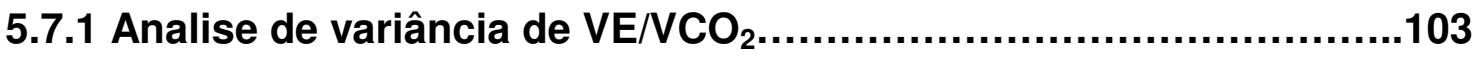

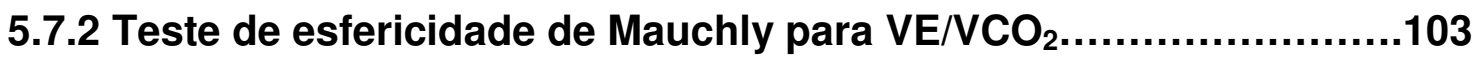

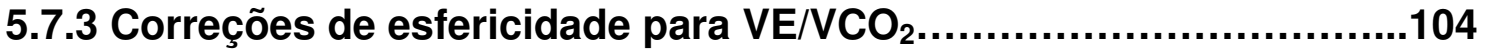

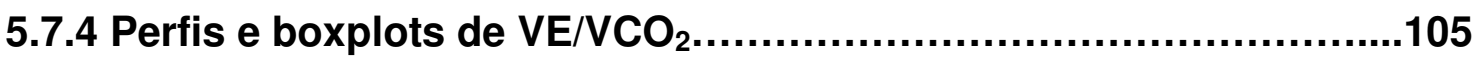

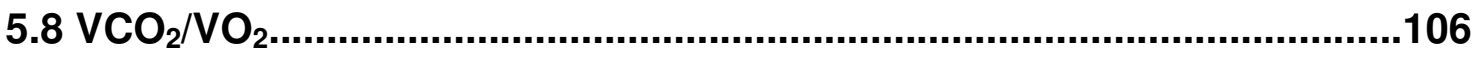

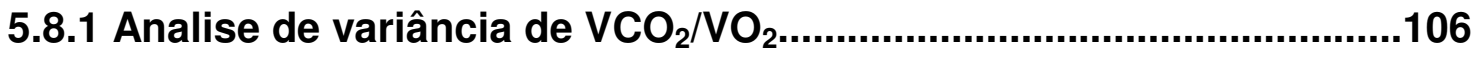

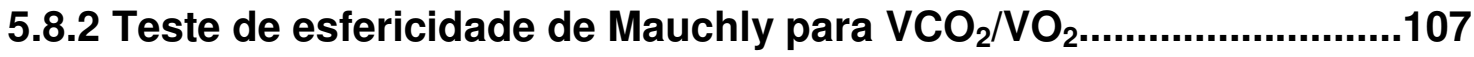

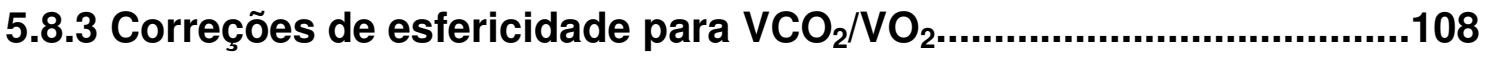

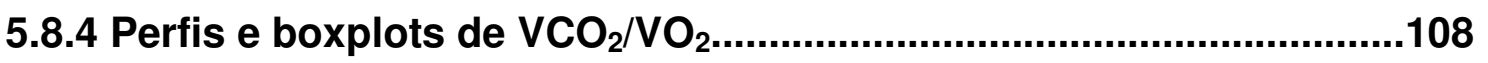

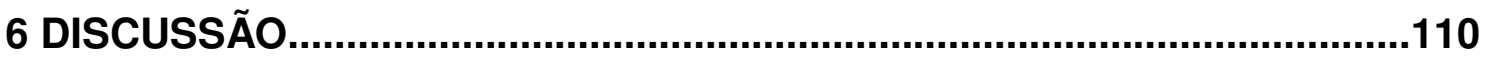

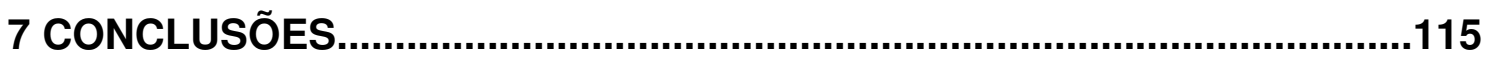

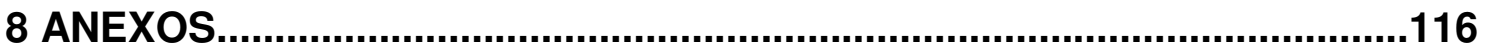

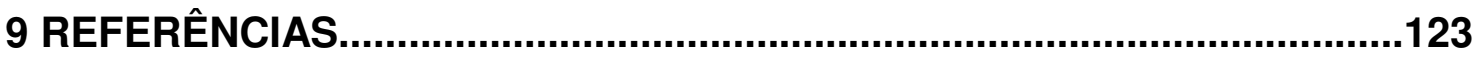

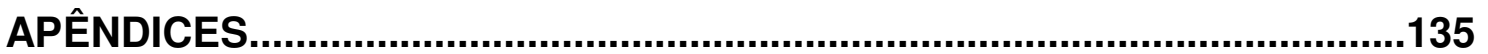




\section{LISTA DE ABREVIATURAS}

VFC $=$ variabilidade da frequência cardíaca

FC = frequência cardíaca

PAS = pressão arterial sistólica

PAD = pressão arterial diastólica

$\mathrm{FEO}_{2}=$ Frações expiradas de Oxigênio

$\mathrm{FECO}_{2}=$ Frações expiradas de Gás Carbônico

$\mathrm{VO}_{2}=$ Consumo de Oxigênio

$\mathrm{VCO}_{2}=$ Produção de Gás Carbônico

$\mathrm{VE} / \mathrm{VO}_{2}=$ Equivalentes Ventilatórios do Oxigênio

$\mathrm{VE} / \mathrm{VCO}_{2}=$ Equivalentes Ventilatórios do Gás Carbônico

$\mathrm{VO}_{2} / \mathrm{FC}=$ Pulso de Oxigênios

$\mathbf{R Q}$ ou $\mathbf{R}=\mathrm{VCO}_{2} / \mathrm{VO}_{2}=$ Quociente Respiratório

ECG $=$ Eletrocardiograma

CM5 - D2M - V2m = Derivação do ECG 


\section{LISTA DE FIGURAS}

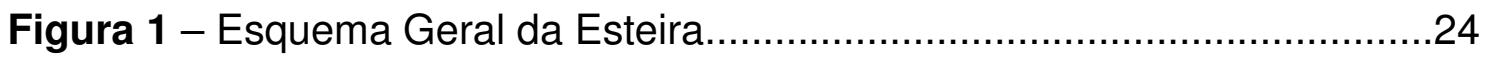

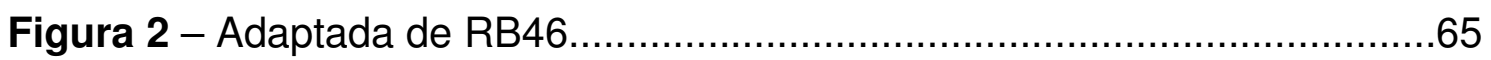

Figura 3 - Teste realizado em esteira no solo............................................76

Figura 4 - Testes realizados em uma esteira subaquática sob supervisão do

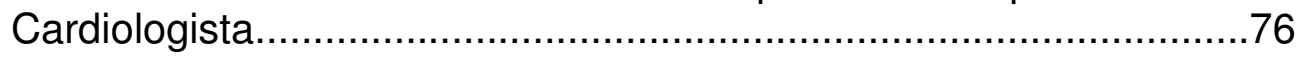

Figura 5 - Dados coletados em 5 momentos, tanto em solo quanto em imersão.

Figura 6 -Perfil da amostra para a variável PEB por tempo de teste, medido em minutos e segundos.

Figura 7 - Perfis médios da amostra para a variável PEB.............................84

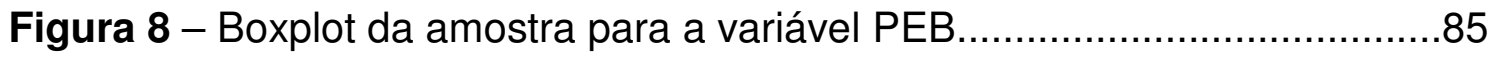

Figura 9 - Perfil da amostra para a variável FC por tempo de teste, medido em minutos e segundos.

Figura 10 - Perfis médios da amostra para a variável FC..............................88

Figura 11 - Boxplots da amostra para variável FC.........................................8

Figura 12 - Perfil da amostra para a variável $\mathrm{VO}_{2}$ por tempo de teste, medido em minutos e segundos..............................................................91

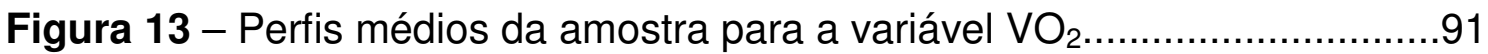

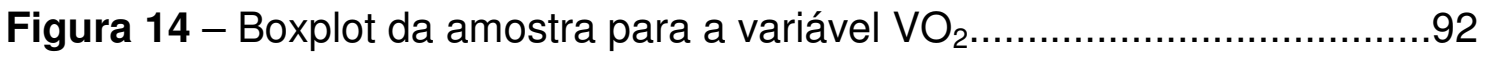

Figura 15 - Perfil da amostra para a variável $\mathrm{VCO}_{2}$ por tempo de teste, medido em minutos e segundos............................................................94

Figura 16 - Perfis médios da amostra para a variável $\mathrm{VCO}_{2} \ldots \ldots \ldots \ldots \ldots \ldots \ldots \ldots \ldots . . . .95$

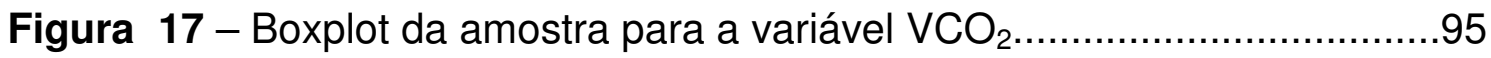

Figura 18 - Perfil da amostra para a variável $\mathrm{VO}_{2} / \mathrm{FC}$ por tempo de teste, medido em minutos e segundos....................................................98

Figura 19 - Perfis médios da amostra para a variável $\mathrm{VO}_{2} / \mathrm{FC} \ldots \ldots \ldots \ldots \ldots \ldots \ldots \ldots . . .98$ 
Figura 20 - Boxplot da amostra para a variável $\mathrm{VO}_{2} / \mathrm{FC}$

Figura 21 - Perfil da amostra para a variável $\mathrm{VE} / \mathrm{VO}_{2}$ por tempo de teste, medido em minutos e segundos.

Figura 22 - Perfis médios da amostra para a variável $\mathrm{VE} / \mathrm{VO}_{2} \ldots \ldots \ldots \ldots \ldots \ldots \ldots \ldots . . . . .102$

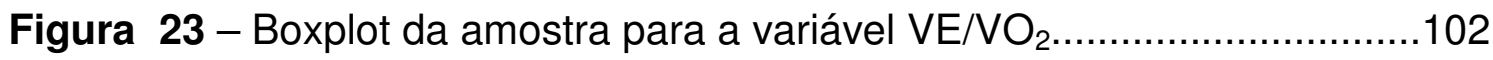

Figura 24 - Perfil da amostra para a variável $\mathrm{VE} / \mathrm{VCO}_{2}$ por tempo de teste, medido em minutos e segundos.............................................105

Figura 25 - Perfis médios da amostra para a variável VE/ $\mathrm{VCO}_{2} \ldots \ldots \ldots \ldots \ldots \ldots \ldots . . .105$

Figura 26 - Boxplot da amostra para a variável VE/ $\mathrm{VCO}_{2} \ldots \ldots \ldots \ldots \ldots \ldots \ldots \ldots \ldots \ldots . . . . .106$

Figura 27 - Perfil da amostra para a variável $\mathrm{VCO}_{2} / \mathrm{VO}_{2}$ por tempo de teste, medido em minutos e segundos.................................................108

Figura 28 - Perfis médios da amostra para a variável $\mathrm{VCO}_{2} / \mathrm{VO}_{2} \ldots \ldots \ldots \ldots \ldots \ldots . . .109$

Figura 29 - Boxplot da amostra para a variável $\mathrm{VCO}_{2} / \mathrm{VO}_{2} \ldots \ldots \ldots \ldots \ldots \ldots \ldots \ldots \ldots . . . . .109$ 


\section{LISTA DE QUADROS}

Quadro 1 - Critérios da New York Heart Association....................................

Quadro 2 - Índice de percepção de esforço de Borg........................................20

Quadro 3 - Fundamentos para a prescrição de exercícios...................................53 


\section{LISTA DE TABELAS}

Tabela 1 - Recomendações para atividade física em pacientes cardiopatas*

Tabela 02 - Alterações cardiovasculares e hormonais com imersão a $32^{\circ}$, $20^{\circ} \mathrm{e} 14^{\circ} \mathrm{C}$.

Tabela 3 - Resumo das alterações cardiovasculares à imersão em água a $30^{\circ} \mathrm{e} 34.5^{\circ} \mathrm{C}$ (repouso).

Tabela 4 - Características de base dos sujeitos. .72

Tabela 5 - Protocolo de Bruce - o estágio muda a cada 3 minutos.....................74

Tabela 6 - Percepção Subjetiva de Esforço de Borg.........................................74

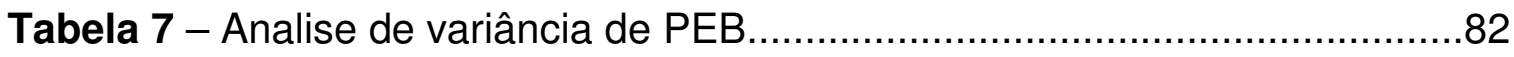

Tabela 8 - Teste de Esfericidade de Mauchly para PEB...................................83

Tabela 9 - Correções de esfericidade para PEB ...............................................

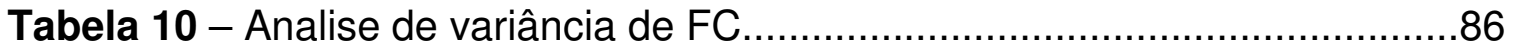

Tabela 11 - Teste de esfericidade de Mauchly para FC..................................86

Tabela 12 - Correções de esfericidade para FC.............................................87

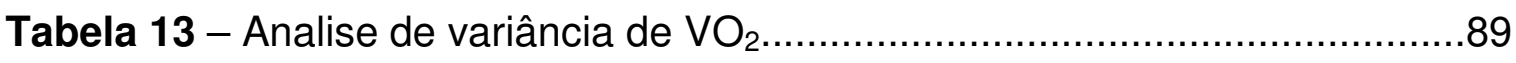

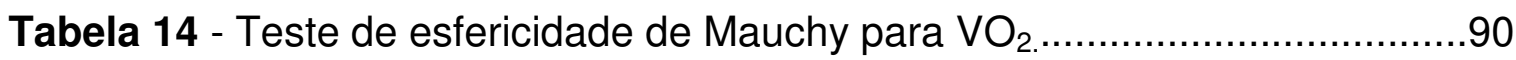

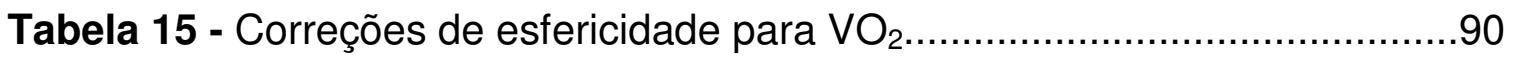

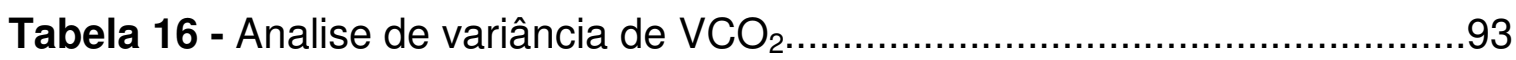

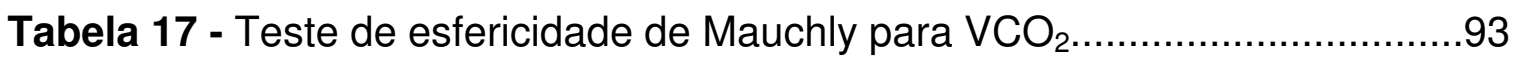

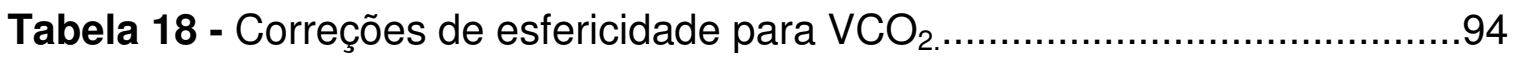

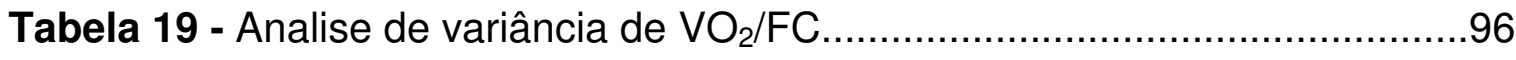

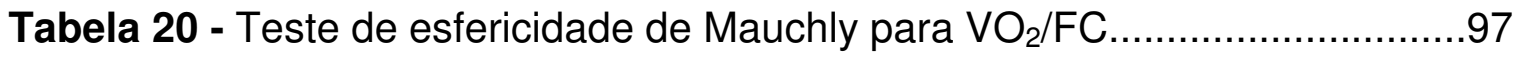

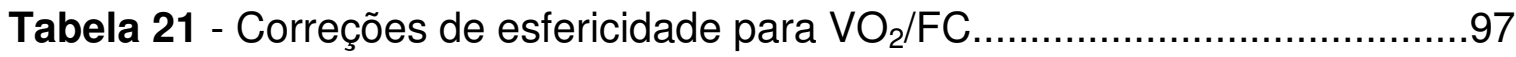




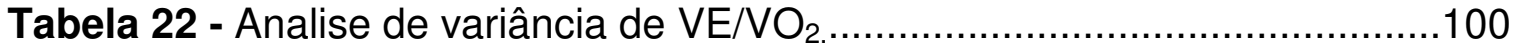

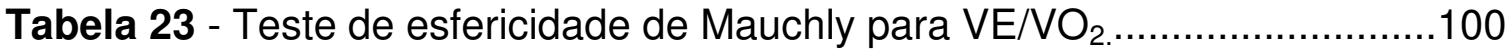

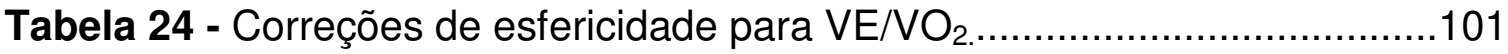

Tabela 25 - Analise de variância de VE/ $\mathrm{VCO}_{2} \ldots \ldots \ldots \ldots \ldots \ldots \ldots \ldots \ldots \ldots \ldots \ldots \ldots \ldots \ldots \ldots \ldots . . . . .103$

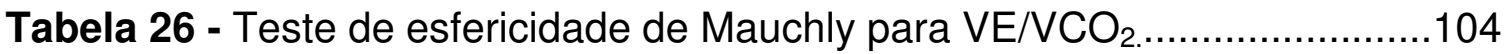

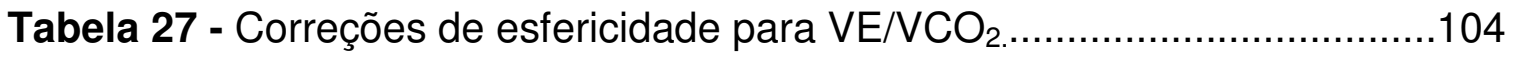

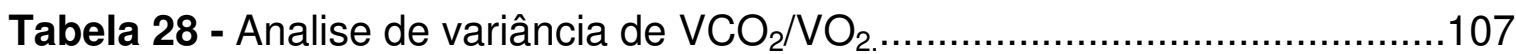

Tabela 29 - Teste de esfericidade de Mauchly para $\mathrm{VCO}_{2} / \mathrm{VO}_{2} \ldots \ldots \ldots \ldots \ldots \ldots \ldots \ldots . . . .107$

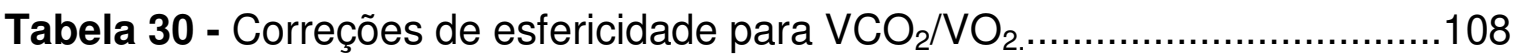


Garcia, M.K. Estudo comparativo das respostas ergoespirométricas em esteira de solo versus subaquática [Tese]. São Paulo: Faculdade de Medicina, Universidade de São Paulo; 2016.

OBJETIVOS: Comparar as respostas do Teste de Esforço Cardiopulmonar (TECP) em imersão, numa esteira subaquáticas, com as de solo; investigar e entender o desempenho cardiorrespiratório de coronariopatas (DAC) durante esforço em imersão comparando-os aos do grupo de indivíduos saudáveis. Entender os procedimentos, materiais e equipamentos necessários na realização do teste em imersão e na coleta de dados reprodutíveis e confiáveis. MÉTODOS: O estudo contou com 40 indivíduos, sendo: 20 pacientes com diagnóstico médico de DAC, 63,7 $\pm 8,89$ anos de idade e classificação I e II segundo New York Heart Association (NYHA) e 20 sujeitos saudáveis, 64,7 $\pm 7,09$ anos; realizaram dois testes ergoespirométricos em uma instalação equipada com esteira no solo, piscina aquecida, esteira subaquática, analisador de gases e Eletrocardiograma (ECG). Foi calculado o Poder Estatístico do teste para ANOVA com erro $\beta$ de 0.861 . Por ser um exame normatizado tecnicamente e reconhecidamente seguro, o primeiro teste foi realizado em esteira no solo de 3 a 7 dias deste, o segundo teste foi realizado em esteira subaquática com imersão ao nível do manúbrio, em uma piscina com temperatura controlada entre 33 e $34^{\circ} \mathrm{C}$. Os dados foram coletados em 5 momentos expressivos: 1- Repouso; 2- Limiar Anaeróbio; 3- Ponto de Compensação Respiratória; 4- Esforço Máximo e 5- Recuperação. RESULTADOS: A análise de variância deste estudo revelou haver efeito principal para DAC nas variáveis: $\mathrm{FC}, \mathrm{VO}_{2}$ e $\mathrm{VCO}_{2} ;(p>0.01)$ em relação ao ambiente. $\mathrm{O}$ teste em imersão apresentou significância nas variáveis $\mathrm{FC}, \mathrm{VO}_{2}, \mathrm{VCO}_{2}$ e $\mathrm{VO}_{2} / \mathrm{FC}$ $(p>0.01)$. As interações com estágio caracterizam o comportamento dos sujeitos ao longo do experimento e neste contexto, as variáveis $\mathrm{PEB}, \mathrm{FC}, \mathrm{VO}_{2}, \mathrm{VCO}_{2} \mathrm{e}$ $\mathrm{VO}_{2} / \mathrm{FC}(\mathrm{p}>0.01)$ mostraram interações significantes entre estágio e ambiente. Em adição, há interação significante entre etiologia e estágio para as variáveis $\mathrm{FC}$, $\mathrm{VO}_{2}$ e $\mathrm{VCO}_{2}(p>0.01)$. DAC e saudáveis possuem comportamentos diferentes no decorrer dos estágios do experimento em relação a estas variáveis. Alterações eletrocardiográficas compatíveis com isquemia miocárdica ou arritmia não foram observadas e a Pressão Arterial Sistólica e Diastólica (PAS/D) não se alterou significativamente. Os indivíduos deste estudo tiveram percepção de esforço na Escala de Borg menor na água em todos os estágios do que em terra $(p>0.01)$. CONCLUSÃO: Os achados deste estudo mostram que os procedimentos operacionais, materiais e equipamentos utilizados no TECP em piscina produziram dados reprodutíveis, confiáveis e que atenderam as determinações estabelecidas no "Clinician's Guide to Cardioplulmonary Exercice Testing in Adults". O esforço foi bem tolerado por todos os participantes, sem ocorrência de evento adverso. As diferenças estatísticas observadas nos testes na água contra os de solo nos levam a entender que o exercício em imersão pode ser realizado por pacientes com DAC e que os efeitos fisiológicos da imersão não causam qualquer risco para este grupo. Conclui-se também que por ser reprodutível e confiável, o teste em imersão pode ser adotado para prognosticar capacidades individuais de pacientes coronariopatas ao exercício dinâmico em piscina. 
Descritores: teste de esforço; imersão; testes de função cardíaca; testes de função respiratória; doença das coronárias; ergometria; estudo comparativo. 
Garcia, M.K. Comparative study of ergospirometric parameters responses on land versus underwater treadmill exercise testes [Thesis]. São Paulo: Faculdade de Medicina, Universidade de São Paulo; 2016.

OBJECTIVES: To compare responses to a Cardiopulmonary Exercise Test (CPX) conducted in water, (on a underwater treadmill), with the responses to the same tests conducted on land, (on a land treadmill); to investigate and assess the cardiorespiratory performance of coronary artery disease (CAD) patients while immersed in warm water when compared to the performance of healthy individuals; to assess the procedures, feasibility, resources and equipment required for conducting a CPX in individuals in water so as to collect reliable and replicable data. METHODS: The sample was comprised by 40 subjects, 20 of whom diagnosed with coronary artery disease (CAD) and aged $63.7 \pm 8.89$, functional class I and II (in compliance with the New York Heart Association [NYHA]), and 20 healthy subjects aged $64.7 \pm 7.09$. Two CPX tests were conducted in a facility equipped with a land treadmill, a warm pool, an underwater treadmill, a gas analyzer and an electrocardiogram (ECG) device. The statistical significances were calculated through a ANOVA test with $(1-\beta)$ power of 0.861 . As CPX is technically regulated and acknowledged as safe the first test was conducted on a land treadmill and the second test was conducted 3-7 days later on an underwater treadmill. Subjects were submerged in a temperature-controlled pool $\left(33-34^{\circ} \mathrm{C}\right)$ with water at manubrium level. Data were collected at 5 relevant test stages or cardiorespiratory levels: 1- Rest; 2Anaerobic Threshold (AT); 3- Respiratory Compensation Point (RCP); 4Maximum Effort (ME); and 5- Recovery (R). FINDINGS: ANOVA analysis showed a major significance for $\mathrm{CAD}$ subjects regarding variables $\mathrm{HB}, \mathrm{VO}_{2}$ and $\mathrm{VCO}_{2} \quad(p<0.01)$ in relation to the environment. The test performed with submerged patients showed some significance for variables $\mathrm{HB}, \mathrm{VO}_{2}, \mathrm{VCO}_{2}$ and $\mathrm{VO}_{2} / \mathrm{HB} \quad(p<0.01)$. The stages for data collected featured the subjects performance throughout this experiment, and within the given context, variables $\mathrm{RPE}, \mathrm{HB}, \mathrm{VO}_{2}, \mathrm{VCO}_{2}$ and $\mathrm{VO}_{2} / \mathrm{HB}(\mathrm{p}<0.01)$ showed significant interactions between test stage and environment. Additionally, there was a significant interaction between the etiology and the test stage for variables $\mathrm{HB}, \mathrm{VO}_{2}$ and $\mathrm{VCO}_{2} \quad(p<0.01)$. CAD patients and healthy subjects showed different performances throughout the test stages in relation to the referred variables. Electrocardiographic (ECG) changes that are compatible with myocardial ischemia or arrhythmia were not observed. Systolic and diastolic blood pressure (SDBP) did not show significant changes. The subjects of this study showed lower rates of Borg's perceived exertion scale in the water than at every one of the test stages on land $(p<0.01)$. CONCLUSION: This study show that the procedures, resources and equipment used during CPX conducted in a warm pool demonstrated to be feasible and yielded replicable and reliable data, which complied with the provisions of the "Clinician's Guide to Cardiopulmonary Exercise Testing in Adults". The effort exerted was well tolerated by all the participants without any adverse events. Statistical differences observed in water versus on land allow us to conclude that patients with CAD are able to carry out physical activities in water and that the physiological effects of immersion do not present any risk for such patients. We may also conclude that given its replicability and reliability, CPX conducted in water may be used to 
diagnose and to estimate the exertion capability of CAD patients to perform dynamic exercise in a warm pool.

Descriptors: exercise test; immersion; heart function tests; respiratory function tests; coronary disease; ergometry; comparative study. 


\section{INTRODUÇÃO}

O uso da água para fins terapêuticos, sociais ou religiosos data das mais antigas civilizações conhecidas e de diferentes localizações geográficas: Mesopotâmia, Egito, Índia e China. O banho individual tinha finalidade de cuidado com a saúde e o corpo; o banho social era uma atividade relaxante, restauradora e central ${ }^{1}$. A água é um meio muito diferente do solo. Ao ser inserido neste meio, o corpo humano é submetido a diferentes forças físicas e, em consequência, realiza uma série de adaptações fisiológicas que se estendem sobre todos os sistemas homeostáticos. Tais efeitos podem ser tanto imediatos como tardios, permitindo que a água seja utilizada de maneira eficaz no processo de reabilitação dos mais diversos problemas, como: patologias músculoesqueléticas, neurológicas, cardíacas e pulmonares, entre outras. A atividade física em água termoneutra $\left(31\right.$ a $\left.33,3^{\circ} \mathrm{C}\right)$ é tradicionalmente utilizada em instituições de reabilitação para tratamento de diferentes patologias, uma vez que exercícios para melhora da mobilidade, força e condicionamento físico podem ser facilmente realizados na água ${ }^{2}$.

Ao entrar na água ocorre, no corpo humano, vasoconstrição momentânea (reflexo do mergulho) com elevação da resistência periférica e consequente aumento na pressão arterial. Contudo, durante a imersão em água aquecida, o corpo ganha calor (por condução) e ocorre vasodilatação sistêmica, reduzindo a resistência periférica e consequente queda na pressão arterial. A perda do calor se dá pela pele (sangue nos vasos cutâneos) e nas glândulas sudoríparas das regiões fora da água, também pela respiração. Imersa a $33,3^{\circ} \mathrm{C}$, a pele se 
aquece e vasos superficiais se dilatam, aumentando o suprimento sanguíneo periférico. O retorno venoso e linfático se baseia em um sistema de válvulas que não permitem o refluxo e atuam dividindo a longa coluna líquida em colunas curtas, reduzindo assim, o gradiente de pressão dentro dos vasos. O retorno venoso e linfático é sensível a alterações externas de pressão, inclusive compressão por músculos vizinhos e pressão da água. A pressão hidrostática comprime as veias superficiais e desloca o sangue para cima através do sistema de válvulas unidirecional: primeiro para as coxas, então abdome, tórax e coração. Na imersão até a crista ilíaca, as alterações de volume não são significativas. A pressão venosa central começa a se alterar com imersão até o xifoide e aumenta até a imersão total ${ }^{3}$. Arborelius et al. $^{4}$, em 1972, demonstraram que na imersão até o pescoço ocorre aumento do volume sanguíneo central em $700 \mathrm{ml}$ que representa acréscimo de $60 \%$ no volume central. Desse volume, um quarto, ou seja, 180 a $240 \mathrm{ml}$ são direcionados para o coração o que provoca dilatação das quatro câmaras ${ }^{4,5,6}$. O volume cardíaco aumenta em 27 a 30\% com imersão até o pescoço ${ }^{7}$. Mas o coração não é um receptáculo estático. A resposta cardíaca fisiológica ao aumento do volume é aumentar a força de contração: à medida que ocorre distensão do miocárdio saudável, melhor será a eficiência de contração muscular segundo a Lei de Frank Starling ${ }^{3}$. A maior parte das alterações cardiovasculares depende da temperatura e nível de imersão. Observa-se um aumento progressivo do débito cardíaco quando se eleva a temperatura: o aumento pode variar de $30 \%$ a $33^{\circ} \mathrm{C}$ até $121 \%$ a $39^{\circ} \mathrm{C}^{7}$. O volume sistólico é um dos fatores determinantes na elevação do débito cardíaco que ocorre com o treinamento. Há uma relação significativa entre temperatura e frequência cardíaca: a $25^{\circ} \mathrm{C}$, ocorre redução de 12 a 15 batimentos/min, a temperaturas termoneutras, a redução é de cerca de $15 \%$ e em água quente, constata-se um aumento significativo na frequência cardíaca e, consequentemente, no débito cardíaco. 
Uma vez que essa alteração no volume sanguíneo central pode sobrecarregar os mecanismos cardiovasculares adaptativos em pacientes com insuficiência cardíaca e ocasionar descompensação do ventrículo esquerdo, vários autores recomendam que pacientes com disfunção diastólica e sistólica evitem a natação ${ }^{8,9,10}$. Por outro lado, a imersão em água termoneutra desencadeia respostas fisiológicas que podem ser benéficas para pacientes com insuficiência cardíaca.

Diversos estudos validaram o uso de terapia aquática na reabilitação cardiovascular após infarto e cardiomiopatia isquêmica. Durante a imersão até o pescoço, a resistência vascular sistêmica diminui em $30 \%$ devido à redução na vasoconstrição simpática e se mantém baixa por algumas horas após a primeira hora de imersão. Esse efeito também é temperatura-dependente, quanto maior a temperatura, maior a redução ${ }^{4,3}$. Segundo Gianuzzi et al. $^{8}$, em 2001, a imersão prolongada reduz significativamente a pressão arterial média, sendo que pacientes hipertensos sensíveis ao sódio demonstraram maior redução (18 a 20mmHg) do que os normotensos e pacientes não sensíveis ao sódio ${ }^{11}$. Outros estudos não demonstraram alteração significativa na pressão arterial sistólica e média ${ }^{2,12,}$ 13,14 .

O fluxo sanguíneo pulmonar eleva-se com o aumento do volume e pressão sanguínea central. A pressão média da artéria pulmonar varia de $5 \mathrm{mmHg}$ no solo para $22 \mathrm{mmHg}$ durante a imersão até o pescoço. A maior parte do volume pulmonar é distribuída para vasos maiores do leito vascular pulmonar ${ }^{5}$. 
Em 1989, Gleim e Nicholas ${ }^{15}$ demonstraram que o consumo de oxigênio $\left(\mathrm{VO}_{2}\right)$ durante a corrida foi três vezes maior na água do que no solo para uma mesma velocidade $(53 \mathrm{~m} / \mathrm{min})$. Portanto, durante a marcha ou corrida na água, apenas metade ou um terço da velocidade é necessária para atingir a mesma intensidade metabólica da atividade no solo. Consequentemente, a intensidade metabólica na água pode ser predita através da monitoração da frequência cardíaca. Com base nas evidências atuais, a terapia aquática parece ser um método seguro para indivíduos normotensos e hipertensos, e pode ser considerado um método ideal para condicionamento cardiovascular ${ }^{3}$.

O emprego de técnicas que envolve o exercício com o objetivo de investigar a presença de sinais e sintomas de doenças ou avaliar o resultado de intervenções terapêuticas constitui, o que se chamaria, teste de exercício Clínico ${ }^{16}$.

O teste ergométrico é um procedimento não invasivo, que pode conferir informações diagnósticas e prognósticas, além de avaliar a capacidade individual para exercícios dinâmicos ${ }^{16}$. As técnicas de avaliação cardiopulmonar têm se expandido nas últimas duas décadas simultaneamente aos estudos da fisiologia do exercício, tornando-se metodologia indispensável para avaliação funcional em atletas, sedentários e cardiopatas. A aplicação é ampla em estudos e pesquisas devido à maior acurácia em quantificar a capacidade funcional e avaliar com maior precisão a gravidade de doenças cardíacas, pulmonares e musculoesqueléticas, possibilitando esclarecer as causas da intolerância aos esforços ${ }^{17}$. O teste de esforço (avaliação do trabalho cardíaco e pulmonar em resposta ao exercício) 
é o método mais empregado na avaliação de portadores de insuficiência cardíaca, definindo intensidade de comprometimento, prognóstico e eficácia medicamentosa ${ }^{18}$. Determina de maneira individualizada, a capacidade cardiorrespiratória, a equivalência entre frequência cardíaca de equilíbrio e a carga de trabalho. Permite ainda a estratificação de risco e o acompanhamento das respostas clínicas, cardiovasculares, cardiorrespiratórias, eletrocardiográficas e metabólicas na evolução do programa de exercício ${ }^{19}$. O teste reflete a análise dos aspectos metabólicos e eletromecânicos do miocárdio, e de maneira indireta, informações da anatomia cardíaca. Os resultados obtidos ressaltam a correlação existente entre alterações anatômicas e grau de resposta isquêmica na ergometria, principalmente se a sua interpretação se basear em análise multifatorial das variáveis obtidas durante o exercício.

Os equipamentos disponíveis para a realização de diferentes testes, que envolvem o esforço físico, apresentam características distintas, podendo variar de sistemas mais simples a equipamentos com elevado grau de sofisticação tecnológica. Independentemente do local onde o exame seja realizado, é fundamental que algumas premissas devam ser respeitadas: ambiente adequado; equipamento básico; pessoal treinado, preparado para atuar em situações de emergências e orientar o paciente de acordo com o objetivo do exame ${ }^{16}$. 


\section{OBJETIVO}

Este estudo tem como objetivo comparar as respostas de um Teste de Esforço Cardiopulmonar (TECP) realizado na esteira em solo, contra um teste em imersão realizado em uma esteira subaquática. Pretende, ainda, investigar e entender o desempenho cardiorrespiratório de coronariopatas (DAC) durante esforço em imersão comparando-os aos do grupo de indivíduos saudáveis e testar procedimentos, materiais e equipamentos para a realização do teste em imersão tornando a coleta de dados do TECP em imersão reprodutível, segura e confiável. 


\section{REVISÃO DE LITERATURA}

As doenças cardiovasculares são a principal causa de morte no mundo. Dentre suas diversas formas, a doença arterial coronariana (DAC) é a forma, predominante, causadora de morte nos países desenvolvidos. Dados dos Estados Unidos mostram que aproximadamente 13,2 milhões de pessoas têm doença isquêmica do coração e destes, aproximadamente 6,5 milhões cursam com DAC crônica sintomática ${ }^{20}$.

No Brasil, a doença arterial coronariana é uma das principais causas de morte e internação hospitalar segundo dados do Datasus. Além da alta prevalência, a DAC cursa com alta morbidade e alto custo para os sistemas de saúde ${ }^{20}$.

\subsection{Insuficiência Cardíaca}

\subsubsection{Definição}

A Insuficiência Cardíaca (IC) é definida como uma síndrome clínica complexa, de características malignas, que tem início com um evento que lesa o coração e representa nas formas avançadas alta mortalidade em pacientes. Resulta de anormalidades intrínsecas e extrínseca no coração e envolve vários mecanismos celulares. Barretto ${ }^{21}$, em 2000, caracteriza a IC como uma afecção muito limitante, mais que o diabetes ou doença pulmonar obstrutiva crônica, por proporcionar grande desconforto resultante de dispneia, cansaço e edema. 
A doença é descrita por Milton Packer, em Barreto ${ }^{21}$, como uma "síndrome clínica complexa caracterizada por anormalidades da função do ventrículo esquerdo e regulação neuro-hormonal que são acompanhadas por intolerância ao esforço, retenção de fluido e redução da longevidade".

Tais característica se explicam pelo fato de que na IC ocorre uma necrose celular responsável pela perda de miócitos e consequente alteração estrutural do miocárdio (hipertrofia celular). Esta por sua vez, implica em mudanças no padrão da matriz extracelular, anormalidades no complexo contração-excitação, deficiência na utilização de energia e alteração na responsividade neuro-humoral celular; o conjunto desses mecanismos contribuem para a falência cardíaca global ${ }^{22,23}$. Uma lesão inicial no coração desencadeia todo esse processo citado levando a uma mudança estrutural do coração, interferindo em sua eficiência mecânica e resultando na disfunção ventricular (conhecida como remodelamento ventricular).

Os portadores de insuficiência cardíaca podem ser classificados com base nos sintomas apresentados, através da classificação funcional, elaborada pela New York Heart Association, ilustrada no Quadro 1. "A classificação mostra boa correlação com os dados de morbimortalidade da IC, sendo esta tanto maior quanto mais sintomático for o paciente" ${ }^{21}$. 
Classe I - sem limitações: atividade física usual não causa fadiga, dispnéia ou palpitações.

Classe II - discreta limitação à atividade física: esses pacientes estão confortáveis no repouso. Atividade física usual resulta em fadiga, palpitações, dispnéia e angina.

Classe III - limitação significativa da atividade física: apesar de pacientes permanecerem confortáveis em repouso, a menor atividade física que o usual pode levar o paciente a apresentar sintomas.

Classe IV - inabilidade em realizar qualquer atividade física sem desconforto: os sintomas de insuficiência cardíaca estão presentes até no repouso e qualquer atividade física leva a desconforto.

Fonte: New York Heart Association.

\subsubsection{Incidência e epidemiologia}

Atualmente a insuficiência cardíaca é mais bem conhecida. Muitos estudos sobre sua fisiopatologia permitiram o avanço nas opções terapêuticas e controle sobre a evolução da doença.

Segundo Barretto ${ }^{21}$, em 2000, apesar do grande desenvolvimento tecnológico e de maiores recursos farmacológicos é possível notar um aumento na incidência da IC. Tal aumento pode ser justificado pelo envelhecimento populacional, uma vez que a IC é mais frequente em idosos. Outra justificativa consiste no fato de que se morre menos em decorrência da patologia de base e, portanto, convive-se mais com a IC, fase final comum das doenças cardiológicas.

Estudos apontam que a IC afeta $2,5 \%$ da população com idade igual ou superior a 45 anos, sendo mais encontrada nos indivíduos mais velhos. As causas da IC variam, em seus estudos, Framingham ${ }^{24}$, indica a 
doença isquêmica como a principal causa da doença em adultos, após o melhor controle atingido sobre o tratamento da hipertensão arterial; estudos de Andrade $^{25}$ colocam a doença coronária como a principal causa de IC, enquanto no Brasil, levantamentos realizados no INCOR por Barreto ${ }^{26}$ em 1998, evidenciaram a miocardiopatia isquêmica como a principal causa da IC, seguida da miocardiopatia dilatada. No Brasil, pacientes com doença de Chagas podem apresentar insuficiência cardíaca com pior evolução ${ }^{21}$.

Um grande avanço tecnológico que contribuí para o diagnóstico da IC é o exame de eletrocardiograma. Através dele identifica-se a disfunção ventricular e estudos mostram que a incidência da disfunção ventricular na população é de $4 \%$, sendo em $50 \%$ de forma assintomática ${ }^{21}$.

Um método cada vez mais empregado na avaliação dos portadores de IC e descrito mais adiante é o teste de esforço. A aplicação dele procura definir a intensidade do comprometimento, prognóstico e eficácia medicamentosa ${ }^{21,27}$.

Vários estudos revelam que a mortalidade na IC chega a 50\% em um ano em pacientes na classe funcional IV da classificação da New York Heart Association (Quadro 1), em contrapartida pacientes pouco sintomáticos têm boa evolução, mesmo que apresentem fração de ejeção bastante reduzida ${ }^{21}$. A realização do eletrocardiograma pode contribuir muito para o melhor controle da doença, seja para avaliar a conduta terapêutica empregada ou identificar a patologia em sua forma inicial.

Considerando a alta incidência da IC e suas manifestações clínicas podemos classificá-la como uma doença de saúde pública. Dados do SUS no artigo de revisão - Insuficiência cardíaca um problema de Saúde 
Pública, mostraram que em 1997 a insuficiência cardíaca foi a principal causa de hospitalização entre as doenças cardíacas. As despesas tornam-se ainda maiores quando se considera os dias não trabalhados pelos doentes e os gastos familiares na assistência ao paciente.

O correto tratamento dos pacientes proporciona melhor qualidade de vida, reduzindo sua mortalidade e custos médicos. Se os pacientes tiverem acesso aos medicamentos e receberem o tratamento correto, as despesas com a doença certamente reduzirão.

\subsubsection{Fisiopatologia}

O início da insuficiência cardíaca caracteriza-se pela redução do débito cardíaco, que irá desencadear uma sequência de mecanismos compensatórios para manter a perfusão de órgãos-alvo. Com o débito cardíaco diminuído, a redução crônica do enchimento arterial resulta em um decréscimo na inibição do centro reflexo cardiovascular, causando um aumento significativo na resistência vascular sistêmica. A disfunção dos reflexos cardiovasculares, por outro lado, leva ao aumento da atividade adrenérgica com vaso constrição sistêmica. Adicionalmente, ativação simpática pode ter ações secundárias levando à ativação de sistemas locais e neuro-humorais, por exemplo, sistema renina-angiotensina-aldosterona levando à retenção ávida de sódio secundária à reabsorção aumentada renal de sódio.

A IC é caracterizada por concentrações teciduais e circulantes elevadas de angiotensina II, um vasoconstritor que aumenta a pós-carga e 
causa hipertrofia de miócitos, apoptose, fibrose intersticial, remodelamento cardíaco e vascular, e secreção de aldosterona. Essa última também desempenha um papel importante no remodelamento cardíaco, na proliferação de fibroblastos e na deposição de colágeno. Essas alterações aumentam o endurecimento passivo dos ventrículos e do leito arterial, interferindo no enchimento ventricular e reduzem a complacência arterial. Concentrações elevadas de aldosterona circulante são preditivas de prognóstico adverso na IC. Inibidores do sistema renina-angiotensinaaldosterona (SRAA), isto é, inibidores da enzima conversora de angiotensina (ECA), bloqueadores dos receptores de angiotensina e inibidores da aldosterona, todos eles exercem efeitos salutares no tratamento da IC. Além disso, inibidores da ECA são considerados fundamentais no manejo de muitas formas da IC e de hipertrofia cardíaca.

Existem evidências crescentes sobre a interligação do sistema adrenérgico com o SRAA. A aldosterona reduz a reutilização neuronal de norepinefrina e, portanto, aumenta as arritmias cardíacas. Assim, em pacientes com IC, inibidores da ECA parecem reduzir o impulso nervoso simpático periférico que está aumentado e o drive cardíaco adrenérgico.

Em relação ao sistema nervoso simpático, ocorre uma ativação como resposta à redução da contratilidade miocárdica e do débito cardíaco. Embora a vasoconstrição e o aumento da contratilidade miocárdica sejam essenciais para manter a pressão sanguínea, a contínua ativação aumenta a pós-carga ventricular sobrecarregando um ventrículo já insuficiente. Ao mesmo tempo, a ativação deste sistema contribui para um aumento para da frequência cardíaca e do consumo de energia pelo miocárdio; isto pode 
causar hipertrofia, isquemia, taquirritmias e dano adicional aos miócitos, talvez por meio da sobrecarga de cálcio para o miocárdio ou apoptose. Ainda como efeito deletério da hiperativação simpática neste contexto, há uma diminuição tanto no número como na sensibilidade dos receptores beta-1 adrenérgicos miocárdicos, contribuindo para uma dessensibilização miocárdica ao estímulo adrenérgico. Finalmente, a estimulação betaadrenérgica crônica parece induzir à expressão de citocinas pró-inflamatórias que podem deprimir a contração cardíaca, promover aumento das câmaras, tendo um papel importante no fenótipo da miocardiopatia dilatada.

Quando analisada a IC grave, observa-se que um bloqueio agudo dos receptores beta-adrenérgicos pode intensificar a IC. Entretanto, um aumento gradual da dose de betabloqueadores tem mostrado ter um benefício clínico substancial, e o tratamento com betabloqueadores é agora recomendado para todos os casos mais avançados de insuficiência cardíaca sistólica crônica. Os efeitos funcionais do miocárdio produzidos pelo betabloqueio crônico são de fato opostos aos efeitos agudos, porque a longo prazo ( $\geq 3$ meses) o bloqueio está associado com uma melhora da função sistólica intrínseca e um decréscimo no volume ventricular. O uso de betabloqueadores parece restaurar o número e a sensibilidade dos receptores beta-1 adrenérgicos na superfície do miocárdio, modulando de maneira benéfica a resposta do coração ao estímulo simpático. Estes efeitos salutares na função e estrutura miocárdica são provavelmente os responsáveis pela maioria dos benefícios clínicos produzidos pelos betabloqueadores, os quais incluem redução na mortalidade e nas hospitalizações relacionadas à IC na insuficiência cardíaca crônica. 
O sistema endotelina, uma vez estimulado, ativa os receptores de endotelina A, causando vasoconstrição na musculatura lisa. A endotelina também estimula o crescimento, contribuindo para o remodelamento cardíaco e vascular.

Paralelamente à ativação neuro-humoral, citocinas próinflamatórias apresentam-se de forma aumentada na IC. Sua produção resulta da sobrecarga de volume e produz respostas inflamatórias sistêmicas e locais (coração). Incluem caquexia e miopatia da musculatura esquelética, além de inflamação miocárdica, proliferação celular e apoptose, contribuindo assim para o remodelamento ventricular e a progressão da falência cardíaca 21,23

\subsection{Testes Ergoespirométricos}

\section{2.1 Definição}

A comunidade se conscientizou da importância da atividade física regular, solicitando cada vez mais ao médico orientação relacionada quanto ao exercício físico ${ }^{28}$. As técnicas de avaliação cardiopulmonar têm se expandido nas últimas duas décadas simultaneamente aos estudos da fisiologia do exercício, tornando-se metodologia indispensável para avaliação funcional não só em atletas, como também em sedentários e cardiopatas, com ampla aplicação em estudos e pesquisas pela maior acurácia em quantificar a capacidade funcional e avaliar com maior precisão a gravidade de doenças cardíacas, pulmonares e musculoesqueléticas, com possibilidade de esclarecer e localizar as causas de uma intolerância aos esforços ${ }^{17}$. 
O teste de esforço (avaliação do trabalho cardíaco e pulmonar em resposta ao exercício) é o método mais empregado na avaliação de portadores de insuficiência cardíaca, definindo intensidade de comprometimento, prognóstico e eficácia medicamentosa ${ }^{18}$. Determina de maneira individualizada, a capacidade cardiorrespiratória, a equivalência entre frequência cardíaca de equilíbrio e a carga de trabalho. Permite ainda a estratificação de risco e o acompanhamento das respostas clínicas, cardiovascular, cardiorrespiratórias, eletrocardiográfica e metabólica na evolução do programa de exercício ${ }^{28}$. Ele reflete a análise dos aspectos metabólicos e eletromecânicos do miocárdio, e de maneira indireta, informações da anatomia cardíaca. Entretanto, os resultados obtidos ressaltam a correlação existente entre alterações anatômicas e grau de resposta isquêmica na ergometria, principalmente se a sua interpretação baseia-se em análise multifatorial das variáveis obtidas durante o exercício.

\subsubsection{Avaliação}

- Capacidade aeróbica $\left(\mathrm{VO}_{2}\right)$, isto é, o consumo central e a utilização periférica de $\mathrm{O}_{2}$;

- Capacidade aeróbica do miocárdio;

- Alterações associadas às atividades elétrica do coração: atividade ectópica, condução atrioventricular e intraventricular e alterações da repolarização ventricular (alterações no segmento ST). 


\subsubsection{Indicações e Contra-indicações}

\subsubsection{Indicação}

- Adultos sob risco de morte súbita relacionada à prática de exercícios;

- Adultos "sadios" com baixa capacidade funcional cardiorrespiratória;

- Pacientes portadores de doenças cardiovasculares;

- Adultos hipertensos que iniciarão prática desportiva;

- Crianças e adolescentes com sinais e sintomas cardiovasculares, esforço-induzidos, dispnéia de esforço, síncope de esforço e angina de esforço;

- População sadia candidata a programa de condicionamento físico com idade superior a 30 anos (sexo masculino) e 45 anos (sexo feminino);

- Meio auxiliar em atletas para avaliação da dor torácica não traumática, além de arritmias cardíacas;

- Complementação de check-up;

- Avaliação de alterações do eletrocardiograma durante o exercício físico.

\subsubsection{Contra-indicações}

\subsection{Cardíacas}

\section{Absolutas}

- Infarto agudo do miocárdio com má evolução;

- Angina instável ou progressiva;

- Insuficiência cardíaca descompensada, choque cardiogênico; 
- Miocardite ou pericardite aguda, endocardite infecciosa, febre reumática aguda;

- Arritmia atrial e ventricular de alta frequência;

- Tromboflebite ativa;

- Fenômeno embólico recente;

- Aneurisma ventricular importante;

- Estenose aórtica grave;

- Embolia pulmonar recente;

- Hipertensão pulmonar grave.

\section{Relativas}

- Estenose aórtica valvar;

- Hipertensão arterial sistêmica com níveis de pressão diastólica de 120 a $140 \mathrm{mmHg}$;

- Insuficiência respiratória;

- Arritmia supraventricular não controlada;

- Marcapasso de frequência fixa;

- Cardiomegalia importante;

- Taquiarritimias ou bradiarritmias não tão severas;

- Distúrbios de condução ventricular.

\subsection{Não cardíacas}

- Qualquer enfermidade aguda ou grave (pulmonar, renal, hepática, comprometimento no sistema nervoso central ou câncer); 
- Incapacidade física: amputados, artrite severa, deformidade ósseas acentuadas, afecções neurológicas, claudicação, trombo flebites, obesidade acentuada;

- Ansiedade exagerada ou distúrbios psiconeuróticos;

- Anemia severa;

- Hipertireoidismo;

- Condições metabólicas instáveis (diabetes, mixedema);

- Intoxicação medicamentosa (digitálicos antiarrítmicos);

- Pacientes sob efeito de álcool, sedativos, anestésicos;

- Distúrbios eletrolíticos.

\subsubsection{Critérios para suspensão do teste}

- Frequência cardíaca máxima teórica preconizada;

- Angina de peito de moderada a severa intensidade;

- Depressão do segmento ST de 3 mm ou mais;

- Elevação do segmento ST de $3 \mathrm{~mm}$ ou mais, em ausência de zona inativa;

- Sinais e sintomas de baixo fluxo cerebral;

- Elevação da pressão arterial acima de $240 \mathrm{mmHg} \times 140 \mathrm{mmHg}$, em presença ou não de sintomas;

- Cansaço físico importante desproporcional ao esforço. 


\subsection{Ambiente para realização do exame no solo e na piscina}

No solo, a sala de exames deve ser ampla para acomodar todo o equipamento e material a ser usados durante eventuais emergências médicas. A área da sala deverá ser livre para a circulação de pelo menos 3 pessoas, caso ocorra necessidade de situações emergenciais. Uma área reservada para o preparo do paciente também é importante, juntamente com um vestiário e um banheiro ${ }^{29}$.

O laboratório deverá ser iluminado, limpo e com controle da temperatura ambiente (entre $18^{\circ} \mathrm{C}$ e $22^{\circ} \mathrm{C}$ ) e umidade relativa do ar (entre 50 e $70 \%$ ). Esses valores devem ser obtidos através de equipamentos de refrigeração/aquecimento e umidificadores/ desumidificadores e aferidos através de higrômetros e termômetros. Quando realizado testes com medidas simultâneas da ventilação pulmonar e de gases expirados (ergoespirométricos), a pressão barométrica também deverá ser registrada 29 .

Durante testes ergoespirométricos é impossível a comunicação verbal do paciente com o examinador, sendo conveniente a utilização de um pôster apresentando a escala de Borg modificada, para a indicação manual da sensação subjetiva do cansaço. Essa peculiaridade da ergoespirometria deverá ser explicada ao paciente antes do início do teste ${ }^{29}$.

O exame em imersão a piscina deve ter dimensões suficiente que permita a instalação da esteira subaquática, com profundidade modulável entre $1,20 \mathrm{~m}$ a $1,45 \mathrm{~m}$, permitir o acesso doa paciente diretamente na esteira. A temperatura ambiente varia devido a temperatura da água da piscina, mas através do sistema de exaustão e insuflação de ar conseguimos condições 
ideais (entre $20^{\circ} \mathrm{C}$ e $24^{\circ} \mathrm{C}$ ) e umidade relativa do ar (entre 50 e $70 \%$ ). Esses valores são aferidos através de higrômetros e termômetros.

Nos Testes Ergoespirometricos (TE) e nos programas de exercícios utiliza-se o Índice de Percepção de esforço de Borg, em duas variações e terminologias, apresentada no Quadro 2.

Quadro 2 - Índice de percepção de esforço de Borg.

\begin{tabular}{|l|c|c|}
\hline \multicolumn{1}{|c|}{ Índice } & Variação (I) & Variação (II) \\
\hline 6. & & \\
\hline 7. Muito, muito leve & Muito, muito leve & Muito fácil \\
\hline 8. & & Fácil \\
\hline 9. Muito leve & Muito leve & \\
\hline 10. & & Relativamente fácil \\
\hline 11. Leve & Pouco leve & \\
\hline 12. & Um pouco forte & Ligeiramente cansativo \\
\hline 13. Um pouco difícil & & \\
\hline 14. & Forte & Cansativo \\
\hline 15. Difícil & & Muito cansativo \\
\hline 16. & Muito forte & Exaustivo \\
\hline 17. Muito difícil & & \\
\hline 18. & Muito, muito forte & \\
\hline 19. Muito, muito difícil & & \\
\hline 20. & & \\
\hline
\end{tabular}




\subsection{Equipamentos para realização do teste no solo e na água}

No solo, a bicicleta ergométrica e a esteira rolante são os ergômetros mais comumente usados para medirmos indiretamente o consumo máximo de $\mathrm{O}_{2} \max \left(\mathrm{VO}_{2} \max \right)$. A cicloergometria é amplamente usada na Europa e na América do Sul. A esteira rolante é a modalidade de teste dinâmico mais usado nos Estados Unidos e que ganham a aceitação cada vez mais usada no Brasil nos últimos anos ${ }^{30}$.

\subsubsection{Bicicleta ergométrica}

\section{Vantagens}

- Permite aumentos de cargas pequenas em unidade pequenas;

- Mais fácil para se prescrever exercícios;

- Maior facilidade nos registros eletrocadiográficos, tomada de pressão arterial e ausculta durante o exercício físico;

- Técnica mais simples;

- Pode ser usada em diferentes posições, por isso é útil na avaliação de pacientes com problemas neuromusculares e ósseos dos membros inferiores;

- Pode-se usá-las em avaliações simultâneas, por exemplo, ergometria e cateterismo cardíaco;

- Fácil de ser transportada (pesquisas fora do laboratório);

- Menor custo financeiro. 


\section{Desvantagens}

- A bicicleta ergométrica envolve menor massa muscular durante o exercício que a esteira. Por isso, obriga, em geral, o indivíduo a deixar a prova sem atingir o $\mathrm{VO}_{2}$ max mais elevado, comumente observado em teste com esteira rolante;

- Ocorrência de fadiga precoce do quadríceps femoral, antes que um nível adequado de exercício tenha sido atingido;

- Requer que o praticante saiba pedalar;

- Para um mesmo $\mathrm{VO}_{2}$ max, o débito cardíaco é igual ou menor.

\subsubsection{Esteira ergométrica}

\subsubsection{Para Solo}

\section{Vantagens}

- Usa um tipo comum de exercícios (caminhar/correr);

- Usa massa muscular maior;

- Impõe, para um mesmo $\mathrm{VO}_{2}$, menor estresse ao sistema cardiovascular.

\section{Desvantagens}

- Custo financeiro elevado;

- Maior dificuldade na obtenção do eletrocardiograma e tomada da pressão arterial;

- Pesada e barulhenta;

- A potência e o trabalho não podem ser medidos diretamente - são calculados; 
- O peso corporal influi no trabalho realizado ${ }^{30}$.

\subsubsection{Para Piscina}

A esteira ergométrica submersa deve ser totalmente construída em aço inox, seu sistema de acionamento deve ser realizado através de sistema eletro-hidráulico (bomba hidráulica) movido por um motor elétrico instalado em uma unidade hidráulica, longe da esteira, que faz mover um motor hidráulico acoplado ao eixo da esteira. A esteira deve ser em PVC antiderrapante e com sistema escamoteável, permitindo sua colocação ou retirada da água, liberando a piscina para outras atividades quando não está sendo utilizada. O isolamento elétrico deve garantir a segurança dos usuários quanto a acidentes elétricos, assim o isolamento do painel elétrico e unidade hidráulica devem ficar distantes da piscina e serem conectados à esteira através de mangueiras hidráulicas não condutivas. O monitor (painel do usuário) com funcionamento em 12 volts $\mathrm{DC}$, deve ser protegido contra fugas de energia (interruptor diferencial) e ter uma chave de segurança, ligada ao corpo da máquina e ao pulso do usuário que desliga a esteira quando puxada.

As funções básicas são contagem progressiva ou regressiva do tempo de percurso com intervalos de 1s; velocidade: de 2 a $10 \mathrm{~km} / \mathrm{h}$, eletronicamente comandada, com intervalos de $0,1 \mathrm{~km} / \mathrm{h}$, inclinação de 0 a $13 \%$ com intervalos de $1 \%$, distância total percorrida e relógio real time. As funções avançadas tais como: consumo calórico, programas pré-gravados (PRE SET ROUTINES) tempo x velocidade x inclinação pré-programados; 
programas personalizados (PERSONAL PROGRAM), monitoramento do batimento cardíaco: compatível com cinta Polar e função HEART RATE SYSTEM que altera os parâmetros de inclinação e velocidade da esteira durante seu funcionamento, tentando manter constante a frequência cardíaca a partir de dados inseridos, são encontradas somente em esteiras com desenvolvimento tecnológico de ponta e permite melhor acurácia e confiabilidade quando comparado com dados obtidos em solo.

As dimensões da esteira ergométrica determinam o tamanho da piscina. No mercado nacional o único fabricante que atende as normas para o teste ergométrico em esteira subaquática é a SAHINCO que dispões de dois modelos: Concept e Hi-Tech, ambos com largura de cinta de $50 \mathrm{~cm}$ e comprimento de corrida de 1,35m (Figura 1).

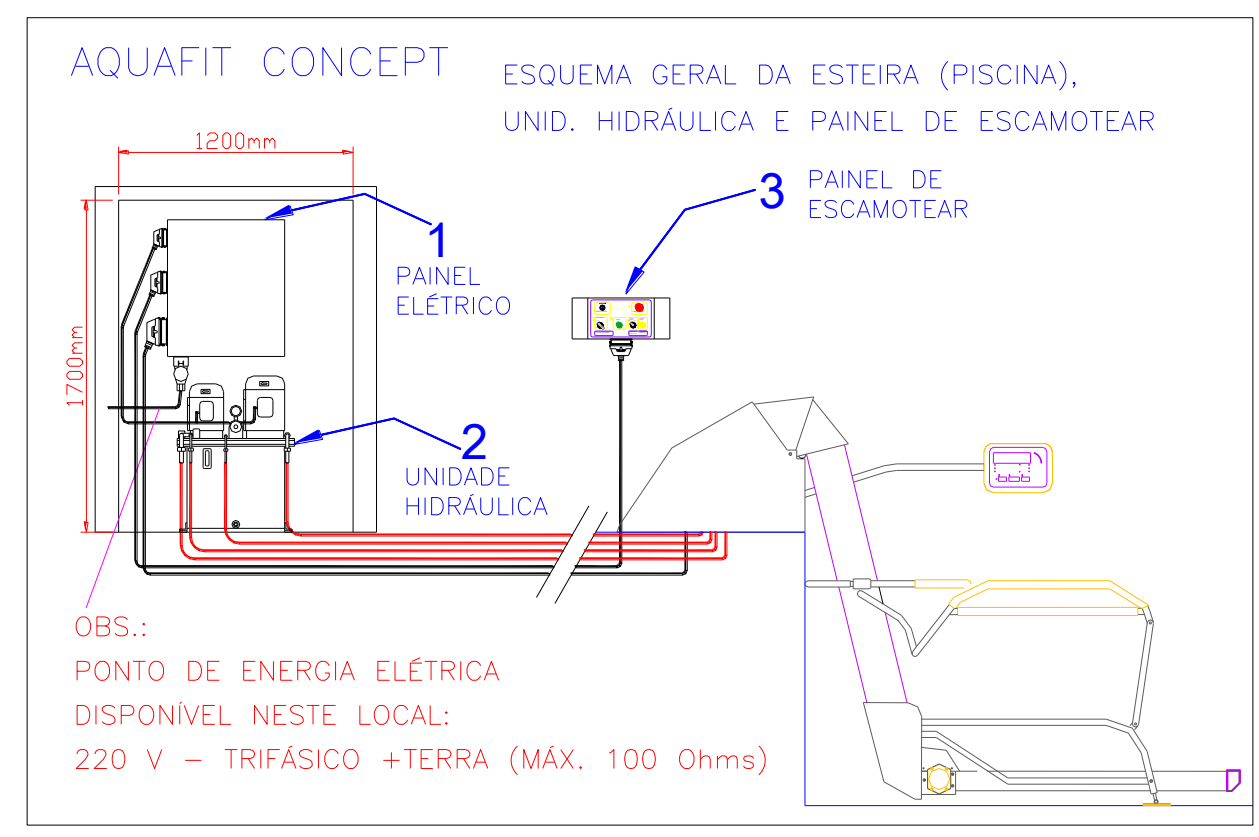

Figura 1 - Esquema Geral da Esteira.

A Esteira deve permitir a interligação ao sistema de ergometria, software Micromed e impressora Hewlett Packard Deskjet 650C. 


\subsection{Aparelho para medida da ventilação}

O aparelho para medida da ventilação deverá ter acurácia suficiente para medidas de diferentes volumes e velocidades de fluxos e baixas resistência e inércia. Além disso, é desejável que o aparelho permita sua conexão ao computador, para maior facilidade da correlação dos dados obtidos.

A medida da ventilação durante o exercício requer que o indivíduo testado tenha suas narinas fechadas por um clipe nasal e que o bocal não permita qualquer escape de ar. O espaço morto do equipamento também é importante $($ máximo $=100 \mathrm{ml})$.

Para realização de medidas precisas, é necessário que seja determinada a umidade relativa do ar, realizando-se os ajustes para temperatura e pressão padronizados (ou seja, STPD). Atualmente, a análise de gases é realizada "on-line". Vários tipos de fluxômetros podem ser utilizados: transdutores de massa, pneumotacômetros de Fleish, anemômetros, entre outros. Esses sistemas permitem medidas das trocas gasosas a cada ciclo respiratório (respiração por respiração - do inglês "breath by breath"). Com estes sistemas, as respostas do paciente tornam-se disponíveis imediatamente, e, com o sistema acoplado ao computador, as medidas são continuamente disponibilizadas na tela (durante o exame).

Os pneumotacômetros medem as reduções de pressão geradas pelo fluxo através de um tubo. A relação entre fluxo e queda da pressão é analisada através da Lei de Bernoulli (o fluxo é proporcional à raiz quadrada da diferença de pressão). Essa lei permite a medida do fluxo com o pneumotacógrafo. Os transdutores de volume à turbina medem o 
fluxobidirecional de ar na boca. Os anemômetros consistem em um tubo fino com um arame aquecido em seu interior. Conforme o ar flui pelo tubo, ele esfria o arame. $\mathrm{O}$ volume de fluxo do ar é proporcional à quantidade de eletricidade necessária para reaquecer o arame.

\subsection{Análise dos gases}

Os dois tipos de analisadores de oxigênio comumente utilizados são: paramagnético e eletroquímico. Na verdade, esses analisadores medem pressões parciais: o gás é expresso como porcentagem através da razão entre a pressão parcial de oxigênio e a pressão barométrica.

Os analisadores eletroquímicos são os mais utilizados nos sistemas automatizados atualmente disponíveis. Geralmente, esses sistemas utilizam uma célula de óxido de zircônio aquecida a temperaturas extremas. Uma corrente será gerada proporcionalmente às diferenças na pressão parcial de oxigênio em qualquer dos lados da membrana semipermeável da célula (isto é, diferença entre o ar da sala e o ar dentro do sensor). Analisadores paramagnéticos medem alterações no campo magnético causadas por mudanças nas concentrações de oxigênio. Esse tipo de sistema é frequentemente utilizado para medidas em campo (aparelhos portáteis), mas seu tempo de resposta é lento, por isso esse sistema de análise não costuma ser utilizado nos sistemas metabólicos de exercício.

O dióxido de carbono, geralmente, é medido por um analisador infravermelho. Este sistema baseia-se na teoria de que o dióxido de carbono absorve energia de uma porção específica do espectro infravermelho. Assim, 
a luz infravermelha passará por uma célula contendo determinada quantidade de dióxido de carbono, e o volume de luz transmitido é comparado com um valor constante conhecido. A diferença será proporcional à pressão parcial de dióxido de carbono na amostra analisada. Os sensores infravermelhos para medida do dióxido de carbono são sistemas bem validados e têm tempos de resposta rápidos. Este sistema é utilizado em praticamente todos os analisadores metabólicos disponíveis no mercado ${ }^{31}$.

\subsection{Protocolos e Interpretação}

É polêmica a discussão dos protocolos a serem empregados. Logo, a escolha deve ser feita levando em consideração o que melhor se adapta ao caso estudado.

O protocolo de Rampa tem sido muito utilizado, porém não se pode descartar o uso de avaliações que forneçam o que chamamos de steady-state ou equilíbrio de carga durante algum intervalo de tempo, muito útil quando queremos realmente saber se o paciente ou atleta encontra-se em condições aeróbias. É estipulado o tempo em torno de $12 \mathrm{~min}$ como necessário para uma boa eficácia de prova, caso não haja limitações por cardiopatia grave ${ }^{31}$.

O protocolo de Bruce é o mais conhecido e difundido no meio. Deve ser empregado com cautela em pacientes cardíacos ou sedentários de baixa condição física. É um protocolo que avança em estágios irregulares que dificultam o ajustamento dos pacientes ao protocolo ${ }^{30}$. 
A obtenção de um teste verdadeiramente máximo $\left(\mathrm{VO}_{2}\right.$ max $)$ Pela ergometria convencional, a obtenção de frequência cardíaca (FC) máxima, com a utilização de fórmulas (220-idade) ou (210-idade x 0,65), é sujeita a um desvio padrão de até $\pm 12 \mathrm{bpm}$, comprometendo muitas vezes o treinamento em pacientes que necessitam controle mais vigoroso pela presença de arritmia, hipertensão arterial, isquemia, etc.

Pelo uso da ergoespirometria é possível determinar, com relativa precisão, o $\mathrm{VO}_{2}$ max com os seguintes dados:

a) presença de $\mathrm{QR}\left(\mathrm{VCO}_{2} / \mathrm{VO}_{2}\right)>1.1$;

b) existência de um limiar anaeróbio (limiar de lactato);

c) VE $>60 \%$ da máxima prevista; e) eventual presença de um platô no $\mathrm{VO}_{2}$ diante de um aumento na carga de esforço.

Estes dados, concomitantes à avaliação de FC atingida e a sensação subjetiva de esforço podem assegurar um teste máximo ${ }^{32}$ sugeriram que a classificação funcional dos pacientes portadores de insuficiência cardíaca congestiva (ICC) teria sido baseada nas respostas de limiar aeróbio (LA) e $\mathrm{VO}_{2}$ max. Os indivíduos que apresentam valores de $\mathrm{VO}_{2}$ no LA entre 11 e $14 \mathrm{~mL} / \mathrm{kg}^{-1} \mathrm{~min}^{-1}$ e VO$_{2}$ max entre 16 e $20 \mathrm{ml} / \mathrm{kg}^{-1} \cdot \mathrm{min}^{-1}$ foram considerados com ICC leve a moderada, enquanto os que tiveram valores de $\mathrm{VO}_{2}$ entre 5 e $8 \mathrm{ml} / \mathrm{kg}^{-1} \mathrm{~min}^{-1}$ no LA e $\mathrm{VO}_{2}$ max $<10 \mathrm{~mL} / \mathrm{kg}^{-1} \mathrm{~min}^{-1}$ foram classificados com ICC grave. Além disso, nesse estudo o $\mathrm{VO}_{2}$ max correlacionou-se estreitamente com o índice cardíaco (IC) durante o exercício. Pacientes com $\mathrm{VO}_{2} \max >20 \mathrm{~mL} / \mathrm{kg}^{-1} \mathrm{~min}^{-1}$ mostraram um IC $>8 \mathrm{Lmin}^{-1} \mathrm{~m}^{2}$, entretanto, aqueles com $\mathrm{VO}_{2} \max <10 \mathrm{ml} \mathrm{kg}{ }^{-1} \mathrm{~mm}^{-1}$ mostraram um IC $<4 \mathrm{Lmin}^{-1} \mathrm{~m}^{2}$. 
A relação $\mathrm{VO}_{2} /$ watt é outra variável importante, medida durante exercício de protocolo de rampa, cujo valor incrementa-se progressivamente até o máximo; o valor normal é de cerca de $10 \mathrm{ml} / \mathrm{min} /$ watt quando um incremento de 10 a 20watt/min de rampa é empregado. Valores inferiores poderão significar uma baixa na função de reserva cardíaca.

Convém lembrar que indivíduos adultos que apresentam valores $>40 \mathrm{~mL} / \mathrm{kg}^{-1} \mathrm{~min}^{-1}$ já apresentam algum tipo de condicionamento físico e os situados entre 20 a $40 \mathrm{~mL} / \mathrm{kg}^{-1} \mathrm{~min}^{-1}$ são quase sempre sedentários não necessariamente portadores de cardiopatia.

Ventilação pulmonar (VE) - Resultante do produto da FR pelo VC. Fisiologicamente, durante o exercício, o incremento da VE é proporcional à produção de dióxido de carbono $\left(\mathrm{VCO}_{2}\right)$. A VE, durante o TE-CP, aumenta progressivamente atingindo um platô máximo, caracterizando uma maior produção de $\mathrm{CO}_{2}$.

Em esforço, a VE poderá atingir até 200L de ar ventilado por minuto (em atletas), sendo limitada em cardiopatas e pneumopatas. Como ela é resultante do produto FRxVC, a avaliação isolada destes dois parâmetros, muitas vezes, faz se necessária. A FR durante o teste, raramente, ultrapassa 50 ciclos/min, e o VC representa, parcialmente, a capacidade de expansibilidade pulmonar. O VC que, em repouso, pode variar de 300 a $600 \mathrm{~mL}$ por movimento respiratório pode aumentar até, aproximadamente, $70 \%$ da capacidade vital ao esforço.

Alguns equipamentos fornecem dados da relação existente entre o espaço morto (VD) e o VC (ou VT - tidal volume). O comportamento normal do chamado VD/VT diminui durante o esforço em indivíduos normais. O 
incremento poderá significar modificações significativas na relação VE/ perfusão pulmonar.

Equivalentes respiratórios de $\mathrm{VO}_{2}$ e $\mathrm{VCO}_{2}$ - As relações $\mathrm{VE} / \mathrm{VO}_{2}$ e $\mathrm{VE} / \mathrm{VCO}_{2}$, mantendo-se a VE em condições de BTPS e $\mathrm{VO}_{2}$ e $\mathrm{VCO}_{2}$ em STPD, relacionam quantos litros de ar por minuto são necessários e devem ser ventilados para consumir $100 \mathrm{~mL}$ de $\mathrm{O}_{2}$ (normal entre 2,3 e $2,8 \mathrm{~L} / 100 \mathrm{~mL}$ ) ou produzir em $\mathrm{CO}_{2}$. Poderá esta relação ser expressa em 23 a 28 litros de ar ventilado para 1 litro de $\mathrm{O}_{2}$ consumido. Durante o esforço crescente, as relações $\mathrm{VE} / \mathrm{VO}_{2}$ e $\mathrm{VE} / \mathrm{VCO}{ }_{2}$ diminuem, progressivamente, para depois aumentar até $\mathrm{o}$ final do esforço. $\mathrm{A} \vee \mathrm{VE} / \mathrm{VO}_{2}$ atinge valores mínimos precedendo a relação $\mathrm{VE} / \mathrm{VCO}_{2}$. As variáveis citadas são de fundamental importância na detecção do limiar anaeróbio (LA) como veremos adiante.

Pressão expirada de $\mathrm{O}_{2}\left(\mathrm{PETO}_{2}\right)$ ou fração expirada de $\mathrm{O}_{2}\left(\mathrm{FEO}_{2}\right)$ - A PETO ${ }_{2}$ em repouso é de $\pm 90 \mathrm{mmHg}$, diminui transitoriamente logo após o início do exercício, desde que o aumento na VE seja mais lento que o incremento no $\mathrm{VO}_{2}$. Ao ultrapassar o LA I, a PETO 2 aumenta 10 a $30 \mathrm{mmHg}$ ao atingir o esforço máximo, devido a hiperventilação provocada pela diminuição do $\mathrm{PH}$. $\mathrm{A} \mathrm{FEO}_{2}$ tem o mesmo comportamento, diminuindo no início do esforço e atingindo um valor mínimo, incrementando-se a seguir. Este parâmetro facilita a detecção do limiar anaeróbio I (LA I).

Pressão expirada de dióxido de carbono $\left(\mathrm{PETCO}_{2}\right)-\mathrm{O}$ valor da $\mathrm{PETCO}_{2}$ ao nível do mar varia de 36 a $42 \mathrm{mmHg}$. Eleva-se 3 a $8 \mathrm{mmHg}$ durante exercício de intensidade leve a moderada, atinge um máximo, caracterizando o LAll, e pode em seguida diminuir. A FE $\mathrm{CO}_{2}$ tem o mesmo comportamento durante exercícios de carga crescente. 
QR e/ou razão de troca respiratória (RER-R) - QR=VCO ${ }_{2} / \mathrm{VO}_{2}-$

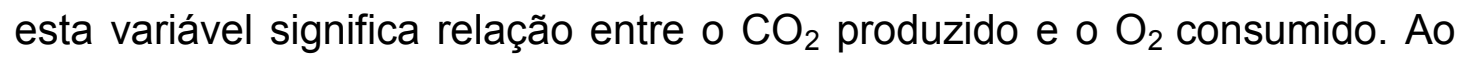
realizar exercício com $\mathrm{R}$ próximo de 0,70, estamos consumindo mais lipídeos. Com valores próximos de 1,00, consumimos mais carboidratos. Durante a combustão de carboidratos, forma-se $830 \mathrm{~cm}^{3}$ de $\mathrm{CO}_{2} \mathrm{com} 1 \mathrm{~g}$ de lípides e $1430 \mathrm{~cm}^{3}$ de $\mathrm{CO}_{2}$. O valor de $n$ será sempre incrementado para a produção do $\mathrm{CO}_{2}$ e, portanto, com gasto energético maior, caracterizando um QR menor do que a unidade.

Pulso de oxigênio $\mathrm{PO}_{2}\left(\mathrm{VO}_{2} / \mathrm{FC}\right)$ - Considerada uma das mais importantes variáveis utilizadas pela ergoespirometria, pois demonstra a quantidade de $\mathrm{O}_{2}$ que é transportada a cada sístole cardíaca. Uma diminuição do desempenho de VE pode ser detectada em uma prova de esforço crescente com observação do pulso de $\mathrm{O}_{2}{ }^{31,17}$.

\subsection{Imersão}

$\mathrm{Na}$ água, o corpo encontra-se numa constante situação de estímulo e aprendizagem, não reproduzível em solo. O conhecimento de suas propriedades e características, além de uma abordagem lógica são fatores fundamentais para a eficiência de um tratamento e ou pesquisa.

A utilização terapêutica da água consiste na arte de combinar, cuidadosamente, suas muitas variáveis para que se produza um resultado eficiente e significativo. 


\subsubsection{Propriedades físicas da água}

Os efeitos fisiológicos da imersão estão relacionados, fundamentalmente, aos princípios da hidrostática, hidrodinâmica e termodinâmica ${ }^{33}$.

O conhecimento sobre a hidrodinâmica e a hidrostática tornará possível a seleção da posição do paciente, a profundidade da imersão e os equipamentos ideais para os tratamentos em piscina funcional. A hidrodinâmica, que significa água em movimento, destaca-se pelos seus princípios físicos e finalidades terapêuticas. A hidrostática ou características próprias da água demonstra características singulares de força e resistência. São eles:

\subsubsection{Propriedades estáticas da água (hidrostática)}

\section{a) Densidade ou gravidade especifica}

A densidade é definida como massa $(\mathrm{Kg})$ por unidade de volume $\left(\mathrm{m}^{3}\right)$ e medida por quilogramas por metro cúbico. A densidade é uma variável dependente da temperatura válida mais para gases que sólidos ou líquidos. Além da densidade, as substâncias são definidas por suas gravidades especificas, que é a relação entre a densidade de uma substância em relação à densidade da água. A água possui uma gravidade específica igual a 1 a $4{ }^{1}$.

O corpo humano possui uma gravidade específica levemente menor que a da água, por isso tende a flutuar. Portanto, um corpo com uma densidade relativa menor que 1 irá flutuar, e maior que 1 irá afundar ${ }^{34}$. Apesar de o corpo humano ser composto principalmente por água, a densidade do corpo é levemente menor do que a água e possui uma gravidade específica em média de 0,974 , sendo que a massa corporal magra (ossos, músculos, tecido conjuntivo e órgãos), apresenta densidade 
específica de 1,1, enquanto a massa corporal gorda (gordura) apresenta densidade de 0,9. Portanto, o conhecimento da densidade relativa é importante no tratamento, pois cada parte de tecido individual do corpo possui suas próprias densidades relativas, o que faz com que o corpo afunde ou flutue.

\section{b) Pressão Hidrostática}

A pressão é definida como força por unidade de área e a medida padrão é Pascal (newtons $/ \mathrm{m}^{2}$ ). As moléculas de um líquido exercem um impulso sobre cada parte de superfície de um corpo imerso ${ }^{34}$. A lei de Pascal afirma que a pressão de um fluido é exercida de forma igual em qualquer nível em uma direção horizontal, o que significa que a pressão é igual em uma profundidade constante. No entanto, a pressão aumenta com a profundidade e com a densidade do fluído. Uma profundidade maior consequentemente terá uma pressão maior, que pode ser utilizada para reduzir mais efetivamente edemas, desde que a parte tratada seja mantida o mais profundo possível ${ }^{35}$.

Um corpo imerso a uma profundidade de 1,20m sofre uma pressão de 88,9 mmhg, que é levemente maior do que a pressão sanguínea diastólica. Essa é a força que auxilia na resolução do edema de uma parte corporal lesada ${ }^{1}$.

\section{c) Empuxo}

Quando mergulhamos um corpo qualquer na água, verificamos que este exerce sobre o corpo uma força de sustentação, isto é uma força dirigida para cima, que tende a impedir que o corpo afunde no líquido. É a força que atua sobre os objetos imersos, num sentido oposto ao da força da 
gravidade. Essa força é gerada pelo volume de água deslocado e de valor igual ao peso de fluído deslocado, e está intimamente ligada à densidade. Esse princípio foi descoberto por Arquimedes. Percebemos a existência desta força ao tentar mergulhar na água um pedaço de madeira. É também essa forca que faz com que uma pedra pareça mais leve quando imersa na água ou em outro líquido qualquer. Por que aparece o empuxo? Considerando um corpo imerso, o líquido exercerá forças de pressão em toda superfície do corpo em contato com este líquido. Essa pressão aumenta conforme a profundidade, sendo maior na parte inferior do corpo que na superior. A resultante dessas forças, portanto, deverá ser dirigida para cima, tendendo a impedir que o corpo afunde no líquido. A causa do empuxo, portanto, é o fato de existir essa diferença de pressão na parte inferior e superior. De acordo com Arquimedes, o resultado do efeito do empuxo é a flutuação. Um ser humano com gravidade especifica de 0,97 alcança o equilíbrio de flutuação quando $97 \%$ do seu volume está imerso ${ }^{1}$. À medida que o corpo é gradualmente submerso, a água é deslocada, criando a força de flutuabilidade, que retira progressivamente o peso das articulações submersas ( $2 \mathrm{Kg}$ com imersão até o pescoço). A imersão até o processo xifóide elimina até $60 \%$ do peso corporal sobre as articulações, o que é de extrema importância em pacientes com fraturas, pós-cirúrgicos, hemofílicos entre outros que necessitam ganhar ADM e força sem sobrecarga nas articulações. 


\section{d) Metacentro}

O conceito de equilíbrio em biomecânica está associado à ideia de corpo em postura estável. Do ponto de vista mecânico, diz-se que um corpo está em equilíbrio quando diversas forças que agem sobre este corpo estão em direções opostas e se anulam, isto é, as forças responsáveis pelo desequilíbrio do corpo para que haja movimento. O centro de gravidade é o ponto onde todos os momentos (torque) da força estão em equilíbrio. Lembrando que torque é o produto de uma força e a distância sobre a qual age essa força, e pode ser chamado também de momento.

No ser humano, que não é homogêneo, o centro de gravidade no solo localiza-se levemente posterior ao plano sagital mediano e ao nível da segunda vértebra sacral (nível S2). Na água, está localizado na altura dos pulmões. Consequentemente o grau de sustentação parcial do peso varia com a profundidade da água. Com água ao nível $\mathrm{C} 7$, as mulheres e homens suportam $8 \%$ do peso corporal, no nível de processo xifóide $28 \%$ para as mulheres e 35\% para os homens e, ao nível da espinha ilíaca ânteroposterior $47 \%$ para as mulheres e $54 \%$ para os homens ${ }^{36}$. Portanto, os exercícios realizados numa profundidade maior, têm menor descarga de peso sendo que com menor profundidade, teremos maior descarga sobre as articulações. O centro de flutuabilidade é definido como centro de flutuação de todos os momentos da força. Consequentemente, o centro humano de flutuação está no meio do tórax. Quando ambos os centros estiverem alinhados em um plano vertical, apenas as forças vetoriais verticais estarão aparentes, podendo haver uma força compressiva. Quando esses centros estiverem desalinhados verticalmente, podemos ter as situações chamadas 
de metacentro positivo ou negativo, ocorrendo como resultado a força rotacional. O princípio do metacentro, também chamado de princípio de Bougier, preocupa-se com o equilíbrio rotacional na água. Um corpo submerso, esta sujeito a duas forças opostas, flutuabilidade (empuxo) e a gravidade, sendo que a gravidade age no sentido para baixo, enquanto a flutuabilidade para cima. Quando estas duas forças estiverem iguais e opostas uma a outra, o corpo estará em equilíbrio e não haverá nenhum movimento. Entretanto, quando essas forças estiverem desalinhadas a rotação será contínua até que as duas forças sejam alinhadas.

\section{e) Equilíbrio Rotacional = Gravidade X Flutuabilidade (Empuxo)}

Essa força é definida pelo deslocamento horizontal dos centros e pela diferença de magnitude dos vetores entre a força ascendente de flutuação e a força descendente no centro de gravidade ${ }^{1}$. Ao traçarmos uma linha imaginária entre esses centros, de gravidade e flutuabilidade, teremos como resultado o vetor de deslocamento horizontal do momento (torque). Caso ele esteja acima do centro de gravidade, será denominado metacentro positivo e o corpo ficara estável e retornará à posição inicial, mas se estiver abaixo, será o metacentro negativo e o corpo assumira uma nova posição. Quando o terapeuta auxilia o paciente a equilibrar-se na água, ele estará interferindo diretamente no alinhamento do centro de gravidade e flutuabilidade. Qualquer movimento dos membros, tronco ou cabeça, seja ele acima ou abaixo da superfície, altera a forma corporal e provoca efeitos rotacionais, o que também acontece com qualquer alteração na forma por causa de uma deficiência. É importante saber se o paciente irá efetivamente 
rolar, se retornará à posição inicial, como irá realizá-la e se ficará numa posição estável e segura para respiração. Deve-se estar apto a observar e analisar a forma de uma pessoa e instruí-la a respeito das ações apropriadas a serem realizadas para contrabalancear os efeitos rotacionais na água, que podem ser tanto nas posições verticais como nas horizontais. A água reage à forma e à densidade de qualquer objeto que estiver dentro dela e o faz flutuar de acordo com esses fatores. Isso acontece com o ser humano na água, e as variações na forma e na densidade das diferentes partes do corpo são responsáveis por numerosas posições de equilíbrio ${ }^{35}$. Campion ${ }^{35}$, em 2000, descreve quatro posições utilizadas com frequência para prover estabilidade sendo da mais estável para instável, a bola, cubo, triângulo e bastão. Essas posturas poderão ser utilizadas tanto para pacientes como para os terapeutas também terem estabilidade na água.

\subsubsection{Propriedades dinâmicas da água (hidrodinâmicas)}

A água em movimento é uma substância física complexa. Os principais princípios do fluxo são conhecidos e podem ser aplicados a atividades gerais.

\section{a) Viscosidade}

Esta é o tipo de atrito que ocorre entre as moléculas de um líquido e que causa resistência ao seu fluxo ${ }^{34}$. 
Os líquidos possuem uma propriedade chamada viscosidade, que se refere à magnitude da fricção interna específica do fluido. Uma energia deve ser exercida para se criar o movimento. Quanto maior a viscosidade do fluído maior será a força necessária para criar o movimento dentro do fluído. A viscosidade é a primeira propriedade aquática dependente do tempo. Quando o movimento na água é lento e constante, é chamado de fluxo laminar e a viscosidade do líquido está diretamente relacionada à velocidade da corrente e, a flutuação é a principal força para agir sobre o corpo. Com o aumento da velocidade da corrente, gera-se o fluxo turbulento. Quanto mais rápido for o movimento, maior será o arrasto ou resistência encontrada. Em terra, a resistência ao movimento e oferecida pelo ar e é definida como resistência de atrito. No meio líquido esta resistência é fornecida pela água e pode variar dependendo da velocidade, forma do corpo, turbulência, densidade do líquido, etc. Na água, a resistência é de 600 a 800 vezes maior que no ar. A viscosidade, com todas as suas propriedades físicas, é uma qualidade que torna a água um meio útil para o fortalecimento ${ }^{1}$.

\section{b) Fricção}

Os fluídos apresentam diferentes atrações moleculares dentro deles e, à medida que as suas camadas são postas em movimento, essa atração cria uma resistência ao movimento e é detectada como fricção. Quando um objeto move-se relativamente a um fluído, ele está sujeito a efeitos de resistência do fluído. Essa força é chamada de arrastamento (arrasto de fricção) e se deve a viscosidade do fluído e à turbulência, quando presente (1). Froud $(1810-1879)^{37}$ e Zahm $(1862-1945)^{38}$ mostraram que a 
fricção provocada pelo movimento da água oferece resistência mínima ao movimento e, portanto, pode ajudar no exercício aquático terapêutico nos pacientes com força muscular diminuída.

\section{c) Tensão superficial}

É a força exercida entre as moléculas da superfície de um líquido ${ }^{34}$. A superfície de um líquido age como uma membrana sob tensão ${ }^{1}$. Dessa forma, uma gota de água pode ficar pendurada na ponta de um canudinho e uma agulha mais pesada do que a água pode flutuar na superfície da mesma, suspensa pôr essa barreira. A força resistiva da tensão superficial torna-se uma variável ativa na medida em que a área da superfície aumenta. Assim, quando o exercício é feito vigorosamente e rompe a superfície, criando espuma e gotículas, uma força considerável é exercida para superar a tensão superficial.

\section{d) Turbulência}

O surgimento do fluxo turbulento é uma função da velocidade do fluído, mas também está relacionado à densidade, à viscosidade e à fricção. Turbulência é um termo que indica os redemoinhos que seguem um objeto quando se movimenta através de um fluído. O grau de turbulência dependerá da velocidade do movimento e da forma do objeto. Quando um objeto movese relativamente a um fluído, ele está sujeito a efeitos da resistência do fluído. Essa força é chamada de arrasto e se deve à viscosidade do fluído e a turbulência, quando presentes. Teorema de Bernoulli preocupa-se com a 
relação entre a pressão e a velocidade do fluído ao longo de uma linha aerodinâmica (teorema de Reynolds e teorema de Prandtl) em um fluxo estável de um líquido sem atrito e que possui uma densidade constante ${ }^{35}$.

De acordo com Reynolds, existem dois tipos de fluxo, o laminar, onde o fluxo e de linhas aerodinâmicas e de moléculas em padrões uniformes e regulares, e o turbulento, onde o movimento das moléculas é rápido, aleatório e não ocorrem numa linha aerodinâmica, criando movimentos de retorno e redemoinhos. A forma do corpo tem uma enorme influência sobre a produção da turbulência. Uma vez que qualquer movimento gera turbulência, esta pode ser utilizada tanto para auxiliar quanto para resistir aos movimentos. Quando um movimento é realizado em um mesmo sentido, a turbulência formará redemoinhos na mesma direção, e o movimento será cada vez mais fácil, caso se inverta o sentido do movimento, exigirá um trabalho da musculatura atuando em oposição ao movimento, exigindo maior esforço ${ }^{36}$.

A cooperação com os efeitos da turbulência exige equilíbrio e coordenação e isso pode ser usado para desenvolver essas habilidades como parte do programa de tratamento. A atividade na água pode se tornar mais difícil em razão da mudança dos movimentos em linhas aerodinâmicas para movimentos fora dessas linhas ${ }^{34}$.

\subsubsection{Termodinâmica}

A propriedade termodinâmica da água corresponde à sua capacidade de absorver e transferir calor, que ocorre através de mecanismos 
físicos como condução, convecção, radiação e evaporação. A utilidade terapêutica da água depende tanto de sua capacidade de reter quanto de sua capacidade em transferir calor. Uma água quente em hidroterapia é considerada a uma temperatura acima de $34^{\circ} \mathrm{C}$; uma água termo neutra entre $31^{\circ} \mathrm{C}$ a $33^{\circ} \mathrm{C}$; e uma água fria entre $28^{\circ} \mathrm{C}$ e $30^{\circ} \mathrm{C}$. Essa troca de energia na forma de calor é conhecida como processo termolítico.

A radiação transfere calor através da transmissão de ondas eletromagnéticas. Se a temperatura ambiental for menor que a corporal, produz um gradiente térmico que aumenta a emissão de ondas eletromagnéticas pelo qual se perde calor (processo termolítico). Se a temperatura ambiental for maior, o corpo recebe a onda eletromagnética, aumentando a temperatura corporal (processo de termogênese). Durante o exercício, a temperatura da água necessária para evitar uma elevação na temperatura central durante atividades prolongadas varia de $17^{\circ} \mathrm{C}$ a $34^{\circ} \mathrm{C}$ dependendo da quantidade de exercícios e da composição corporal da pessoa, principalmente de gordura corporal ${ }^{39}$.

\subsection{Fisiologia da Imersão}

\subsubsection{Efeitos no sistema pulmonar}

O sistema pulmonar é profundamente afetado pela imersão até o tórax. Em parte, devido ao deslocamento de sangue para a cavidade torácica e em parte, pela compressão da parede torácica pela água, resultando na alteração da função pulmonar ${ }^{3}$. 
A capacidade residual funcional diminui em $54 \%$ com imersão até o xifoide ${ }^{40}$, principalmente devido à redução no volume de reserva expiratório. Ocorre redução na capacidade de difusão pulmonar, fluxo expiratório e complacência da parede torácica. O efeito resultante dessas alterações é o aumento do trabalho respiratório em até $60 \%$ durante imersão até o pescoço. Aproximadamente três quartos da sobrecarga são atribuídos ao aumento no trabalho elástico (redistribuição do sangue para o tórax) e o resto deve-se ao trabalho dinâmico (força hidrostática sobre o tórax) ${ }^{41,42}$.

Quando um indivíduo está imerso até a região cervical, há diminuição nas trocas gasosas e também na concentração de oxigênio no sangue devido à distensão dos leitos pulmonares ocasionada pelo fluxo de sangue das extremidades para o abdome. Há também maior resistência da passagem aérea contra o movimento do ar e diminuição do fluxo expiratório, aumentando o tempo necessário para retirar o ar dos pulmões. Devido à pressão hidrostática, há diminuição da circunferência torácica em aproximadamente $10 \%$ e aumento da pressão pleural de $-1 \mathrm{mmHg}$ para + $1 \mathrm{mmHg}^{1}$. Dessa maneira, à imersão até o pescoço ocorre aumento do trabalho total da respiração em $60 \%$ para um volume corrente de 1 litro. Um programa de exercícios aquáticos constitui desafio significativo para o aparelho respiratório, possibilitando a melhora da função respiratória ${ }^{3}$.

\subsubsection{Efeitos nos sistemas renal e endócrino}

Os principais efeitos observados durante a imersão nos sistemas renal e endócrino são: aumento do fluxo sanguíneo renal e clearance de 
creatinina; redução da atividade simpática renal secundária à resposta vagal causada pela distensão do átrio esquerdo com aumento no transporte tubular de sódio; aumento na excreção renal de sódio que por ser acompanhado de água livre estimula a diurese; aumento na excreção renal de potássio; redução da liberação de hormônio anti-diurético e aumento na secreção de peptídeo natriurético e atividade da renina plasmática ${ }^{12}$.

Em geral, a expansão do volume central induzida pela imersão causa aumento no débito urinário e excreção de sódio e potássio. Pode ocorrer diminuição na pressão arterial por várias horas. Historicamente, a imersão foi um dos poucos métodos efetivos de tratamento não invasivo da insuficiência cardíaca congestiva antes da descoberta dos digitalis ${ }^{3}$.

As alterações que ocorrem no sistema renal durante a imersão estão relacionadas com as alterações do sistema circulatório. Isso porque, o aumento de volume de sangue no tórax e coração estimula os barorreceptores do átrio direito, que informam ao sistema renal a sobrecarga atrial. Essa sobrecarga libera um fator natriurético humoral, que produzirá o peptídeo natriurético atrial (PNA), o qual facilita a excreção de sódio e a diurese. A ação renal é fortemente controlada pelos hormônios renina, aldosterona e hormônio antidiurético. Ocorre relaxamento dos músculos lisos vasculares e inibição da produção da aldosterona, responsável pela reabsorção de sódio no túbulo renal distal. A liberação do hormônio antidiurético $(\mathrm{ADH})$ é suprimida durante a imersão em $50 \%$, o que contribui para a diurese. A ligação neuroendócrina entre a percepção de volume e as alterações renais na excreção de sódio está funcionalmente preservada na insuficiência cardíaca compensada, mas a natriurese induzida pela 
estimulação do volume é modulada pela atividade do eixo reninaangiotensina-aldosterona ${ }^{43}$.

Em suma, a expansão volumétrica central resultante da imersão provoca o aumento do clearance urinário (de $1 \mathrm{ml} / \mathrm{min}$ para $7 \mathrm{ml} / \mathrm{min}$ ) e um aumento significativo de excreção de sódio e potássio (imediatamente após a imersão e continua a aumentar constantemente durante várias horas de imersão até diminuir nas horas subsequentes).

Os efeitos combinados dos sistemas renal e nervoso simpático em geral diminuem a pressão sanguínea de um indivíduo hipertenso, durante uma imersão e criam um período de pressão mais baixa durante horas após a imersão ${ }^{1}$.

Acompanhando as alterações no controle renal ocorrem alterações em alguns neurotransmissores do sistema nervoso autônomo catecolaminas (sendo as mais importantes a epinefrina, a norepinefrina e a dopamina) - que agem regulando a resistência vascular, a frequência cardíaca e a força de contração cardíaca e são ativadas logo após a imersão 44,45

\subsubsection{Efeitos no sistema músculo-esquelético}

A imersão diminui a carga sobre as articulações e os ossos: a nível da sínfise púbica, reduz cerca de $40 \%$ do peso corpóreo, na cicatriz umbilical, $50 \%$ e até o xifóide, pelo menos $60 \%{ }^{46}$.

Os efeitos da flutuabilidade e resistência da água possibilitam altos níveis de gasto energético com relativamente pouco movimento e sobrecarga 
articular. Ocorre redução da vasoconstrição simpática e aumento do fluxo sanguíneo muscular. Dessa maneira, há aumento da oferta de oxigênio ao músculo e remoção de metabólitos. A pressão hidrostática promove a redução de edema e eliminação de lactato muscular ${ }^{3}$.

\subsection{Fisiologia do exercício na água}

Em virtude das diferentes propriedades físicas da água, os fatores que determinam o gasto energético do exercício na água são diferentes daqueles no solo. A flutuação reduz o peso do corpo e o gasto de energia necessária para deslocar o corpo contra a gravidade. Por outro lado, a viscosidade da água aumenta o gasto energético necessário para realizar movimentos e deslocamentos. Durante o exercício leve e moderado, usado na reabilitação aquática, a maior parte da energia usada para sustentar a atividade física é suprida pelo metabolismo aeróbio. O exercício na água faz com que o suprimento sanguíneo nos músculos aumente devido ao metabolismo celular. A combustão de oxigênio deve aumentar para que ocorra maior obtenção de energia. Dessa reação há acúmulo de dióxido de carbono, alterando o ph plasmático e, tendo como resposta, o aumento do batimento cardíaco e da frequência respiratória ${ }^{47}$.

Frangolias et al. $^{48}$, em 1995, compararam as respostas de concentração do lactato sanguíneo durante 42 minutos de corrida em imersão e no solo em esteira, a uma intensidade igual ao limiar ventilatório. Para os primeiros 14 minutos de exercício, as respostas de lactato foram similares. Entre os minutos 21 e 42, o lactato sanguíneo diminuiu mais no 
exercício na água (25\%) que em terra (12\%), indicando que a entrada de lactato no sangue foi menor ou sua taxa de remoção foi maior durante estágios avançados de corrida na água ${ }^{48}$.

\subsection{Benefícios da terapia aquática}

Os efeitos terapêuticos desejados com os exercícios na água estão relacionados a:

a) relaxamento, alívio da dor e espasmos musculares;

b) manutenção ou aumento da amplitude de movimento articular, sem sobrecarga;

c) fortalecimento dos músculos e aumento na sua resistência aos exercícios;

d) melhora da circulação e redução de edema;

e) manutenção e melhora do equilíbrio, estabilidade e consciência corporal.

A partir de 1960 ocorreu renovado interesse na reabilitação aquática devido a duas razões principais: a imersão em água possibilita estudar as respostas cardíacas, pulmonares e renais à expansão do volume sanguíneo central, parte importante para a compreensão de como o organismo humano mantém as funções normais durante uma alteração fisiológica. Além disso, é o modelo ideal para simular os efeitos da ausência de gravidade. Foi realizada uma pesquisa básica crítica sobre as respostas dos diferentes sistemas biológicos à imersão. Dessa forma, quando a humanidade se preparava para explorar o espaço, procurou e encontrou as 
respostas naquele que foi seu primeiro ambiente: imersão corporal total

termoneutra ${ }^{1}, 3$. Consequentemente, a reabilitação aquática tem seus fundamentos baseados em pesquisa básica de alta qualidade, sendo uma técnica de tratamento cientificamente estudada e comprovada.

A reabilitação aquática utiliza as propriedades da água para a restauração da mobilidade, função motora e atividade fisiológica ${ }^{1}$.

\subsection{Reabilitação Cardiovascular}

O tratamento da insuficiência cardíaca modificou-se significativamente nos últimos anos. Do ponto de vista medicamentoso, os agentes beta-bloqueadores tornaram-se drogas de primeira escolha, em detrimento dos simpatomiméticos. Em relação à atividade física, a mudança foi mais drástica: até meados de 1980, insuficiência cardíaca, dilatação do coração e disfunção do ventrículo esquerdo eram consideradas contraindicações absolutas ou relativas para a realização de exercícios. O conceito de condicionamento físico para pacientes com insuficiência cardíaca foi desenvolvido após um período de intensa avaliação da eficácia e segurança da reabilitação com exercícios em pacientes coronariopatas e baseado na melhor compreensão dos mecanismos de adaptação periférica na insuficiência cardíaca ${ }^{8}$.

$\mathrm{Na}$ insuficiência cardíaca, a inatividade física leva ao descondicionamento que envolve músculos esqueléticos e respiratórios, assim como a circulação periférica. Ocorre redução da capacidade aeróbia determinada principalmente por alterações vasculares do músculo 
esquelético causando menor perfusão tecidual e anormalidades no metabolismo e massa muscular com maior comprometimento da capacidade funcional $^{49,50,51,52,53}$.

De todos os sintomas da insuficiência cardíaca, a intolerância ao exercício constitui-se no mais importante fator na limitação do paciente ${ }^{10}$ : causa deterioração progressiva da função e diminui a autoconfiança podendo levar à disfunção psicossocial. A etiologia da intolerância ao exercício é multifatorial, sendo as alterações periféricas ao invés da performance do ventrículo esquerdo, os determinantes mais importantes da capacidade física 8. A ausência de correlação entre capacidade do esforço e função ventricular contribuiu para mudar o foco de atuação do coração para a musculatura esquelética: a melhora da função muscular periférica é tão importante quanto a redução das alterações cardiovasculares ${ }^{10,54,55,56}$. Recentemente, foi demonstrado que a força muscular é um importante fator preditivo de mortalidade na insuficiência cardíaca severa, sendo recomendada sua avaliação sistemática nesses pacientes ${ }^{57}$. A redução da tolerância ao exercício deve-se em parte à incapacidade de aumentar o débito cardíaco devido às alterações na vasodilatação periférica, disfunção endotelial, metabolismo muscular alterado e aumento da atividade simpática. Todos esses fatores contribuem para a utilização ineficiente do débito cardíaco limitado ${ }^{58}$.

A interação neurohormonal entre periferia e coração é fator importante na determinação de sintomas e prognóstico. As intervenções terapêuticas que modificam essas interações são consideradas valiosas: o exercício pode ser considerado dessa forma ${ }^{8}$. O treinamento físico é útil no 
tratamento da insuficiência cardíaca, com melhora da tolerância ao esforço, maior força muscular e consumo de oxigênio ${ }^{10}$.

Pacientes com insuficiência cardíaca congestiva das mais diversas etiologias têm se beneficiado com programas de reabilitação supervisionados. Considera-se hoje que o exercício físico é um método secundário de prevenção e tratamento da insuficiência cardíaca congestiva. Vários estudos, nestes casos, têm demonstrado melhora da qualidade de vida ${ }^{59}$. Os pacientes com insuficiência cardíaca apresentam melhora da condição clínica através do treinamento físico devido ao aumento da capacidade aeróbia e melhora do tônus autonômico, anormalidades neurohormonais e atividade oxidativa mitocondrial do músculo esquelético ${ }^{60}$. Internações frequentes e descompensações recorrentes prolongam os períodos de inatividade e prejudicam ainda mais o estado funcional, assim como a habilidade e motivação para realizar exercícios. A desistência de programas de treinamento físico é influenciada, entre outros fatores, pela motivação, ambiente de treino e seleção de atividades ${ }^{60}$. A piora funcional resultante da progressão da insuficiência cardíaca pode limitar a participação e adesão a programas convencionais de treinamento físico. Os pacientes acabam por evitar subir e descer escadas ou até mesmo andar o que resulta em alterações musculares que predominam nos membros inferiores ${ }^{61}$.

Exercícios na água e natação são tradicionalmente recomendados para pacientes com baixo risco cardíaco. No entanto, em pacientes com insuficiência miocárdica severa e insuficiência cardíaca severa ainda não há consenso na literatura sobre a indicação do exercício na água, principalmente 
devido à falta de informação sobre as respostas hemodinâmicas centrais e pressão sistêmica durante a imersão nesses pacientes ${ }^{1}$, 8, 9, 10 . A terapia aquática pode ser considerada potencialmente perigosa para pacientes com insuficiência cardíaca devido ao aumento do retorno venoso e possível efeito adverso sobre a pressão de enchimento ventricular ${ }^{62}$. Por esse motivo, a natação foi contra-indicada para pacientes com insuficiência cardíaca que apresentam disfunção diastólica e sistólica ${ }^{8,9}$. Por outro lado, diversos estudos recentes demonstraram que a terapia aquática é segura e pode beneficiar a capacidade funcional em pacientes com insuficiência cardíaca em grau moderado ${ }^{62,63}$ e até severo ${ }^{60}$.

A terapia aquática pode ser uma alternativa atraente ao treinamento convencional devido ao baixo impacto e ambiente com temperatura controlada que promove relaxamento muscular, vasodilatação periférica e auxilia no movimento das articulações, facilitando, dessa forma, a realização da atividade física ${ }^{60}$. Exercícios para mobilidade, fortalecimento e condicionamento cardiovascular podem ser facilmente realizados na água.

A imersão em água até o esterno resulta em efeitos cardiovasculares, renais e neurohormonais favoráveis em pessoas saudáveis e com insuficiência cardíaca. A imersão aumenta o volume sanguíneo torácico, pressão venosa central e débito cardíaco, reduz os níveis plasmáticos de norepinefrina, epinefrina, renina, angiotensina II e aldosterona, além de promover a diurese ${ }^{12}$.

Os exercícios na água podem facilitar o recondicionamento, principalmente nos membros inferiores, visto que o empuxo minimiza o 
esforço necessário e facilita a atividade física possibilitando o treinamento aeróbio efetivo ${ }^{59}$.

A vasodilatação e hidromassagem promovem o relaxamento muscular, enquanto o treinamento com exercícios afeta positivamente a inflamação sistêmica e ativação neurohormonal observada em estágios avançados da insuficiência cardíaca ${ }^{64}$.

\subsubsection{Recomendações para treinamento físico}

Qualquer recomendação para o treinamento físico de pacientes com insuficiência cardíaca deve ser baseada nas condições clínicas de cada paciente, reposta individual ao exercício (inclusive frequência cardíaca, pressão arterial, sintomas e percepção de esforço), além, é claro, dos resultados obtidos com o teste ergoespirométrico. Outros fatores que devem ser considerados são: medicação atual, fatores de risco, características comportamentais, objetivos e preferências pessoais ${ }^{8}$. Segundo o American Heart Association heart failure guideline de 2005, recomenda-se o exercício físico para todos os pacientes clinicamente estáveis com insuficiência cardíaca e redução da fração de ejeção ventricular ${ }^{65}$.

A segurança é uma preocupação central em programas de exercício para pacientes com insuficiência cardíaca. É importante ressaltar que não há necessidade de exercícios de alta intensidade para que ocorram os benefícios relacionados ao exercício. O paciente não deve se exercitar além do ponto no qual consegue manter uma conversação normal (teste da fala) 66,67 . 
Os efeitos do exercício na doença coronariana devem-se em grande parte ao controle dos fatores de risco com decréscimo substancial na mortalidade: diminuição do LDL, aumento do HDL, perda de peso e redução na pressão arterial e resistência à insulina ${ }^{67}$.

As recomendações para realização de atividade física em pacientes com insuficiência cardíaca e doença coronariana estão resumidas na Tabela 1.

Tabela 1 - Recomendações para atividade física em pacientes cardiopatas*.

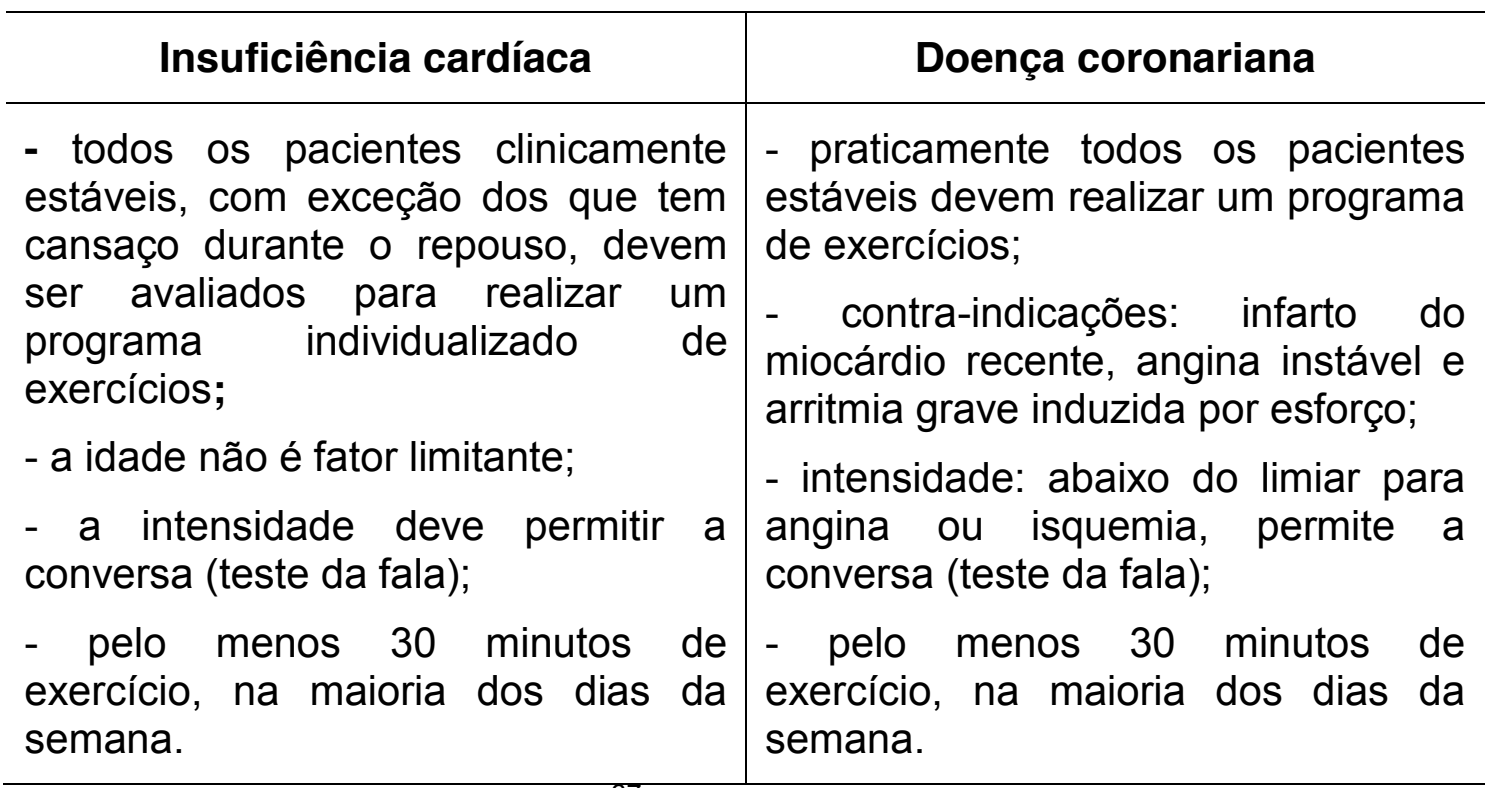

${ }^{*}$ adaptado de Joshi S. B. $2007^{67}$.

As indicações para adiar o início da atividade física são: angina instável, insuficiência cardíaca não controlada, estenose aórtica severa, hipertensão não controlada, hipotensão sintomática, febre aguda, sensação de mal-estar, taquicardia em repouso ou arritmias, diabetes não controlada. A atividade física deverá ser postergada até que o paciente seja avaliado e 
liberado pelo médico. Em geral, são situações que podem ser controladas com o tratamento adequado.

Os sinais de alerta para interrupção imediata de uma determinada atividade física incluem: dor ou desconforto pré-cordial, tontura, vertigem, dificuldade respiratória, náusea, sudorese excessiva, palpitações associadas com desconforto, fadiga desproporcional ao esforço, inabilidade física para continuar e no caso de diabetes, tremor, formigamento, fome, fraqueza ou palpitação. O paciente deverá ser prontamente encaminhado e avaliado por um médico ${ }^{66}$.

Os exercícios devem ser prescritos com o mesmo cuidado do tratamento medicamentoso ${ }^{68}$. A taxa de progressão de treinamento deve ser estabelecida individualmente e seguir três estágios: início, progressão e manutenção ${ }^{8}$. Os fundamentos para o desenvolvimento da prescrição de exercícios são relacionados no Quadro 3.

Quadro 3 - Fundamentos para a prescrição de exercícios.

a) avaliação médica e determinação da frequência cardíaca máxima (de preferência através do teste de esforço).

b) intensidade e duração (taxa de progressão):

1. Início: baixa intensidade (40 a $50 \%$ do $\mathrm{VO}_{2}$ máximo) até atingir duração de 10 - 15 minutos;

2. Progressão: aumento gradual da intensidade $\left(50,60\right.$ até $70 \%$ do $\mathrm{VO}_{2}$ máximo) e duração do exercício (15, 20 e 30 minutos, se possível);

3. Manutenção: geralmente após 6 meses de treinamento.

c) frequência: 4 a 6 vezes por semana.

d) tipo de exercício:

- Exercícios aeróbios com aquecimento e recuperação;

- Exercícios resistidos, 2 a 3 vezes por semana. 


\subsection{Reabilitação aquática}

A prescrição de exercícios na água para indivíduos com insuficiência cardíaca também deve seguir as recomendações supracitadas e ser individualizada. Além disso, há certas variáveis específicas relacionadas ao meio aquático. Os principais fatores que influenciam os efeitos da imersão são: condição clínica, temperatura e nível da água, posicionamento na piscina, tipo de atividade, duração da imersão e adaptação ao meio.

\subsubsection{Condição Clínica}

No estudo de Schmid et al. $^{2}$, em 2007, foram avaliadas as adaptações cardiovasculares em pacientes com doença coronariana e insuficiência cardíaca, classe funcional I e II da NYHA, durante imersão, ginástica na água e natação. A resposta cardíaca à imersão até o tórax caracterizou-se por redução na frequência cardíaca e resistência vascular periférica, aumento no volume sistólico, pressão arterial sistólica inalterada e diastólica discretamente diminuída. Essas respostas resultam provavelmente dos seguintes mecanismos: elevação da pressão atrial devido ao maior retorno venoso resultando em aumento da frequência cardíaca para lidar com o maior volume circulante (reflexo de Bainbridge) e início do mecanismo de Frank-Starling que eleva o volume sistólico e pressão sanguínea sistólica. Observaram que os mecanismos reflexos de Bainbridge e Frank-Starling permanecem intactos nos pacientes com insuficiência cardíaca e que apesar da disfunção severa do ventrículo esquerdo com $\mathrm{VO}_{2}$ máximo entre 15,4 e 
24,1 $\mathrm{ml} / \mathrm{kg} / \mathrm{min}$, esses pacientes toleraram bem a imersão, ginástica e natação do ponto de vista clínico.

Em indivíduos saudáveis, a resposta hemodinâmica ao exercício na água é determinada principalmente por mecanismos que incluem a précarga e volume sistólico enquanto que em pacientes com redução da fração de ejeção, o débito cardíaco é regulado predominantemente por alteração na frequência cardíaca. Há dois pontos importantes para a prática clínica:

1- em pacientes com insuficiência cardíaca, a resposta cronotrópica durante o teste de esforço é parâmetro chave para a avaliação da tolerância à imersão;

2- os dados obtidos por Sheldah et al. ${ }^{69}$, em 1987, e Christie et al. ${ }^{70}$, em 1990, demonstram que indivíduos saudáveis têm resposta similar na frequência cardíaca durante exercício no solo e na água até $60 \%$ do $\mathrm{VO}_{2}$ máximo e menor acréscimo com intensidades maiores. Em pacientes com infarto do miocárdio não foi observada diferença na frequência cardíaca durante exercício no solo e na água até $75 \%$ do $\mathrm{VO}_{2}$ máximo ${ }^{71}$. Dessa maneira, não há necessidade de adaptar a frequência cardíaca de treino para exercícios na água a intensidades menores que $60 \%$ do $\mathrm{VO}_{2}$ máximo, principalmente para pacientes com disfunção do ventrículo esquerdo.

A distensão dos vasos periféricos em água termoneutra resulta em diversos efeitos salutares que podem ser benéficos para pacientes com insuficiência cardíaca: diminuição da resistência vascular sistêmica e supressão de vasopressina, arginina, renina e norepinefrina ${ }^{72}$. A ativação de mecanorreceptores cardíacos desencadeia ajustes reflexos na excreção renal de água e eletrólitos; este mecanismo está preservado em pacientes 
com insuficiência cardíaca ${ }^{12}$. Gabrielsen et al. ${ }^{43}$, em 2001, demonstraram que a expansão de volume intravascular e central na insuficiência cardíaca compensada inibe a atividade do sistema renina-angiotensina-aldosterona, aumenta a liberação de peptídeo atrial natriurético e induz a natriurese que é aumentada quando as concentrações de angiotensina-II e aldosterona são suprimidas pelos inibidores da ECA. Pode-se concluir que a imersão em água elícita respostas fisiológicas similares às obtidas com 0 tratamento farmacológico moderno.

Com relação à recomendação para atividades na água em pacientes com insuficiência cardíaca, os parâmetros de capacidade física parecem ser mais importantes do que as medidas ecocardiográficas. Exercícios na água e natação correspondem a um nível de intensidade 4 do equivalente metabólico (MET) ou $\mathrm{VO}_{2}$ máximo de $14 \mathrm{ml} / \mathrm{kg} / \mathrm{min}(1 \mathrm{MET}=3,5$ $\mathrm{ml} / \mathrm{kg} / \mathrm{min}$ ). A natação nas condições testadas em pacientes com insuficiência cardíaca, doença coronariana e controles saudáveis correspondeu ao nível de intensidade abaixo do limiar anaeróbio. Uma vez que o $\mathrm{VO}_{2}$ é proporcional ao volume sistólico, $\mathrm{o} \mathrm{VO}_{2}$ máximo pode ser usado para estimar as alterações no volume sistólico durante a imersão e natação.

Segundo Schmid et al. $^{2}$, em 2007, é necessário alterar o paradigma de recomendação de exercícios em água termoneutra para pacientes com insuficiência cardíaca estável e classe funcional I e II da NYHA. Em condições clínicas estáveis com um $\mathrm{VO}_{2}$ máximo de pelo menos $15 \mathrm{ml} / \mathrm{kg} / \mathrm{min}$ e limiar anaeróbio > $10 \mathrm{ml} / \mathrm{kg} / \mathrm{min}$ durante teste de esforço limitado por sintoma caracterizam pacientes com redução severa da fração de ejeção que podem realizar atividade física em água termoneutra com 
segurança. De maneira geral, exercitar-se de forma segura em cicloergômetro com carga de 70W (correspondendo a 4 METs) ou 110W (6 METs), é um bom indicador de tolerância ao exercício na água mesmo em pacientes com insuficiência cardíaca. Entretanto, a resposta cronotrópica inadequada ao exercício pode caracterizar pacientes com baixa tolerância a atividades aquáticas uma vez que quando há redução da fração de ejeção, o débito cardíaco durante a imersão e natação é regulado predominantemente pela frequência cardíaca.

Gabrielsen et al. ${ }^{13}$, em 1993, avaliaram os efeitos da imersão a $35^{\circ} \mathrm{C}$ em pacientes com insuficiência cardíaca classe funcional II e III da NYHA, relatando aumento no débito cardíaco, volume sistólico e fração de ejeção enquanto que a resistência vascular sistêmica diminuiu significativamente $^{72}$. Cider et al. ${ }^{73}$, em 2005, realizaram uma série de estudos para avaliar a segurança e efeitos da terapia aquática em pacientes com insuficiência cardíaca classe funcional II e III da NYHA. Descreveram melhora na função física, excelente tolerabilidade e adesão (95\%) com hidroterapia e ênfase no treinamento muscular periférico por 12 semanas $^{63}$. Em outro estudo, afirmaram que os efeitos cardiorrespiratórios da imersão em água medidos por análise de gás parecem ser similares em pacientes e controles saudáveis $^{73}$. Sugeriram ainda que a imersão em água quente induz efeitos hemodinâmicos benéficos em pacientes com insuficiência cardíaca sem reações adversas. Os resultados indicaram que o aumento do retorno venoso é balanceado pela redução da frequência cardíaca e provável diminuição da pós-carga devido à vasodilatação periférica, promovendo melhora no débito do ventrículo esquerdo. Além disso, a redução na frequência cardíaca 
promove o enchimento diastólico e possibilita que os ventrículos lidem melhor com o retorno venoso aumentado sem afetar a pré-carga. Apesar da imersão em água quente reduzir a resistência vascular sistêmica, não houve alteração significativa da pressão arterial, o que pode ser explicado pelo aumento do débito cardíaco no grupo controle e tendência à redução nos pacientes com insuficiência cardíaca ${ }^{62}$.

Municinó et al. ${ }^{60}$, em 2006, demonstraram a eficácia e segurança de um programa de treinamento com exercícios na água em pacientes com insuficiência cardíaca classe funcional II, III e IV da NYHA, fração de ejeção entre 20 e $35 \%$ e $\mathrm{VO}_{2}$ máximo $<18 \mathrm{ml} / \mathrm{kg} / \mathrm{min}$, sendo que 4 pacientes apresentavam valores inferiores a $10 \mathrm{ml} / \mathrm{kg} / \mathrm{min}$ (menor valor de 7.0 $\mathrm{ml} / \mathrm{kg} / \mathrm{min})^{60}$

\subsubsection{Temperatura da água}

Na literatura, há diversas pesquisas sobre o efeito da temperatura da água em indivíduos saudáveis. Segundo Skinner et al. ${ }^{34}$, em 1983, os riscos de hipertermia ou efeitos cardiovasculares adversos não são maiores após 21 minutos de imersão à $40^{\circ} \mathrm{C}$ e $41.5^{\circ} \mathrm{C}$, mas há relato da ocorrência de hipotensão durante o ortostatismo para a saída da água ${ }^{74}$. As respostas termorreguladoras durante caminhada de 60 minutos na água às temperaturas de 25,30 e $35^{\circ} \mathrm{C}$ foram estudadas por Shimizu et al. ${ }^{75}$, em 1998. Concluíram que essa atividade oferece vantagens na melhora da mobilidade e que pode ser desejável que pacientes com performance circulatória comprometida minimizem a sobrecarga cardíaca para uma dada 
intensidade de exercício. À temperatura próxima da termoneutralidade, as demandas termorreguladoras para dissipação de calor são baixas.

Srámek et al. $^{76}$, em 2000, investigaram as alterações cardiovasculares e hormonais após 1 hora de imersão até o pescoço às temperaturas de $32^{\circ}, 20^{\circ}$ e $14^{\circ} \mathrm{C}$. Os resultados estão resumidos na Tabela 02.

Tabela 02 - Alterações cardiovasculares e hormonais com imersão a $32^{\circ}$, $20^{\circ}$ e $14^{\circ} \mathrm{C}$.

\begin{tabular}{lccc}
\hline Temperatura da água & $32^{\circ} \mathrm{C}$ & $20^{\circ} \mathrm{C}$ & $14^{\circ} \mathrm{C}$ \\
\hline Temperatura retal & s.a. & $\downarrow 1{ }^{\circ} \mathrm{C}$ & $\downarrow 1.7^{\circ} \mathrm{C}$ \\
\hline Taxa metabólica & s.a. & $\uparrow 93 \%$ & $\uparrow \uparrow 350 \%$ \\
\hline Frequência cardíaca & $\downarrow 15 \%$ & $\downarrow$ & $\uparrow$ \\
\hline Pressão arterial & $\downarrow$ & $\downarrow$ & $\downarrow$ \\
\hline Renina & $\downarrow 46 \%$ & $\downarrow$ & $\downarrow$ \\
\hline Cortisol & $\downarrow 34 \%$ & $\downarrow$ & $\uparrow$ \\
\hline Aldosterona & $\downarrow 17 \%$ & s.a. & $\uparrow \uparrow 163 \%$ \\
\hline Diurese & $\uparrow 107 \%$ & - & $\uparrow 9 \%$ \\
\hline $\begin{array}{l}\text { Noradrenalina e } \\
\text { dopamina }\end{array}$ & - & &
\end{tabular}

Os dados sugerem que a imersão em água termoneutra estimula principalmente os barorreceptores enquanto que a exposição ao frio estimula os termorreceptores, ativando diferentes sistemas reguladores e mecanismos efetores. A imersão em água termoneutra induziu bradicardia e redução da 
pressão arterial. A imersão em água fria $\left(14^{\circ} \mathrm{C}\right)$ reduziu a temperatura corpórea em $1.7^{\circ} \mathrm{C}$ o que induziu à termogênese e ativação do sistema nervoso simpático, evidenciada pelo aumento na concentração de noradrenalina. Consequentemente, houve acréscimo na frequência cardíaca e pressão arterial. Deve-se lembrar que a imersão à $14^{\circ} \mathrm{C}$ induz tremores que podem ser considerados como exercício leve.

O estudo de Park et al. ${ }^{77}$, em 1999, avaliou os efeitos da imersão em água fria sobre as funções cardiovasculares durante o repouso e exercício (resultados na Tabela 3). Observaram elevação de 50\% no débito cardíaco à imersão a $30^{\circ}$ e $34.5^{\circ} \mathrm{C}$, principalmente por aumento no volume sistólico e não na frequência cardíaca. Por outro lado, durante exercício de intensidade moderada, a elevação no débito cardíaco resultou de aumento na frequência cardíaca e não no volume sistólico. Apesar da diminuição acentuada na resistência periférica, não relataram redução significativa da pressão arterial à imersão. Sugerem que durante a imersão em água fria, a vasoconstrição periférica aumenta ainda mais a pré-carga e o volume sistólico. Além disso, o aumento no débito cardíaco durante a imersão é necessário para manter a pressão arterial frente à redução na resistência vascular periférica ${ }^{76}$. 
Tabela 3 - Resumo das alterações cardiovasculares à imersão em água a $30^{\circ}$ e $34.5^{\circ} \mathrm{C}$ (repouso).

\begin{tabular}{lcc}
\hline Temperatura da água & $30^{\circ} \mathrm{C}$ & $34.5^{\circ} \mathrm{C}$ \\
\hline Volume sistólico & $\uparrow 69 \%$ & $\uparrow 55 \%$ \\
\hline Frequência cardíaca & $\downarrow 15 \%$ & s.a. \\
\hline Pressão arterial sistólica & $\uparrow 11 \%$ & $\uparrow 8 \%$ \\
\hline Pressão arterial diastólica & $\uparrow 15 \%$ & s.a. ${ }^{*}$ \\
\hline Resistência vascular periférica & $\downarrow 32 \%$ & $\downarrow 37 \%$ \\
\hline
\end{tabular}

*s.a. = sem alteração

Segundo Weston et al. ${ }^{7}$, em 1987, a imersão é uma técnica simples e não invasiva de estudo das respostas cardiovasculares ao estresse para uma variedade de estados patológicos. Em indivíduos saudáveis, o débito cardíaco aumentou e a resistência periférica diminuiu progressivamente com a elevação da temperatura da água. Às temperaturas de 33 e $35^{\circ} \mathrm{C}$, observou-se aumento de $50 \%$ no volume sistólico apesar da redução significativa no débito cardíaco. Houve maior acréscimo no volume sistólico e frequência cardíaca às temperaturas de 37 e $39^{\circ} \mathrm{C}$.

\subsubsection{Nível de Imersão e Posicionamento}

Segundo Meyer \& Bücking ${ }^{78}$, em 2004, há um ponto crítico a partir do qual as alterações hemodinâmicas centrais resultam em respostas cardíacas anormais. Em um estudo com pacientes com infarto miocárdico moderado e severo e insuficiência cardíaca moderada e severa (classes II e III da NYHA), foram realizados cateterização cardíaca com Swan-Ganz, 
ecocardiografia subxifóide e doppler durante imersão gradativa em ortostatismo (4 níveis: tornozelo, crista ilíaca, apêndice xifoide e pescoço), além de natação em supino comparada à cicloergometria em supino fora da água.

Os principais achados foram:

a) aumento da pré-carga em pacientes com infarto do miocárdio: a imersão gradativa até o apêndice xifóide não alterou a pressão média da artéria pulmonar (PAm). No entanto, durante a imersão até o pescoço e na posição supino em repouso na água, a ação da pressão hidrostática sobre a superfície do corpo resultou em valores patológicos da PAm e pressão média capilar pulmonar (PCPm), respectivamente. Mesmo em repouso, as alterações no volume sanguíneo sugerem que o maior retorno venoso causado pela imersão pode resultar em aumento significativo da pré-carga. Durante a natação e cicloergometria em supino, a PAm e PCPm atingiram valores patológicos;

b) aumento da sobrecarga do ventrículo esquerdo e redução do volume sistólico em pacientes com insuficiência cardíaca severa: o aumento na précarga durante a imersão pode comprometer a complacência ventricular com risco de piora na dilatação do miocárdio danificado;

c) os sintomas não se correlacionam com os achados hemodinâmicos: os pacientes relataram sensação de bem-estar durante a natação apesar de deterioração hemodinâmica o que pode ser explicado pela menor redução na saturação venosa mista de oxigênio.

As limitações do estudo referem-se ao tamanho da amostra, diferenças quanto à etiologia, gravidade e medicação, além da ênfase nas 
respostas agudas. Apesar disso, suas sugestões preliminares podem ser utilizadas para guiar a terapia aquática em pacientes com cardiopatias:

1) a sensação de bem-estar se mantém apesar da deterioração hemodinâmica, sugerindo que o relato subjetivo na água não é garantia de que o ventrículo esquerdo possa tolerar o aumento da pré-carga;

2) a insuficiência cardíaca descompensada é contra-indicação absoluta para imersão e natação;

3) pacientes com infarto do miocárdio e/ou insuficiência cardíaca grave que conseguem dormir em decúbito podem utilizar banheira na posição sentada com imersão até o xifoide;

4) exercícios terapêuticos na água podem ser realizados por pacientes com infarto do miocárdio e insuficiência cardíaca grave, desde que o paciente fique em pé (posição ortostática) com imersão até o xifoide.

Há duas conclusões de grande relevância clínica nesse estudo: do ponto de vista hemodinâmico, a imersão crucial começa a partir do nível diafragmático/ apêndice xifoide e a sensação subjetiva de bem-estar pode não ser um parâmetro válido durante a realização de exercícios na água. Dessa maneira, apesar da existência de estudos que validam as escalas de percepção do esforço para a terapia aquática ${ }^{1,}{ }^{79}$, podem ser levantadas ressalvas quanto à segurança da utilização das mesmas se considerarmos as alterações hemodinâmicas que ocorrem com a imersão em pacientes com insuficiência cardíaca. 


\subsubsection{Tipo de Atividade}

Uma vez que na insuficiência cardíaca as alterações são centrais, periféricas e metabólicas, recomenda-se o treinamento aeróbio associado ao fortalecimento muscular com estímulo suficiente para os músculos esqueléticos sem sobrecarga significativa do sistema cardiovascular ${ }^{8}$.

Cider et al. ${ }^{63}$, em 2003, combinaram exercícios aeróbios com treinamento de força e resistência em piscina aquecida a $33-34^{\circ} \mathrm{C}$, sessões de 45 minutos, três vezes por semana durante 8 semanas. Demonstraram que a hidroterapia pode melhorar a performance máxima, força muscular e qualidade de vida sendo bem tolerada (adesão de 95\%).

Um programa piloto de treinamento, denominado cardiohidrocinesioterapia, foi desenvolvido por pesquisadores italianos em 2006. Consistiu em 2 sessões diárias de terapia aquática, 5 dias por semana, durante 3 semanas com aumento progressivo do tempo de imersão de 30 a 50 minutos e temperatura da água ao redor de 31 a $32^{\circ} \mathrm{C}$. Cada sessão era composta por 3 fases: aquecimento, treinamento e recuperação com avaliação da frequência cardíaca e escala de Borg modificada a cada 2 minutos e monitoração da saturação de oxigênio e pressão arterial antes e após o exercício ${ }^{60}$. 


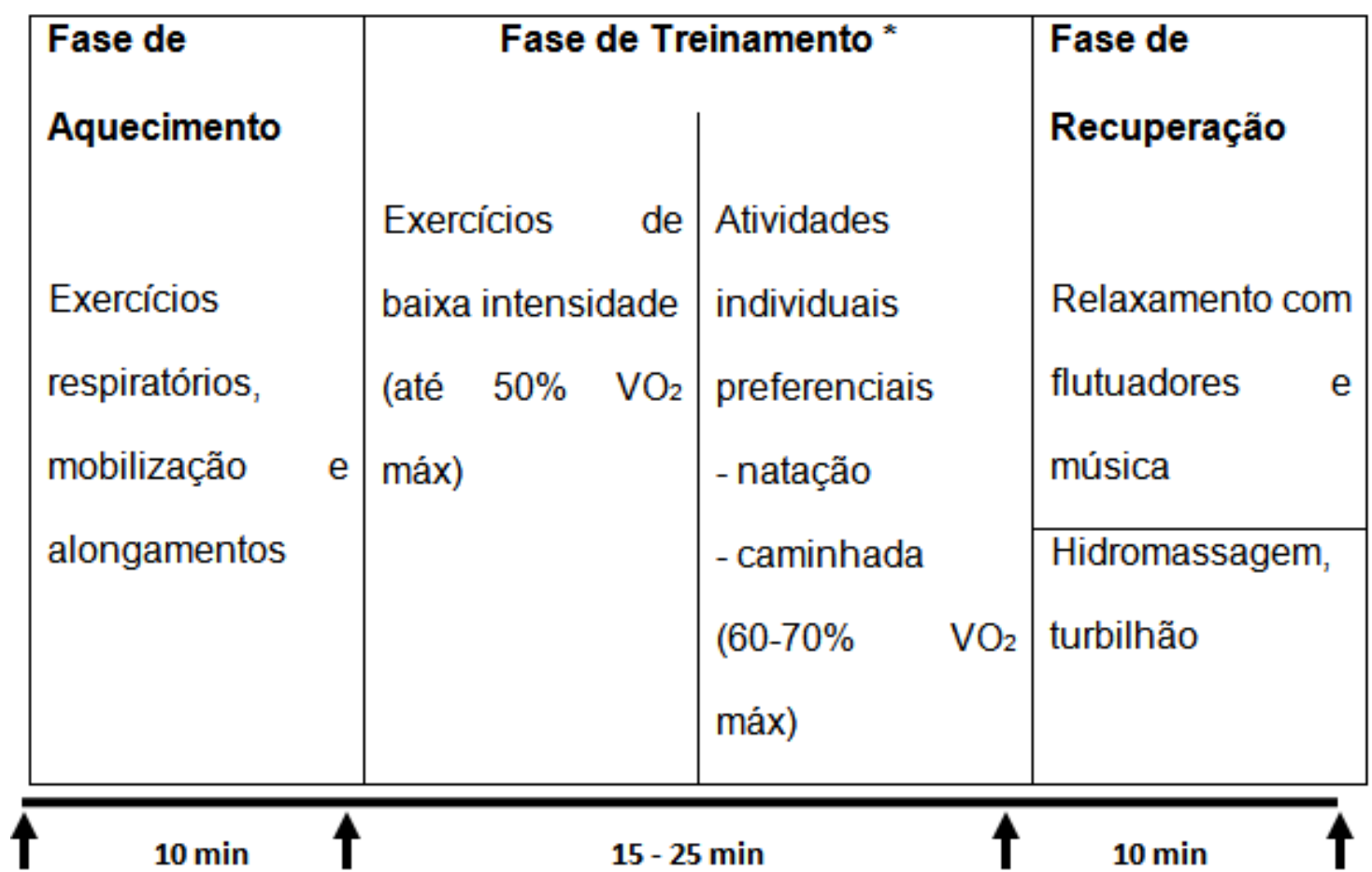

* Monitoração de frequência cardíaca e percepção de cansaço a cada 2 minutos.

Figura 02 - Adaptada de RB46.

O programa Cardio-HKT foi bem tolerado e não foram observados efeitos adversos. O estudo demonstrou que o programa é seguro e efetivo em pacientes com insuficiência cardíaca avançada (classe funcional III e IV da NYHA). O treino por 3 semanas melhorou significativamente a capacidade funcional e qualidade de vida nesses pacientes. Os achados ampliam a utilização de terapia aquática para pacientes com maior comprometimento cardíaco e funcional. As recomendações do estudo incluem: supervisão especializada contínua, monitoração frequente de sinais vitais durante o exercício para minimizar a incidência de eventos adversos, além de atividades educativas e psico-comportamentais para promover mudanças saudáveis no estilo de vida, controle de peso e adequação da dieta. 
De acordo com Biro et al. ${ }^{80}$, em 2003, a termoterapia sistêmica, como por exemplo, o banho em água quente e sauna, induz à vasodilatação sistêmica. Sessões repetidas de terapia com sauna a $60^{\circ} \mathrm{C}$ por 15 minutos podem melhorar os parâmetros hemodinâmicos, sintomas clínicos, função cardíaca e função endotelial vascular em pacientes com insuficiência cardíaca congestiva. A função endotelial vascular está alterada em pacientes com doenças relacionadas aos hábitos de vida, como hipertensão, hiperlipidemia, diabetes e obesidade. A terapia com sauna nesses pacientes parece reduzir a disfunção endotelial sugerindo um possível papel preventivo para aterosclerose.

\subsubsection{Duração da imersão e adaptação}

Os efeitos combinados dos sistemas renal e nervoso simpático podem diminuir a pressão arterial sanguínea de um indivíduo hipertenso durante a imersão e promover um período de pressão mais baixa que se estende por algumas horas (1). Segundo Coruzzi et al. ${ }^{11}$, em 1985, a imersão prolongada reduz significativamente a pressão arterial média, sendo que pacientes hipertensos sensíveis ao sódio demonstraram maior redução (18 a $20 \mathrm{mmHg}$ ) do que os normotensos e não sensíveis ao sódio.

Já foi citado que na água, o corpo está em constante situação de estímulo e aprendizagem não reproduzível no solo. A adaptação ao meio é essencial para a realização das atividades propostas e a eficácia do programa de reabilitação aquática. Caso o paciente demonstre pouca adaptação durante a imersão, os efeitos benéficos da mesma podem ser 
anulados pela contração muscular prolongada, com elevação da pressão arterial e dor muscular.

\subsubsection{Efeitos Colaterais}

\subsubsection{Edema pulmonar induzido por natação}

Não há relatos de efeitos adversos associados à prática da reabilitação aquática devidamente supervisionada $2,60,62,63,78$. O edema pulmonar induzido por natação (EPIN) é uma síndrome que se caracteriza por dispneia, tosse, taquipnéia, hemoptise e confusão ${ }^{81}$. Na literatura há relatos de EPIN em nadadores, fuzileiros navais, triatletas e mergulhadores durante atividade intensa em água fria ${ }^{81,82,83,84}$. Adir et al. ${ }^{82}$, em 2004, relataram a incidência de $1.8 \%$ para EPIN em estudo com indivíduos sadios submetidos a um treinamento de condicionamento físico através da natação em mar aberto (temperatura média da água de $19.6^{\circ} \mathrm{C}$ ).

O EPIN resulta, provavelmente, da associação entre esforço intenso, imersão em água fria e hiperhidratação ${ }^{83,85}$ :

- esforço intenso com aumento do débito cardíaco;

- natação em água fria (aumento da pré-carga, pós-carga e resistência vascular pulmonar);

- hiperhidratação (aumento da pré-carga e pressão capilar pulmonar).

- Esses fatores associados podem levar ao extravasamento de fluidos pela pressão hidrostática e ruptura por estresse dos capilares pulmonares.

O tratamento é sintomático e conservador com resolução geralmente rápida dos sintomas e normalização radiográfica em 24 a 48 
horas. Indivíduos que apresentaram EPIN são aconselhados a melhorar a técnica utilizada para natação (aumento da eficiência e redução do débito cardíaco) associada à mudança rotineira de lados e hidratação leve ${ }^{81,83}$.

\section{14 Aspectos Técnicos}

3.14.1 Instalações: piscina terapêutica em centros de reabilitação (ambiente controlado), piscinas comunitárias (água a temperatura ambiente), tanque de Hubbard, turbilhão, banheiras, spa. A piscina terapêutica é uma estrutura artificial que engloba o reservatório de água e áreas anexas, proporciona aos pacientes e profissionais condições de trabalho, higiene, acessibilidade, conforto e segurança, permitindo uma abordagem lógica, confiável e de resultados eficientes.

3.14.2 Equipamentos: flutuadores, dispositivos resistivos e instrumentos de avaliação funcional.

\subsection{Técnicas empregadas em programas de terapias em piscina}

\subsubsection{Método Halliwick}

Criado por James Mac Millan, em 1949, é uma metodologia que, através de seu programa dos 10 pontos visa ensinar aos pacientes habilidades diversas na água possibilitando movimentação segura e 
independente. Baseia-se em princípios científicos e nas reações do corpo quando imerso na água.

\subsubsection{Método Bad Ragaz}

Técnica que se desenvolveu nas águas termais da cidade de Bad Ragaz - Suíça nos anos 30, aperfeiçoando-se na Alemanha nos anos 50 . É um programa de importância na recuperação de condições músculoesqueléticas, no condicionamento pré e pós-cirúrgico e em algumas afecções reumáticas e neurológicas.

\subsubsection{Método Watsu}

O Shiatsu na água (Water shiatsu - Watsu) é uma prática pioneira de trabalho corporal que, desenvolvida por Harold Dull nos anos 80, tem demonstrado alta eficiência no relaxamento, alívio de dores e redução do estresse físico e emocional.

\subsubsection{Hold / Relax - Prende / Solta}

Técnica usada para aumentar a mobilidade articular, principalmente quando o fator limitante é o espasmo muscular. A flutuação é utilizada para manter o movimento. 


\subsubsection{Co-contrações}

Técnica que utiliza contrações musculares repetidas, isométricas ou isotônicas, a fim de promover a educação ou reeducação de movimentos, desenvolver a força e a resistência muscular. 


\section{METODOLOGIA}

A população deste estudo constituiu-se de pacientes do Programa de Condicionamento Físico (PCF) do Instituto de Medicina Física e Reabilitação do Hospital das Clínicas da Faculdade de Medicina da Universidade de São Paulo, com antecedentes de síndrome coronariana aguda, angioplastia coronariana, cirurgia de revascularização miocárdica ou com doença coronariana conhecida e idade entre 55 a 80 anos. Para adesão, os pacientes foram inicialmente avaliados por um médico cardiologista que analisou o histórico clínico e confirmou a sua condição de candidato para o estudo. Foram excluídos do estudo os pacientes que não cumpriram o prazo e frequência na marcação dos testes, indivíduos com presença de doença arterial periférica, diabetes, doença pulmonar crônica, hipertensão (pressão arterial> 160/90), instáveis com medicação ou morbidade cardiovascular significativa. A amostra final foi composta de 40 indivíduos, sendo: vinte com diagnóstico médico de DAC e vinte saudáveis (Tabela 4). 
Tabela 4 - Características de base dos sujeitos

\begin{tabular}{|c|c|c|c|c|}
\hline & DAC & DP & Saudáveis & DP \\
\hline $\mathrm{N}$ & 20 & & 20 & \\
\hline Homens ( $n$ ) & 20 & & 20 & \\
\hline Idade (anos) & 63,7 & $\pm 8,89$ & 64,7 & $\pm 7,09$ \\
\hline Peso (Kg) & 73,7 & $\pm 10,6$ & 73,6 & $\pm 18,8$ \\
\hline Estatura $(\mathrm{cm})$ & 168 & $\pm 5,95$ & 170,6 & $\pm 11,7$ \\
\hline Índice de Massa Corporal - IMC $\left(\mathrm{kg} / \mathrm{m}^{2}\right)$ & 22,83 & & 23,19 & \\
\hline \multicolumn{5}{|l|}{ DAC Medicação em uso } \\
\hline Anti-hipertensivo & 18 & & & \\
\hline Diuréticos & 6 & & & \\
\hline Hipercolesterolemia & 9 & & & \\
\hline Classe funcional I VO $\mathrm{V}_{2} \max <20 \mathrm{ml} / \mathrm{kg}^{-1} \mathrm{~min}^{-1}$ & 8 & & & \\
\hline Classe funcional I $\mathrm{VO}_{2}$ no $(\mathrm{LA})>14 \mathrm{ml} / \mathrm{kg}^{-1} \mathrm{~min}^{-1}$ & 8 & & & \\
\hline $\begin{array}{l}\text { Classe funcional } \| \mathrm{VO}_{2} \max \text { entre } 16 \mathrm{e} \\
20 \mathrm{~mL} / \mathrm{kg}^{-1} \mathrm{~min}^{-1}\end{array}$ & 12 & & & \\
\hline $\begin{array}{l}\text { Classe funcional II } \mathrm{VO}_{2} \text { no (LA) entre } 11 \mathrm{e} \\
14 \mathrm{~mL} / \mathrm{kg}^{-1} \mathrm{~min}^{-1}\end{array}$ & 12 & & & \\
\hline Etiologia de base - Revascularização /Stend & $11 / 7$ & & & \\
\hline
\end{tabular}

\subsection{Desenho do Teste}

Ambos os grupos realizaram dois TECP acompanhados por um único avaliador, médico cardiologista especialista, que manteve constante supervisão e monitoramento durante o teste e elaborou a interpretação dos dados. Todos os participantes foram orientados quanto à metodologia e, 
após a leitura do Termo de Consentimento Livre e Esclarecido, foi realizada a coleta de dados clínicos e mensurada a massa corporal e a altura. Em solo, o TECP é muito conhecido e aplicado, razão pela qual foi o primeiro teste a ser realizado. De 3 a 7 dias, o segundo teste foi feito em uma piscina coberta e aquecida com volume de $48 \mathrm{~m}^{3}$ de água e profundidade entre 1,10 m a 2,10 m. A equipe de enfermagem preparou os participantes para os testes, tanto em solo quanto em imersão, limpando as áreas de fixação dos eletrodos, conexão do cabo, colocação da máscara e verificação da Pressão Arterial Sistólica e Diastólica (PAS/D). O analisador de gás foi calibrado a cada teste. Em solo, a temperatura do laboratório manteve-se entre $20 \pm 2{ }^{\circ} \mathrm{C}$ e umidade relativa do ar de 50 a $70 \%^{86}$. Na piscina, a temperatura de água manteve-se entre 33 a $34^{\circ} \mathrm{C}$, a umidade relativa do ar de 60 a $80 \%$. Para os testes em imersão, os participantes foram preparados da mesma maneira que em solo. Entretanto, para melhorar a condução dos impulsos elétricos, sem interferência de sinal, os eletrodos do ECG receberam proteção extra, por cima do terminal do cabo com um curativo oclusivo 3M. A adaptação dos participantes à água foi verificada através de um exame prático específico na piscina a fim de excluir indivíduos com pouca adaptação ou medo da água e, uma breve simulação, permitiu a familiarização dos participantes com o ambiente e equipamento, o que diminuiu a ansiedade. O Protocolo de Bruce foi empregado, pois foi o mais adequado à realidade de esteira subaquática, sem interface, ligada diretamente ao computador. A percepção de esforço e o nível de dispnéia foram relatados através da escala subjetiva de Esforço de Borg ${ }^{70}$ (Tabela 5). 
Tabela 5 - Protocolo de Bruce - o estágio muda a cada 3 minutos.

\begin{tabular}{cccccc}
\hline Estágio & minutos & $\begin{array}{c}\text { Inclinação } \\
\%\end{array}$ & $\mathbf{K m} / \mathbf{h}$ & $\mathbf{m p h}$ & mets \\
\hline 1 & 3 & 10 & 2.7 & 1.7 & 4.7 \\
2 & 6 & 12 & 4.0 & 2.5 & 7.0 \\
3 & 9 & 14 & 5.4 & 3.4 & 10.1 \\
4 & 12 & 16 & 6.7 & 4.2 & 12.9 \\
5 & 15 & 18 & 8.0 & 5.0 & 15.0 \\
\hline
\end{tabular}

A percepção de esforço e o nível de dispnéia foram relatados através da Escala Subjetiva de Esforço de Borg $^{87}$ (Tabela 6).

Tabela 6 - Percepção Subjetiva de Esforço de Borg.

\begin{tabular}{cc}
\hline 6 & - \\
\hline 7 & Muito fácil \\
\hline 8 & - \\
\hline 9 & Fácil \\
\hline 10 & - \\
\hline 11 & Relativamente fácil \\
\hline 12 & - \\
\hline 13 & Ligeiramente cansativo \\
\hline 14 & Cansativo \\
\hline 15 & - \\
\hline 16 & Muito cansativo \\
\hline 17 & - \\
\hline 18 & Exaustivo \\
\hline 19 & - \\
\hline 20 &
\end{tabular}


Para conduzir o ar expirado ao analisador de gás foi utilizado um conjunto de máscara com vedação da boca e nariz, gorro e sensor de fluxo. O modelo Metalyzer II (Cortex CPET) mensurou as variáveis respiratórias e metabólicas que conectado a um programa de computador Ergo-Elite (Micromed), forneceu informações sobre: gás expirado (média/ min), consumo de oxigênio $\left(\mathrm{VO}_{2}\right)$, produção de dióxido de carbono $\left(\mathrm{VCO}_{2}\right)$, equivalentes respiratórios de oxigênio $\left(\mathrm{VE} / \mathrm{VO}_{2}\right)$ e gás carbônico $\left(\mathrm{VE} / \mathrm{VCO}_{2}\right)$ e Razão de Troca Respiratória (RER $\left.\quad \mathrm{VCO}_{2} / \mathrm{VO}_{2}\right)$. Eletrodos Meditrace conectados a um cabo especial com cinco derivações torácicas transmitiu os sinais elétricos para o aparelho de ECG Micromed digital permitindo monitorização contínua do eletrocardiograma pelo cardiologista. Um esfigmomanômetro modelo MF621 SE foi posicionado no braço direito dos participantes para verificação da PAS/D. No teste em imersão, pelas condições desfavoráveis de acesso, a PAS/D foi verificada no início, no final e após dois minutos do final do teste. No teste em solo foi utilizada a esteira ergométrica modelo KT- ATL Milênio - Inbramed/ Inbrasorpt $₫$, Porto Alegre, RS e em imersão, a esteira modelo Aquafit Hi-Tec®, fornecida pela indústria Sahinco, São Paulo, SP. Produzida em aço inoxidável e alimentada por um sistema de direção eletro hidráulica instalado longe da piscina, ofereceu proteção contra choque elétrico acidental e reproduziu, através de programação eletrônica, mas sem interface computacional, com precisão as velocidades de 2 a $10 \mathrm{~km} / \mathrm{h}$ e inclinação de 0\% a 13\% (Figura 3 e 4), mesmas estabelecidas pela esteira em solo. 


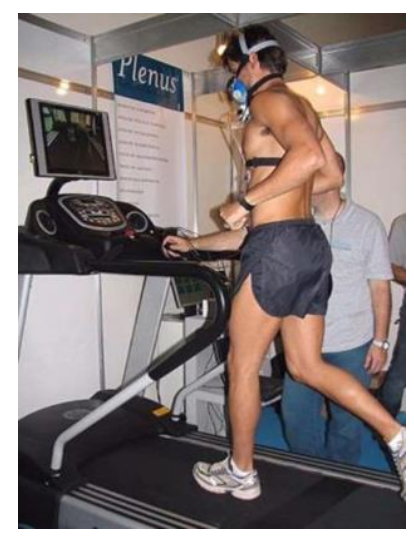

Figura 3 - Teste realizado em esteira no solo.
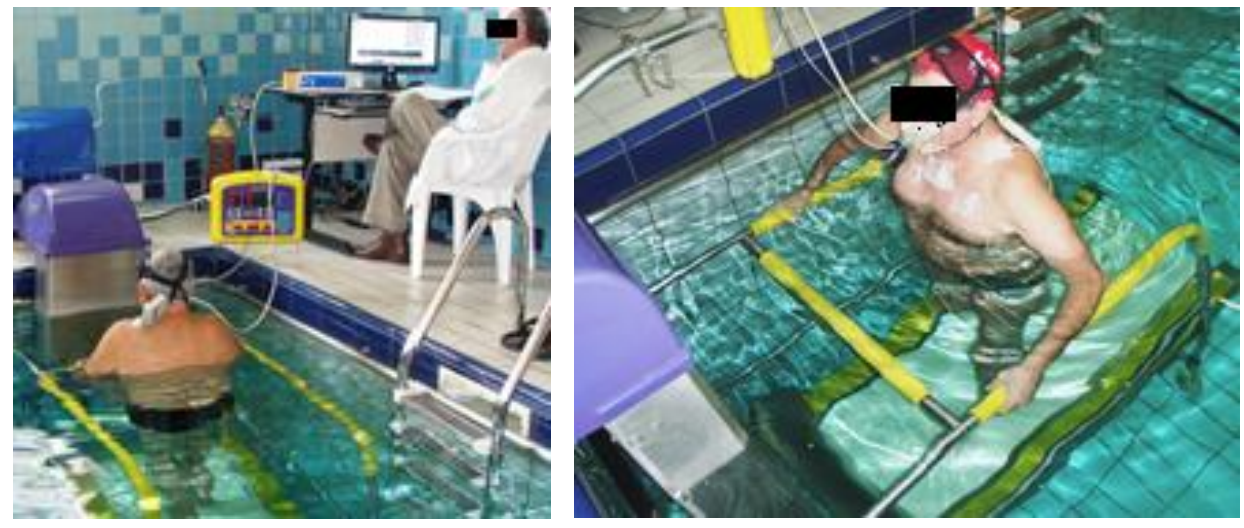

Figuras 4 - Testes realizados em uma esteira subaquática sob supervisão do Cardiologista.

O teste iniciou no Estágio 1 do Protocolo de Bruce, com 3 minutos em atividades, com inclinação de $10 \%$ a velocidade de $2,7 \mathrm{~km} / \mathrm{h}$ e finalizou quando o Quociente Respiratório (QR) atingiu o valor de 1,1 ou maior. Ainda monitorados, os sujeitos continuaram caminhando na esteira por 2 minutos na velocidade de $2,7 \mathrm{~km} / \mathrm{h}$ e inclinação de $0 \%$. O teste poderia ser interrompido se observado algum dos critérios definidos pelas diretrizes do American College Cardiology/ American Heart Association ${ }^{31}$.

Os dados foram coletados em cinco momentos do teste: 
1- Repouso (REP), com observação de ventilação acelerada, frequência cardíaca e consumo de oxigênio, indicadores de indivíduos ansiosos ou distúrbios metabólicos;

2- Limiar Anaeróbio (LA) caracterizado pelo nível de esforço em que o $\mathrm{CO}_{2}$ aumenta e o corpo começa a mudar do metabolismo aeróbio para anaeróbico. Esta variável indica a capacidade individual para o exercício e respostas fisiológicas do organismo;

3- Ponto de Compensação Respiratória (PCR) reflete a taxa de metabolismo aeróbio e anaeróbio. É o ponto onde o organismo não consegue manter o exercício por longa duração, pois a capacidade do corpo de remover o lactato fica diminuída e o sistema anaeróbio predomina sobre o aeróbio;

4- Máximo Esforço (ME) que define os limites do sistema cardiopulmonar;

5- Recuperação (REC) mostra a recuperação da freqüência cardíaca, qualquer sofrimento cardíaco e o nível de acidose metabólica após um esforço tornando a respiração mais profunda e rápida à medida que o organismo tenta livrar o sangue do excesso de ácido reduzindo a quantidade de dióxido de carbono (Figura 5). 


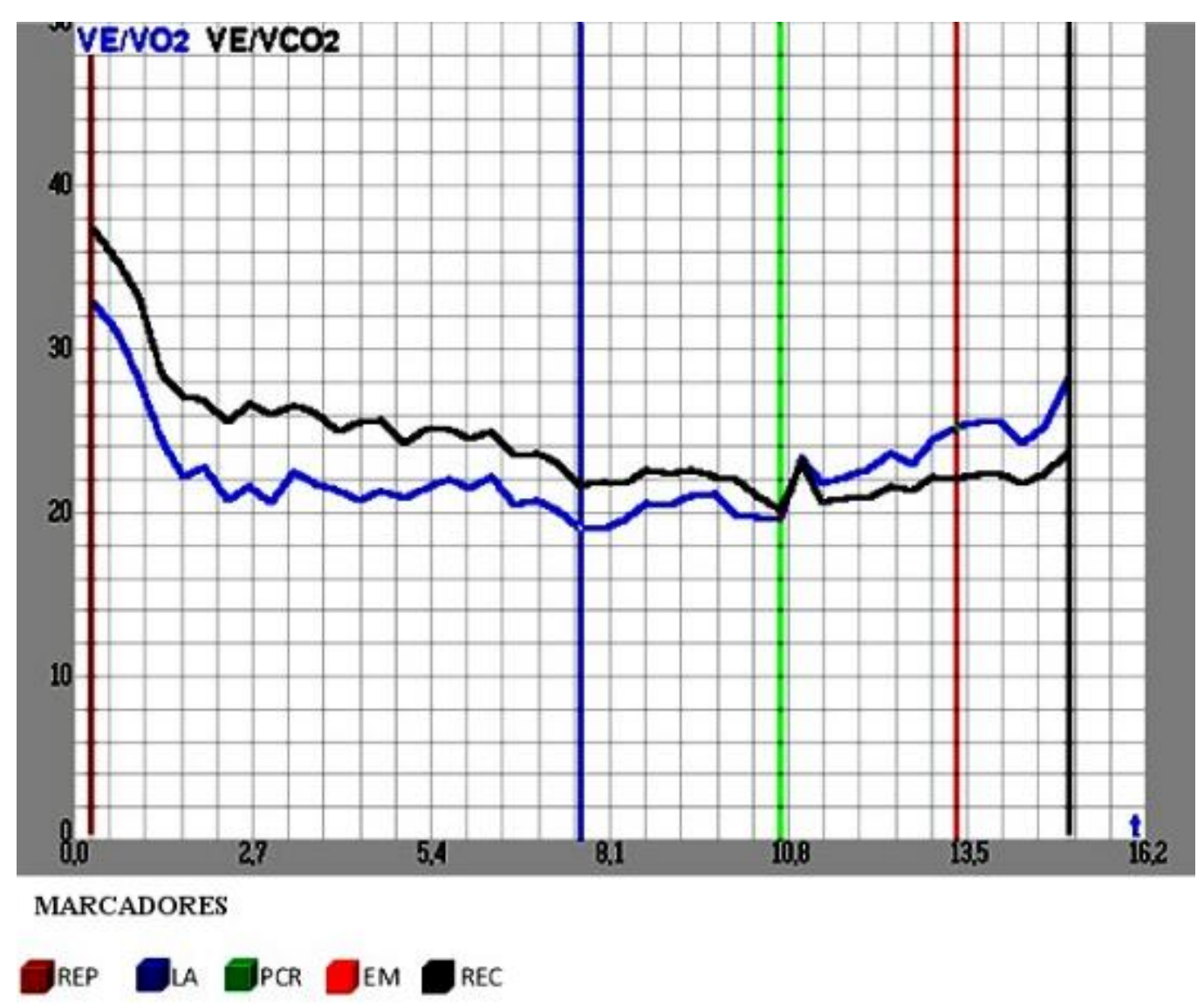

Figura 5 - Dados coletados em 5 momentos, tanto em solo quanto em imersão.

A segurança do grupo foi considerada com ambiente protegido, saída de emergência, equipe de especialistas, supervisão contínua, monitoramento constante, carrinho de emergência equipado com desfibrilador e medicamentos. Esta pesquisa foi aprovada pelo Comitê de Ética em Pesquisa da Faculdade de Medicina da Universidade de São Paulo sob o numero 0532/08. 


\subsection{Estatística}

\subsubsection{Analise de variância}

Analise de variância consiste em ajustar um modelo linear as variáveis em estudo e particionar o quando cada uma destas contribui para o ajuste do modelo. O modelo usado aqui inclui efeitos principais e interações. A interpretação destes é melhor compreendida em gráficos de perfis. Nestes gráficos as distâncias entre as linhas definidas pelas medias dos fatores em estudo representa o efeito principal, em analogia ao coeficiente linear das mesmas. Os ângulos formados entre estas linhas são as interações, em analogia ao coeficiente angular.

Para esta análise, as variáveis ESTAGIO e AMBIENTE foram consideradas como intragrupo e a variável ETIOLOGIA como variável intergrupo. Tal escolha justifica-se pelo fato das duas primeiras terem sido medidas nos mesmo sujeito. Apesar de ETIOLOGIA não ser propriamente um tratamento, procedeu-se por analogia a um experimento caso-controle. Em resumo, foi feita uma análise de variância em medidas repetidas em 2 fatores para cada uma das variáveis dependentes (PEB, $\mathrm{FC}, \mathrm{VO}_{2}, \mathrm{VCO}_{2}$, $\left.\mathrm{VO}_{2} / \mathrm{FC}, \mathrm{VE} / \mathrm{VO}_{2}, \mathrm{VE} / \mathrm{VCO}_{2}, \mathrm{VCO}_{2} / \mathrm{VO}_{2}\right)$. Os intervalos de tempo entre as variáveis de ESTAGIO foram considerados equivalentes e não compuseram o termo de erro intragrupo na análise. Além disso, uma avaliação prévia demonstrou que a covariável IDADE não altera os resultados. Podemos dispensar a análise de covariância posterior.

Dado o grande número de variáveis dependentes, o procedimento aqui adotado produz uma análise por variável dependente, simplificando sobremaneira a interpretação. 


\subsubsection{Esfericidade}

Para cada análise realizada também foi avaliada a esfericidade das variâncias através do teste de Mauchly. A esfericidade nada mais é que uma medida da homogeneidade da variância entre os níveis de uma dada variável com mais de dois níveis. Como a variável ESTAGIO tem mais de dois níveis, é necessário verificar sua esfericidade. Os efeitos que resultaram em testes significantes foram submetidos a correção de esfericidade de Greenhouse-Geisser ou Huynh-Feldt de acordo com o tamanho do desvio observado.

\subsubsection{Localização das diferenças}

Não há metodologia canônica para testes post hoc para este tipo de modelagem. Foi utilizada uma abordagem conservadora para localizar as diferenças, com base em testes $\boldsymbol{t}$ par a par com correção de Holm-Bonferroni para comparações múltiplas. Para tanto, foram criados grupos pela composição de uma variável de ESTAGIO, AMBIENTE e ETIOLOGIA. Cada uma das possíveis combinações foi testada contra todas as outras ajustandose para desvio-padrão agregado. Esse procedimento tende a subestimar as estatísticas dos testes, por isso 'e considerado conservador.

\subsubsection{Perfis temporais e boxplots}

As figuras a seguir exibem os perfis temporais médios para as variáveis numéricas do estudo $\left(\mathrm{FC}, \mathrm{VO}_{2}, \mathrm{VCO}_{2}, \mathrm{VO}_{2} / \mathrm{FC}, \mathrm{VE} / \mathrm{VO}_{2}, \mathrm{VE} / \mathrm{VCO}_{2}\right.$, 
$\mathrm{VCO}_{2} / \mathrm{VO}_{2}$ ). A observação destes é essencial para a elaboração as análises subsequentes e correta especificação dos modelos. Em particular, vale relembrar os conceitos essenciais na intepretação das figuras. Congruência sempre indica ausência de efeito entre os grupos e tratamentos estudados. Paralelismo entre segmentos é indicação de efeito fixo potencialmente significante. Aproximação/distanciamento são evidências de efeito associados à interação entre as variáveis.

Também foram produzidos boxplots para cada uma das variáveis dependentes, a exceção de PEB pelo seu caráter categórico. Nos dois conjuntos de figuras, estão apresentados a agregação tanto por AMBIENTE quanto por ETIOLOGIA. Vale notar que os valores são os mesmos. 


\section{RESULTADOS}

\subsection{PEB}

\subsubsection{Análise de variância de PEB}

Os resultados mostram que há efeito em ESTAGIO, bem como interação entre ESTAGIO e AMBIENTE em relação à variável PEB (Tabela 7).

Tabela 7 - Analise de variância de PEB.

\begin{tabular}{|c|c|c|c|c|c|}
\hline Efeito & $\begin{array}{l}\text { DF } \\
\text { efeito }\end{array}$ & $\begin{array}{l}\text { DF } \\
\text { erro }\end{array}$ & $\mathbf{F}$ & $\mathbf{p}$ & $\eta^{2}$ \\
\hline ETIOLOGIA & 1 & 38 & 2.81 & 0.10 & 0.01 \\
\hline ESTAGIO & 4 & 152 & 651.25 & $<0.01$ & 0.86 \\
\hline AMBIENTE & 1 & 38 & 0.00 & 1.00 & $<0.01$ \\
\hline ETIOLOGIA:ESTAGIO & 4 & 152 & 0.32 & 0.87 & $<0.01$ \\
\hline ETIOLOGIA:AMBIENTE & 1 & 38 & 1.08 & 0.31 & $<0.01$ \\
\hline ESTAGIO:AMBIENTE & 4 & 152 & 5.67 & $<0.01$ & 0.05 \\
\hline ETIOLOGIA:ESTAGIO:AMBIENTE & 4 & 152 & 1.05 & 0.38 & $<0.01$ \\
\hline
\end{tabular}

\subsubsection{Teste de esfericidade de Mauchly para PEB}

Ha desvio de esfericidade para o efeito principais ESTAGIO e as interações ETIOLOGIA e ESTAGIO, ESTAGIO e AMBIENTE e ETIOLOGIA, ESTAGIO e AMBIENTE (Tabela 8). 
Tabela 8 - Teste de Esfericidade de Mauchly para PEB.

\begin{tabular}{lll}
\hline \multicolumn{1}{c}{ Efeito } & w & p \\
\hline ESTAGIO & 0.59 & 0.02 \\
\hline ETIOLOGIA:ESTAGIO & 0.59 & 0.02 \\
\hline ESTAGIO:AMBIENTE & 0.61 & 0.04 \\
\hline ETIOLOGIA:ESTAGIO:AMBIENTE & 0.61 & 0.04 \\
\hline
\end{tabular}

\subsubsection{Correções de esfericidade para PEB}

Os Valores de $€$ e $\boldsymbol{p}$ para a correção de Greenhouse-Geisser (GG) e de Huynh-Feldt (HF) são apresentados na Tabela 9. As correções de esfericidade não alteraram as conclusões da análise inicial.

Tabela 9 - Correções de esfericidade para PEB.

\begin{tabular}{lcccc}
\hline \multicolumn{1}{c}{ Efeito } & GG & pGG & HF & pHF \\
\hline ESTAGIO & 0.79 & $<0.01$ & 0.87 & $<0.01$ \\
\hline ETIOLOGIA:ESTAGIO & 0.79 & 0.82 & 0.87 & 0.84 \\
\hline ESTAGIO:AMBIENTE & 0.80 & $<0.01$ & 0.88 & $<0.01$ \\
\hline ETIOLOGIA:ESTAGIO:AMBIENTE & 0.80 & 0.37 & 0.88 & 0.38 \\
\hline
\end{tabular}




\subsubsection{Perfis e boxplots de PEB}
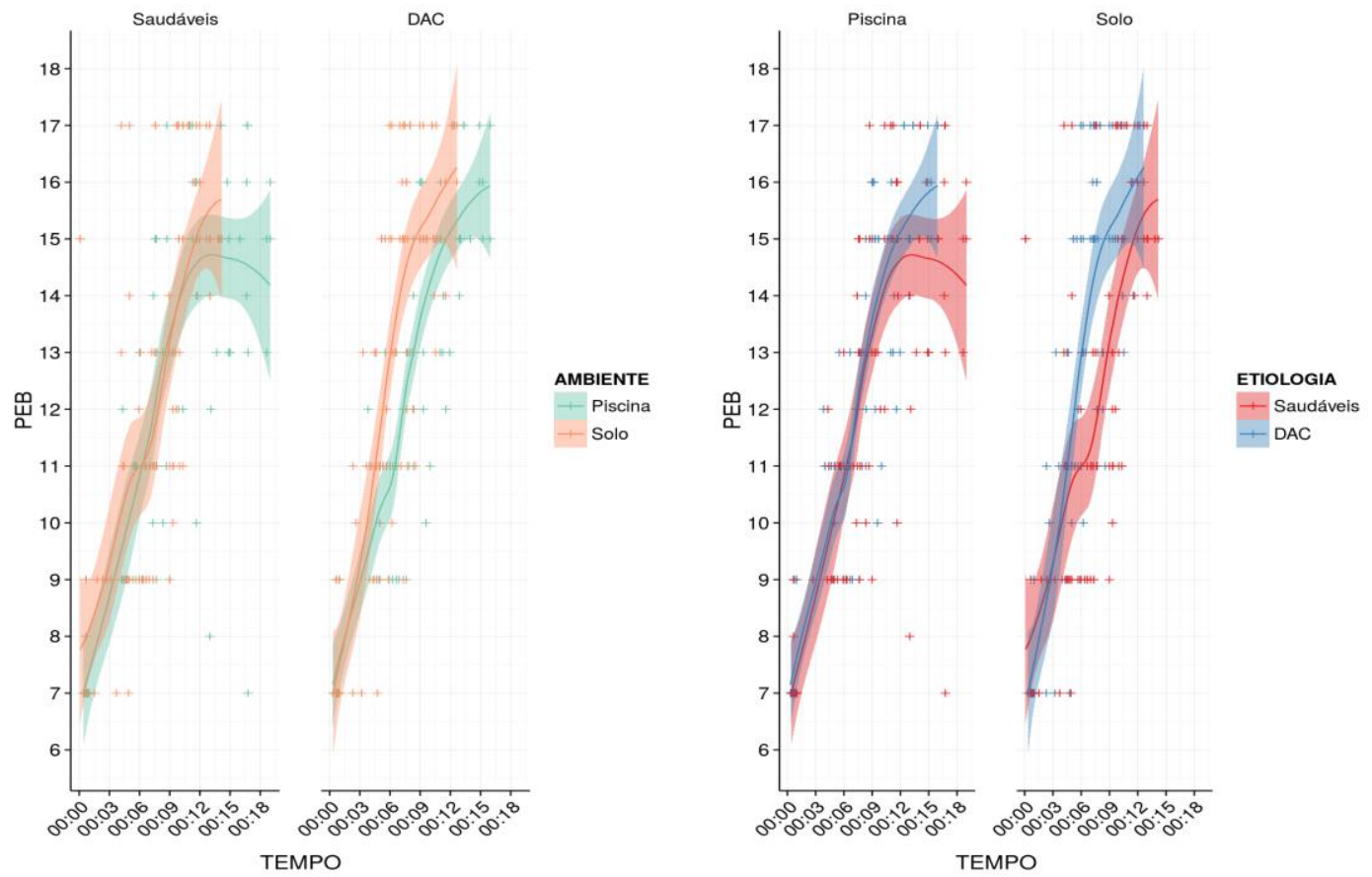

Figura 6 -Perfil da amostra para a variável PEB por tempo de teste, medido em minutos e segundos.
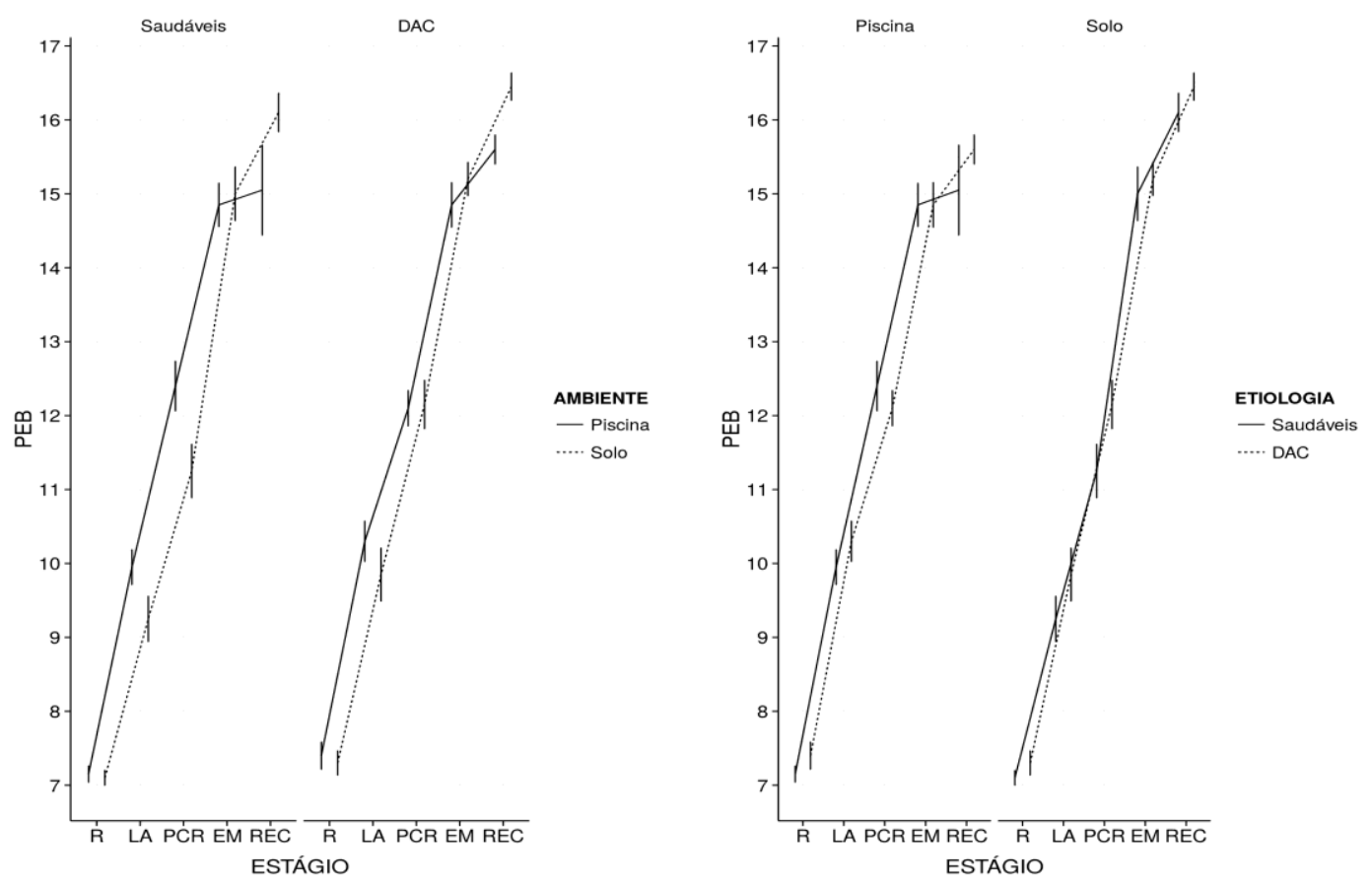

Figura 7 - Perfis médios da amostra para a variável PEB. 

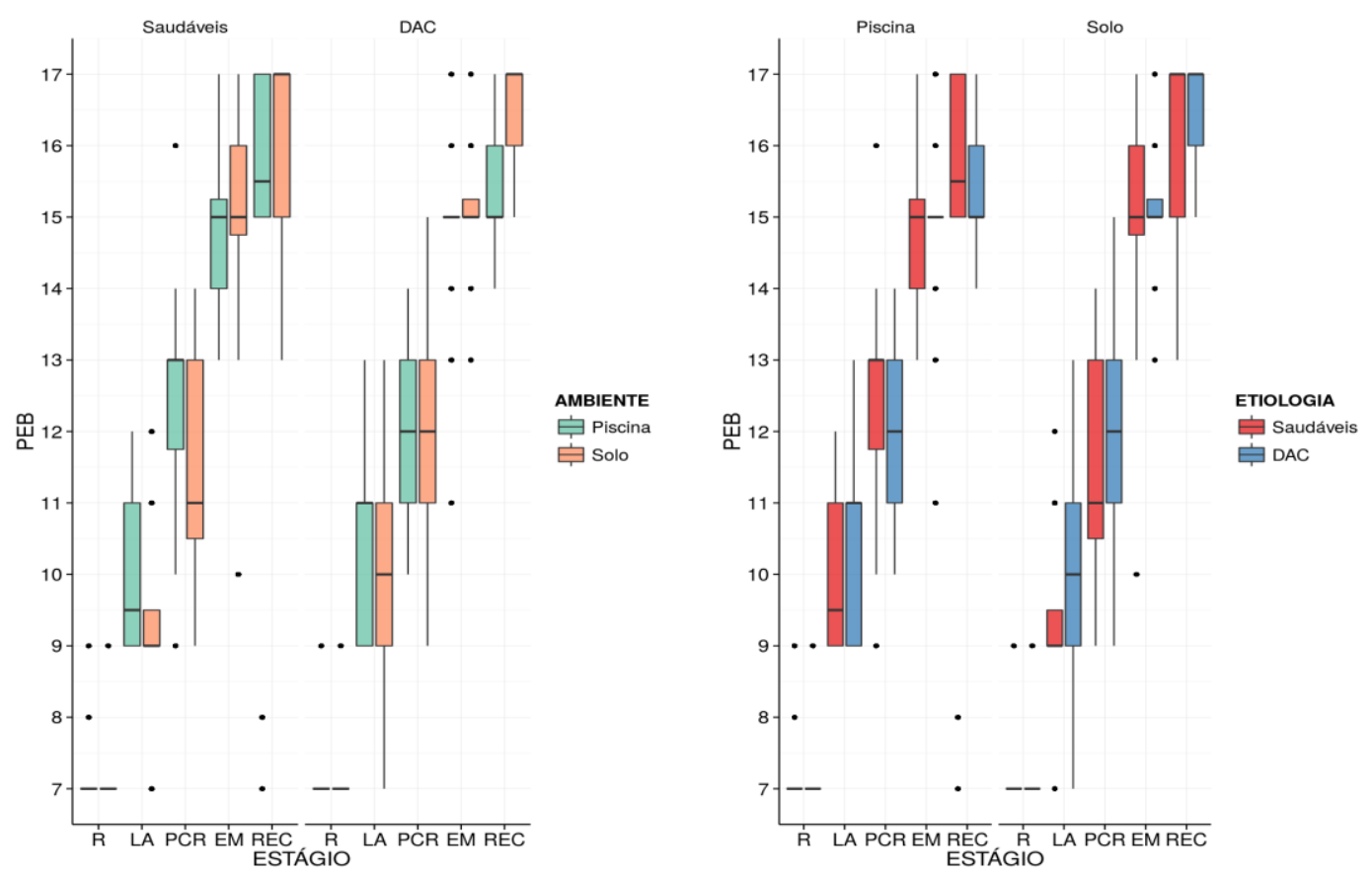

Figura 8 - Boxplot da amostra para a variável PEB.

\subsection{FC}

\subsubsection{Análise de variância de FC}

Os resultados mostram que há efeitos significantes nos três grupos de variáveis (efeitos principais) bem como interações significantes entre ETIOLOGIA e ESTAGIO, ESTAGIO e AMBIENTE (efeitos interativos) em relação à variável FC (Tabela 10). 
Tabela 10 - Analise de variância de FC.

\begin{tabular}{lccccc}
\hline \multicolumn{1}{c}{ Efeito } & $\begin{array}{c}\text { DF } \\
\text { efeito }\end{array}$ & $\begin{array}{c}\text { DF } \\
\text { erro }\end{array}$ & $\mathbf{F}$ & $\mathbf{p}$ & $\boldsymbol{\eta}^{2}$ \\
\hline ETIOLOGIA & 1 & 38 & 17.00 & $<0.01$ & 0.22 \\
\hline ESTAGIO & 4 & 152 & 260.06 & $<0.01$ & 0.58 \\
\hline AMBIENTE & 1 & 38 & 12.96 & $<0.01$ & 0.03 \\
\hline ETIOLOGIA:ESTAGIO & 4 & 152 & 7.10 & $<0.01$ & 0.04 \\
\hline ETIOLOGIA:AMBIENTE & 1 & 38 & 0.75 & 0.39 & $<0.01$ \\
\hline ESTAGIO:AMBIENTE & 4 & 152 & 3.01 & 0.02 & $<0.01$ \\
\hline ETIOLOGIA:ESTAGIO:AMBIENTE & 4 & 152 & 1.45 & 0.22 & $<0.01$ \\
\hline
\end{tabular}

\subsubsection{Teste de esfericidade de Mauchly para FC}

Desvio de esfericidade para o efeito principal ESTAGIO e a interação ETIOLOGIA e ESTAGIO na Tabela 11.

Tabela 11 - Teste de esfericidade de Mauchly para FC.

\begin{tabular}{lcc}
\hline \multicolumn{1}{c}{ Efeito } & w & $\mathbf{p}$ \\
\hline ESTAGIO & 0.32 & $<0.01$ \\
\hline ETIOLOGIA:ESTAGIO & 0.32 & $<0.01$ \\
\hline ESTAGIO:AMBIENTE & 0.66 & 0.09 \\
\hline ETIOLOGIA:ESTAGIO:AMBIENTE & 0.66 & 0.09
\end{tabular}




\subsubsection{Correções de esfericidade para FC}

Valores de de $€$ e $\boldsymbol{p}$ para a correção de Greenhouse-Geisser (GG) e de Huynh-Feldt (HF) (Tabela 12). As correções de esfericidade não alteraram as conclusões da análise inicial.

Tabela 12 - Correções de esfericidade para FC.

\begin{tabular}{lllll}
\hline \multicolumn{1}{c}{ Efeito } & GG & pGG & HF & pHF \\
\hline ESTAGIO & 0.68 & $<0.01$ & 0.74 & $<0.01$ \\
\hline ETIOLOGIA:ESTAGIO & 0.68 & $<0.01$ & 0.74 & $<0.01$ \\
\hline ESTAGIO:AMBIENTE & 0.84 & 0.03 & 0.94 & 0.02 \\
\hline ETIOLOGIA:ESTAGIO:AMBIENTE & 0.84 & 0.23 & 0.94 & 0.22 \\
\hline
\end{tabular}

\subsubsection{Perfis e boxplots de FC}
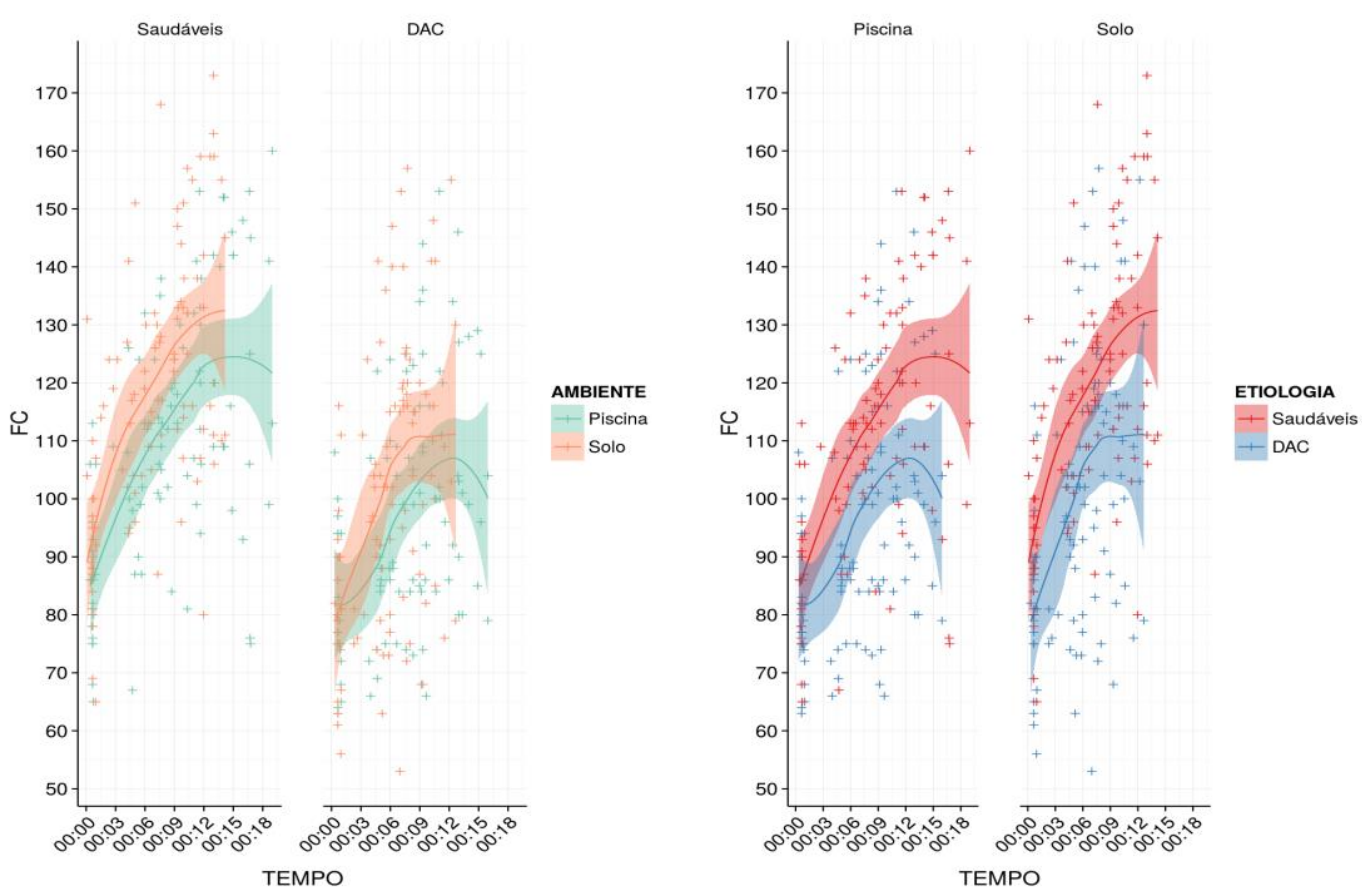

Figura 9 - Perfil da amostra para a variável FC por tempo de teste, medido em minutos e segundos. 

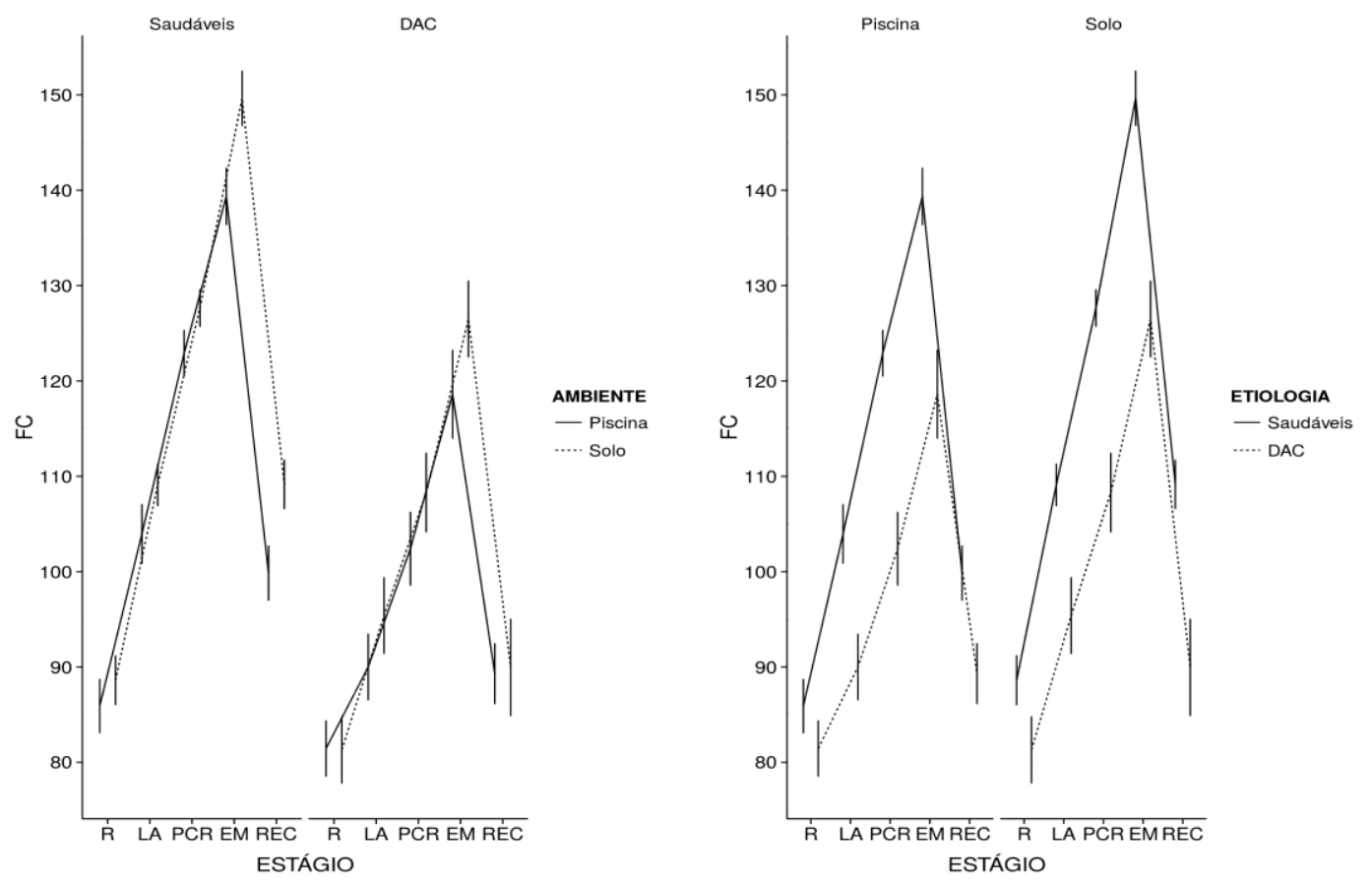

Figura 10 - Perfis médios da amostra para a variável FC.
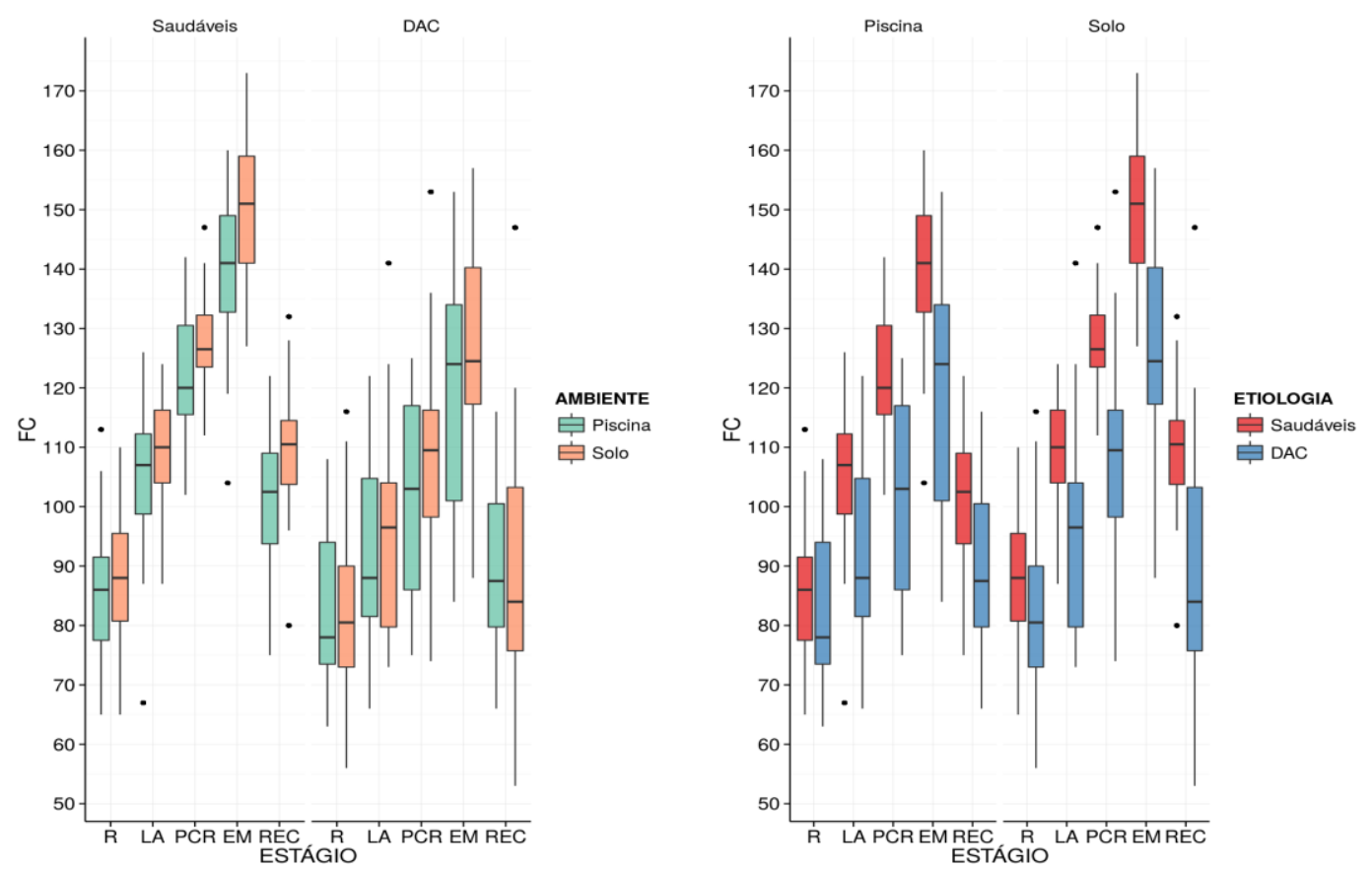

Figuras 11 - Boxplots da amostra para variável FC. 


\section{$5.3 \mathrm{VO}_{2}$}

\subsubsection{Analise de variância de $\mathrm{VO}_{2}$}

Os resultados mostram que há efeitos em ETIOLOGIA, ESTAGIO e AMBIENTE, bem como interações entre ETIOLOGIA e ESTAGIO e ESTAGIO e AMBIENTE em relação à variável $\mathrm{VO}_{2}$ (Tabela 13).

Tabela 13 - Analise de variância de $\mathrm{VO}_{2}$.

\begin{tabular}{lccccc}
\hline \multicolumn{1}{c}{ Efeito } & $\begin{array}{c}\text { DF } \\
\text { efeito }\end{array}$ & $\begin{array}{c}\text { DF } \\
\text { erro }\end{array}$ & $\mathbf{F}$ & $\mathbf{p}$ & $\boldsymbol{\eta}^{2}$ \\
\hline ETIOLOGIA & 1 & 38 & 12.21 & $<0.01$ & 0.14 \\
\hline ESTAGIO & 4 & 152 & 180.54 & $<0.01$ & 0.59 \\
\hline AMBIENTE & 1 & 38 & 25.64 & $<0.01$ & 0.06 \\
\hline ETIOLOGIA:ESTAGIO & 4 & 152 & 6.40 & $<0.01$ & 0.05 \\
\hline ETIOLOGIA:AMBIENTE & 1 & 38 & 0.06 & 0.81 & $<0.01$ \\
\hline ESTAGIO:AMBIENTE & 4 & 152 & 10.10 & $<0.01$ & 0.02 \\
\hline ETIOLOGIA:ESTAGIO:AMBIENTE & 4 & 152 & 1.72 & 0.15 & $<0.01$ \\
\hline
\end{tabular}

\subsubsection{Teste de esfericidade de Mauchy para $\mathrm{VO}_{2}$.}

Houve desvio de esfericidade para o efeito principais ESTAGIO e as interações ETIOLOGIA e ESTAGIO, ESTAGIO e AMBIENTE e ESTAGIO, AMBIENTE e ETIOLOGIA (Tabela 14). 
Tabela 14 - Teste de esfericidade de Mauchy para $\mathrm{VO}_{2}$.

\begin{tabular}{lcc}
\hline \multicolumn{1}{c}{ Efeito } & w & p \\
\hline ESTAGIO & 0.12 & $<0.01$ \\
\hline ETIOLOGIA:ESTAGIO & 0.12 & $<0.01$ \\
\hline ESTAGIO:AMBIENTE & 0.58 & 0.02 \\
\hline ETIOLOGIA:ESTAGIO:AMBIENTE & 0.58 & 0.02 \\
\hline
\end{tabular}

\subsubsection{Correções de esfericidade para $\mathrm{VO}_{2}$}

Valores de $\boldsymbol{\epsilon}$ e $\boldsymbol{p}$ para a correção de Greenhouse-Geisser (GG) e de Huynh-Feldt (HF) estão na Tabela 15. As correções de esfericidade não alteraram as conclusões da análise inicial.

Tabela 15 - Correções de esfericidade para $\mathrm{VO}_{2}$.

\begin{tabular}{lcccc}
\hline \multicolumn{1}{c}{ Efeito } & GG & pGG & HF & pHF \\
\hline ESTAGIO & 0.45 & $<0.01$ & 0.47 & $<0.01$ \\
\hline ETIOLOGIA:ESTAGIO & 0.45 & $<0.01$ & 0.47 & $<0.01$ \\
\hline ESTAGIO:AMBIENTE & 0.79 & $<0.01$ & 0.87 & $<0.01$ \\
\hline ETIOLOGIA:ESTAGIO:AMBIENTE & 0.79 & 0.16 & 0.87 & 0.16 \\
\hline
\end{tabular}


5.3.4 Perfis e boxplot de $\mathrm{VO}_{2}$.
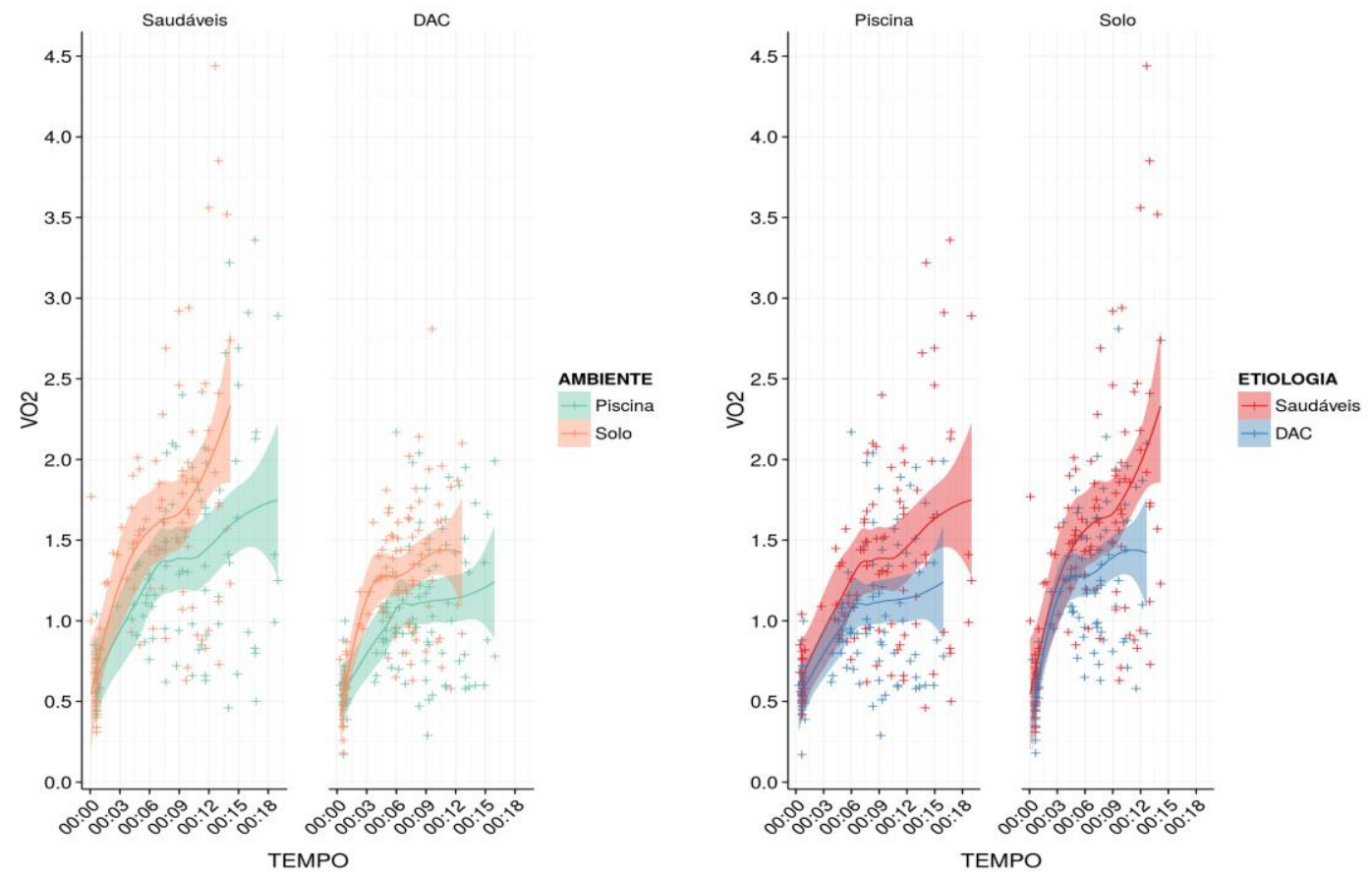

Figura 12 - Perfil da amostra para a variável $\mathrm{VO}_{2}$ por tempo de teste, medido em minutos e segundos.
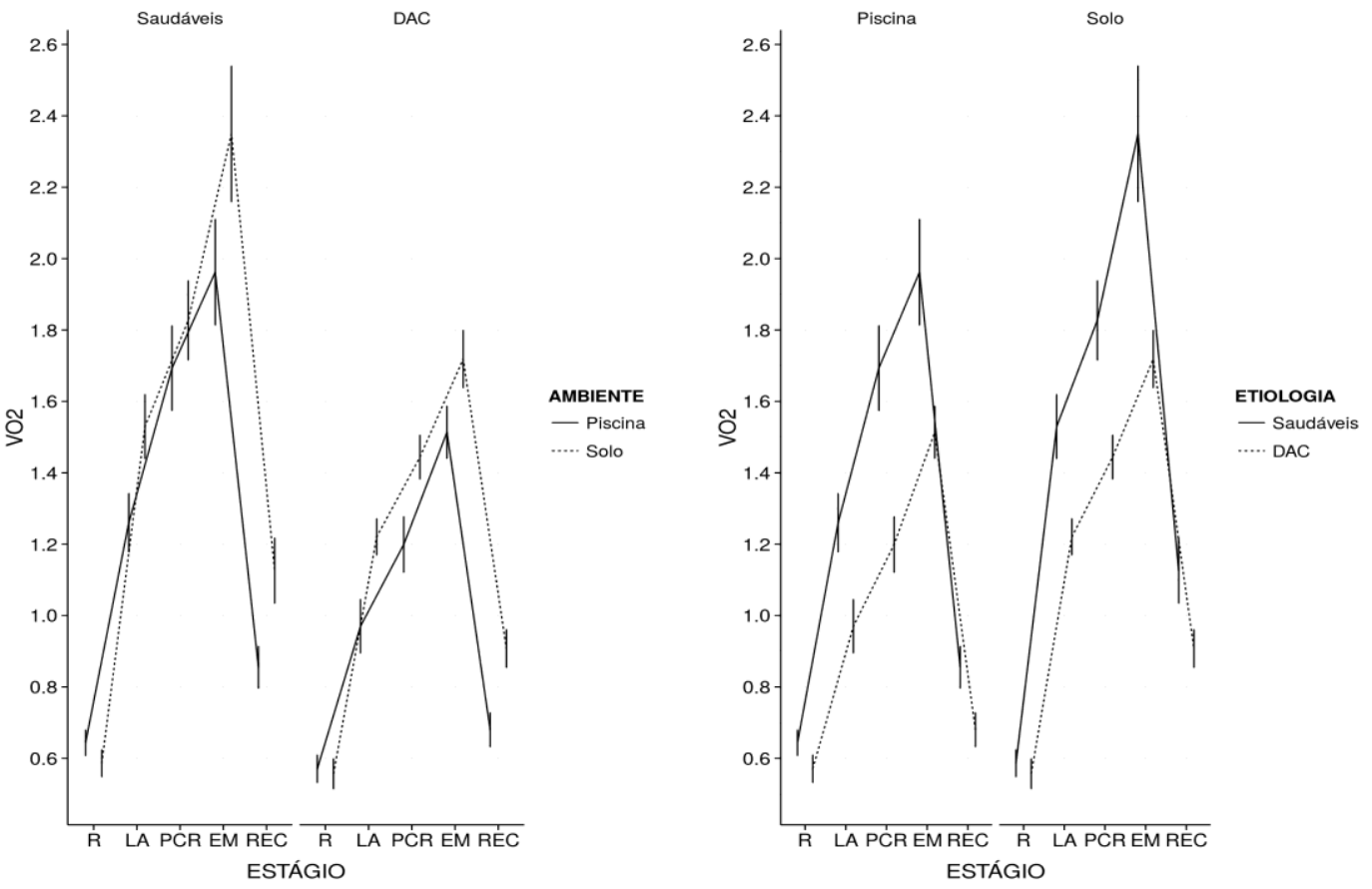

Figura 13 - Perfis médios da amostra para a variável $\mathrm{VO}_{2}$. 

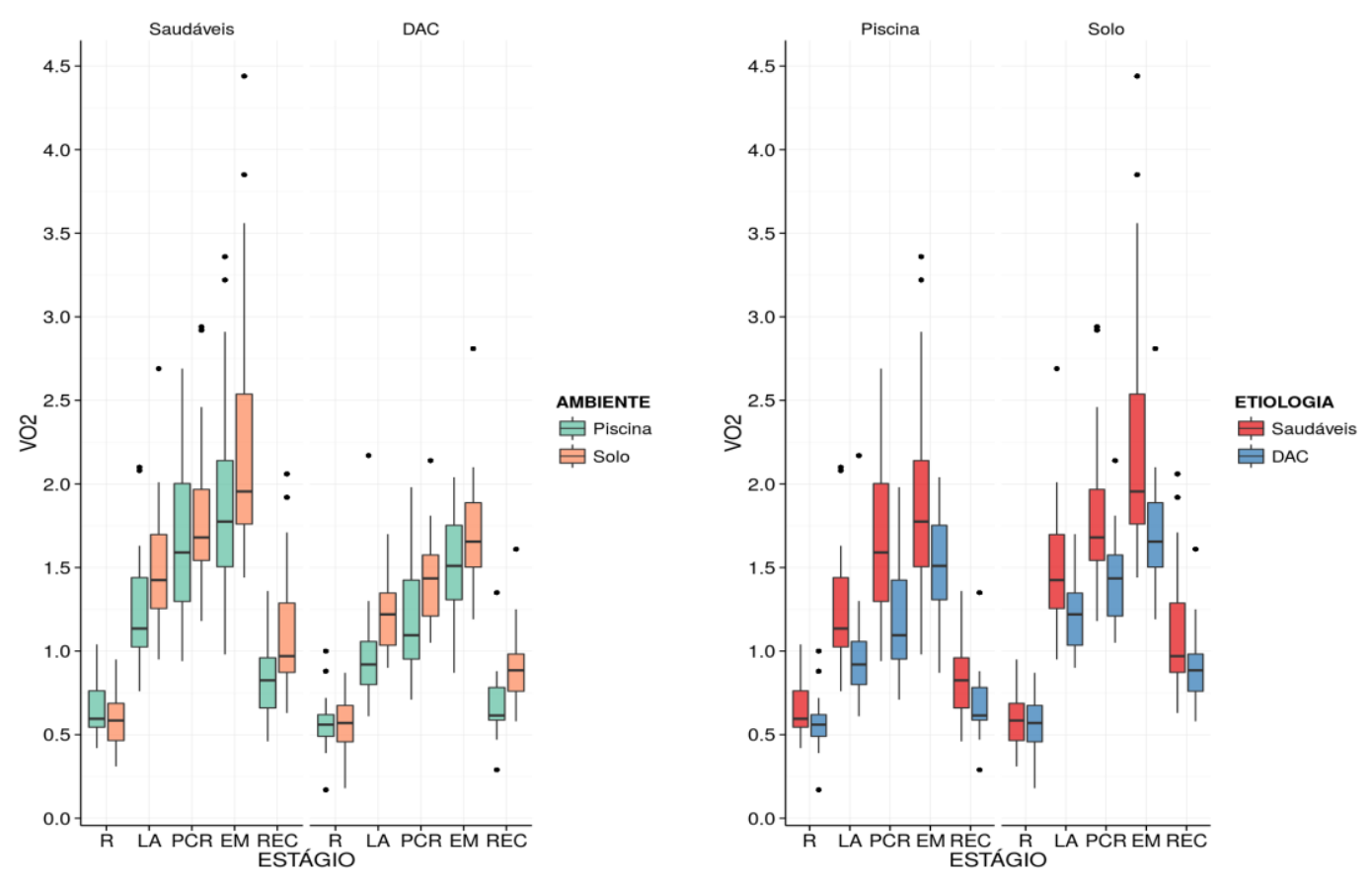

Figura 14 - Boxplot da amostra para a variável $\mathrm{VO}_{2}$.

\section{$5.4 \mathrm{VCO}_{2}$}

\subsubsection{Analise de variância de $\mathrm{VCO}_{2}$}

Os resultados mostram que há efeitos significantes em ETIOLOGIA, ESTAGIO e AMBIENTE, bem como interações significantes entre ETIOLOGIA e ESTAGIO e ESTAGIO e AMBIENTE em relação à variável $\mathrm{VCO}_{2}$ (Tabela 16). 
Tabela 16 - Analise de variância de $\mathrm{VCO}_{2}$.

\begin{tabular}{lccccc}
\hline \multicolumn{1}{c}{ Efeito } & $\begin{array}{c}\text { DF } \\
\text { efeito }\end{array}$ & $\begin{array}{c}\text { DF } \\
\text { erro }\end{array}$ & $\mathbf{F}$ & $\mathbf{p}$ & $\boldsymbol{\eta}^{2}$ \\
\hline ETIOLOGIA & 1 & 38 & 16.47 & $<0.01$ & 0.17 \\
\hline ESTAGIO & 4 & 152 & 192.18 & $<0.01$ & 0.63 \\
\hline AMBIENTE & 1 & 38 & 25.41 & $<0.01$ & 0.06 \\
\hline ETIOLOGIA:ESTAGIO & 4 & 152 & 8.17 & $<0.01$ & 0.07 \\
\hline ETIOLOGIA:AMBIENTE & 1 & 38 & 1.29 & 0.26 & $<0.01$ \\
\hline ESTAGIO:AMBIENTE & 4 & 152 & 8.43 & $<0.01$ & 0.02 \\
\hline ETIOLOGIA:ESTAGIO:AMBIENTE & 4 & 152 & 2.22 & 0.07 & $<0.01$ \\
\hline
\end{tabular}

\subsubsection{Teste de esfericidade de Mauchly para $\mathrm{VCO}_{2}$}

Houve desvio de esfericidade para o efeito principal ESTAGIO e a interação ETIOLOGIA e ESTAGIO (Tabela 17).

Tabela 17 - Teste de esfericidade de Mauchly para $\mathrm{VCO}_{2}$.

\begin{tabular}{lcc}
\hline \multicolumn{1}{c}{ Efeito } & w & p \\
\hline ESTAGIO & 0.11 & $<0.01$ \\
\hline ETIOLOGIA:ESTAGIO & 0.11 & $<0.01$ \\
\hline ESTAGIO:AMBIENTE & 0.72 & 0.22 \\
\hline ETIOLOGIA:ESTAGIO:AMBIENTE & 0.72 & 0.22 \\
\hline
\end{tabular}




\subsubsection{Correções de esfericidade para $\mathrm{VCO}_{2}$}

Valores de $€$ e $\boldsymbol{p}$ para a correção de Greenhouse-Geisser (GG) e de Huynh-Feldt (HF) (Tabela 18). As correções de esfericidade não alteraram as conclusões da análise inicial.

Tabela 18 - Correções de esfericidade para $\mathrm{VCO}_{2}$

\begin{tabular}{lllll}
\hline \multicolumn{1}{c}{ Efeito } & GG & pGG & HF & pHF \\
\hline ESTAGIO & 0.45 & $<0.01$ & 0.47 & $<0.01$ \\
\hline ETIOLOGIA:ESTAGIO & 0.45 & $<0.01$ & 0.47 & $<0.01$ \\
\hline ESTAGIO:AMBIENTE & 0.84 & $<0.01$ & 0.93 & $<0.01$ \\
\hline ETIOLOGIA:ESTAGIO:AMBIENTE & 0.84 & 0.08 & 0.93 & 0.08 \\
\hline
\end{tabular}

\subsubsection{Perfis e boxplots de $\mathrm{VCO}_{2}$}
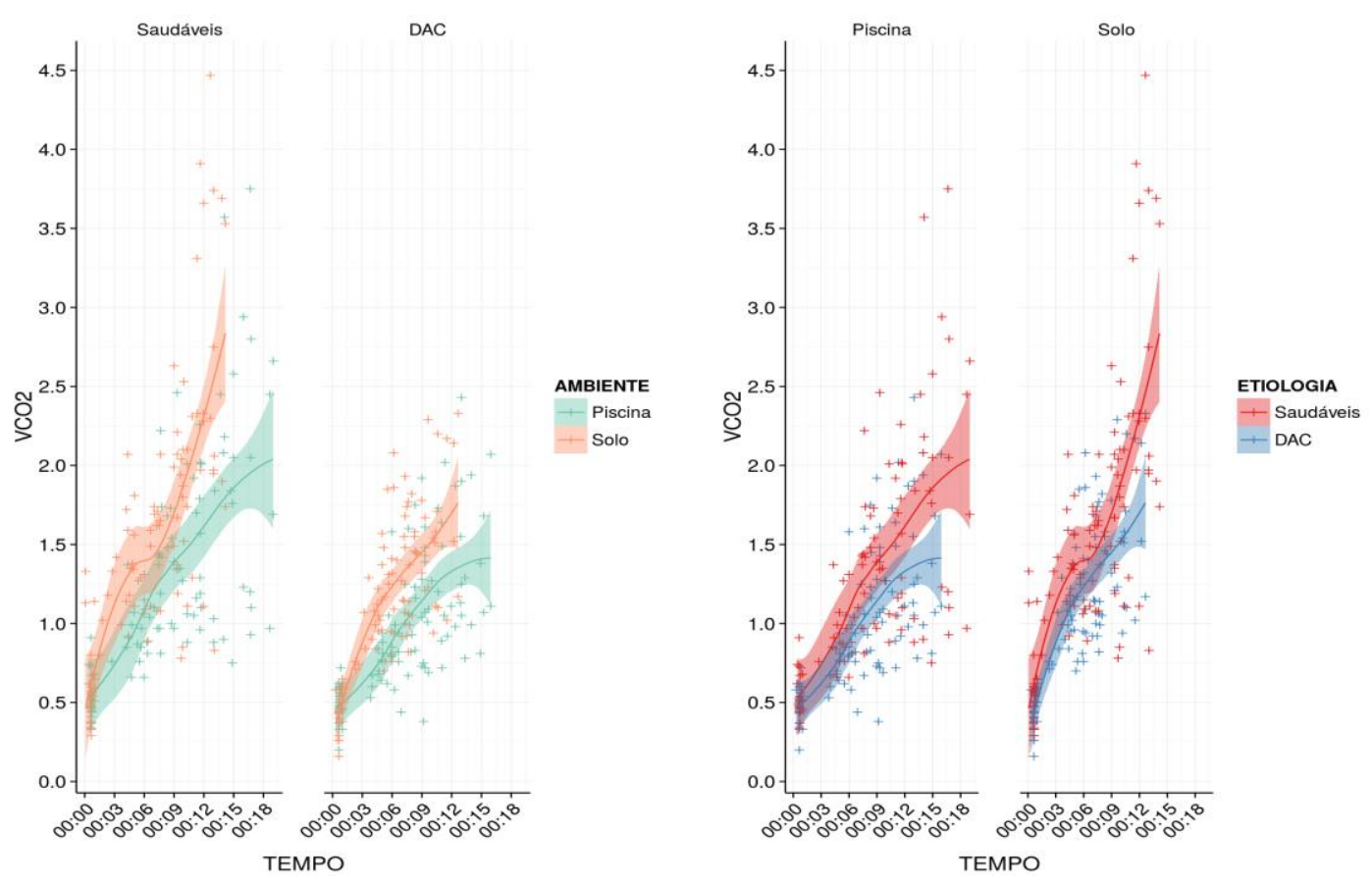

Figura 15 - Perfil da amostra para a variável $\mathrm{VCO}_{2}$ por tempo de teste, medido em minutos e segundos. 

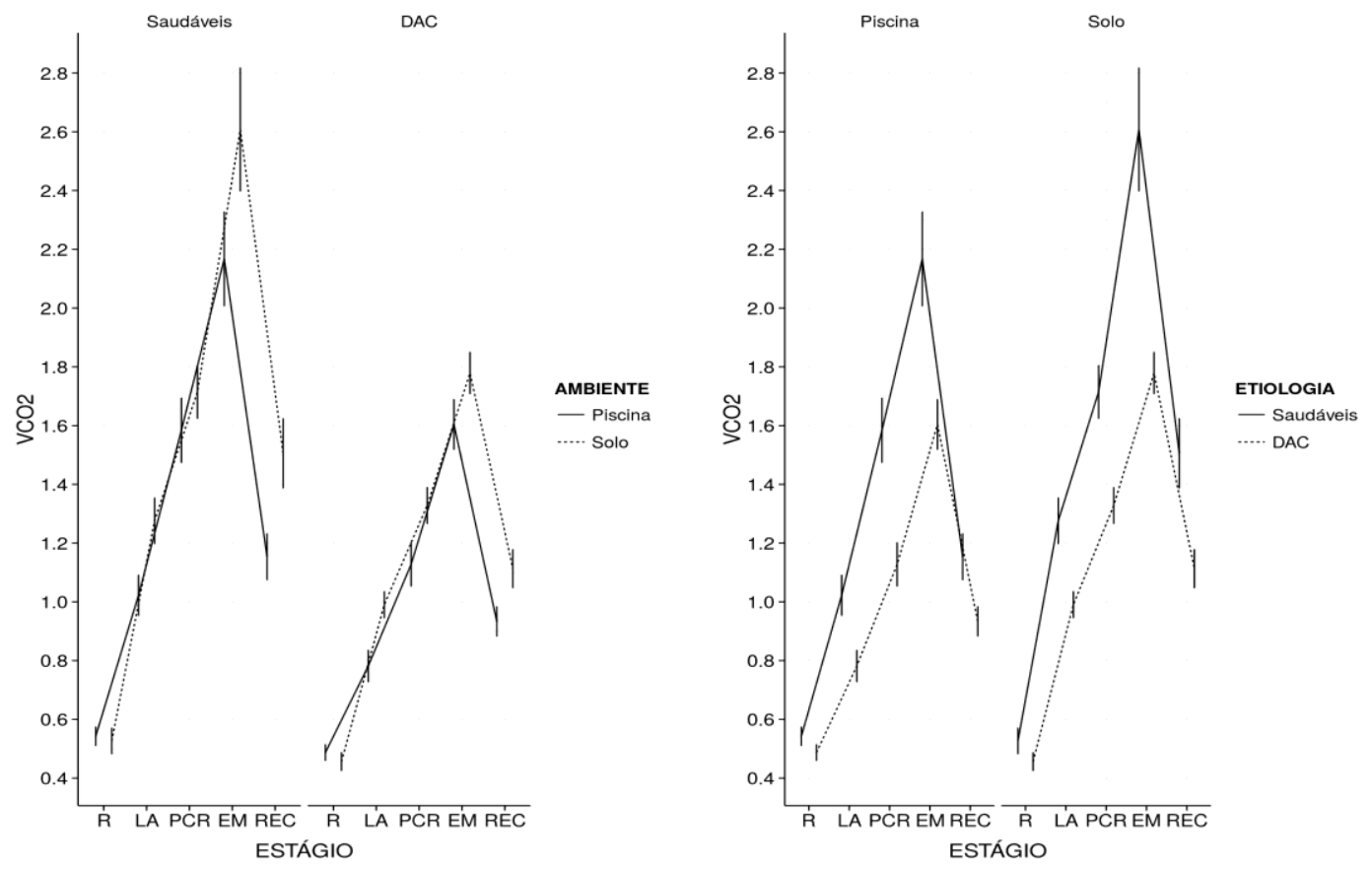

Figura 16 - Perfis médios da amostra para a variável $\mathrm{VCO}_{2}$.
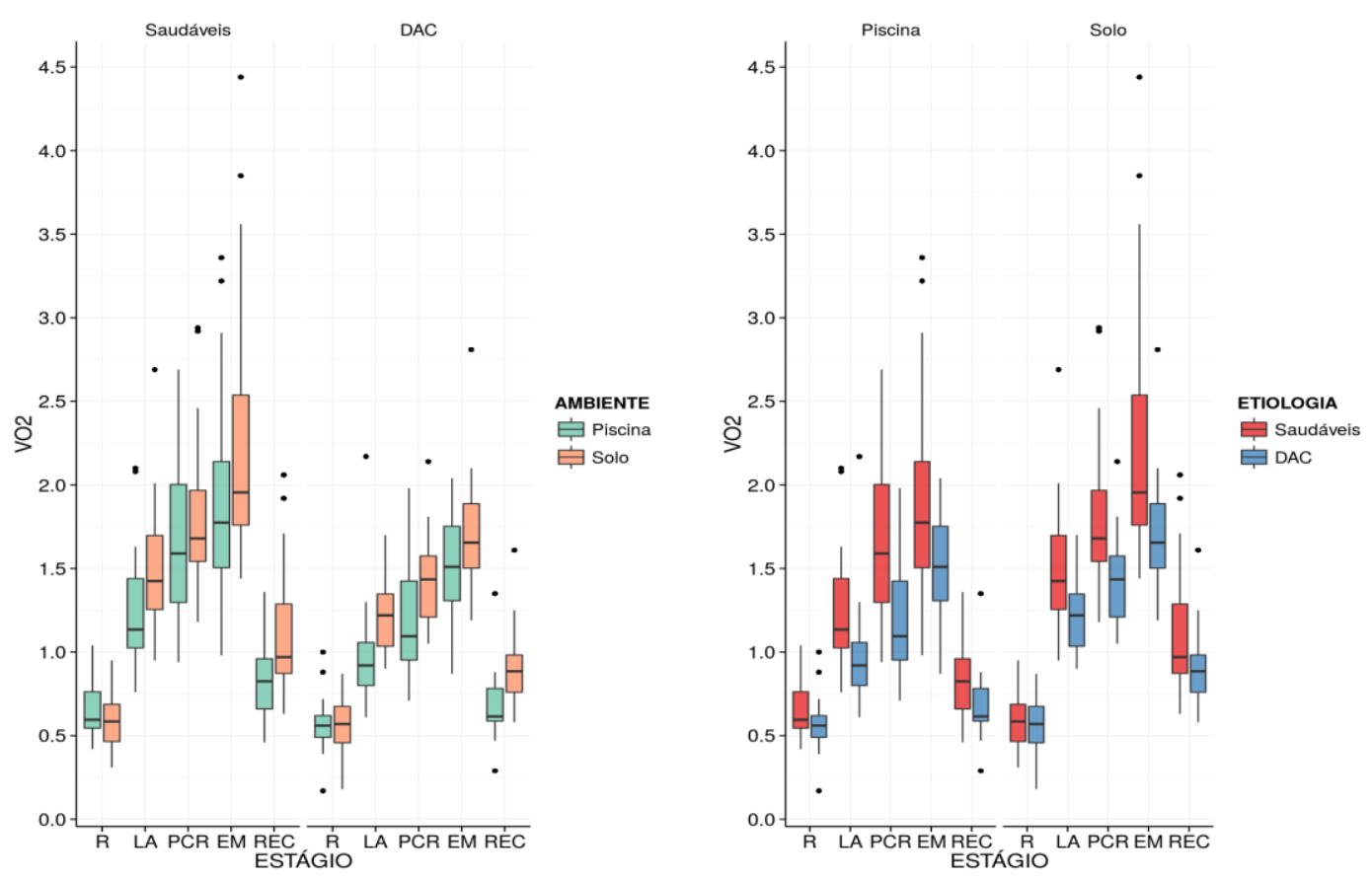

Figura 17 - Boxplot da amostra para a variável $\mathrm{VCO}_{2}$. 


\section{$5.5 \mathrm{VO}_{2} / \mathrm{FC}$}

5.5.1 Analise de variância de $\mathrm{VO}_{2} / \mathrm{FC}$.

Os resultados mostram que há efeitos significantes em ETIOLOGIA, ESTAGIO e AMBIENTE, bem como interações significantes entre ETIOLOGIA e ESTAGIO e ESTAGIO e AMBIENTE em relação à variável $\mathrm{VO}_{2} / \mathrm{FC}$ (Tabela 19).

Tabela 19 - Analise de variância de $\mathrm{VO}_{2} / \mathrm{FC}$.

\begin{tabular}{lccccc}
\hline \multicolumn{1}{c}{ Efeito } & $\begin{array}{c}\text { DF } \\
\text { efeito }\end{array}$ & $\begin{array}{c}\text { DF } \\
\text { erro }\end{array}$ & $\mathbf{F}$ & $\mathbf{p}$ & $\boldsymbol{\eta}^{2}$ \\
\hline ETIOLOGIA & 1 & 38 & 1.39 & 0.25 & 0.02 \\
\hline ESTAGIO & 4 & 152 & 125.22 & $<0.01$ & 0.43 \\
\hline AMBIENTE & 1 & 38 & 15.35 & $<0.01$ & 0.04 \\
\hline ETIOLOGIA:ESTAGIO & 4 & 152 & 0.48 & 0.75 & $<0.01$ \\
\hline ETIOLOGIA:AMBIENTE & 1 & 38 & 2.11 & 0.15 & $<0.01$ \\
\hline ESTAGIO:AMBIENTE & 4 & 152 & 6.79 & $<0.01$ & 0.03 \\
\hline ETIOLOGIA:ESTAGIO:AMBIENTE & 4 & 152 & 0.35 & 0.84 & $<0.01$
\end{tabular}

\subsubsection{Teste de esfericidade de Mauchly para $\mathrm{VO}_{2} / \mathrm{FC}$.}

Houve desvio de esfericidade para o efeito principal ESTAGIO e a interação ETIOLOGIA e ESTAGIO (Tabela 20). 
Tabela 20 - Teste de esfericidade de Mauchly para $\mathrm{VO}_{2} / \mathrm{FC}$.

\begin{tabular}{lcc}
\hline \multicolumn{1}{c}{ Efeito } & w & p \\
\hline ESTAGIO & 0.37 & $<0.01$ \\
\hline ETIOLOGIA:ESTAGIO & 0.37 & $<0.01$ \\
\hline ESTAGIO:AMBIENTE & 0.64 & 0.06 \\
\hline ETIOLOGIA:ESTAGIO:AMBIENTE & 0.64 & 0.06 \\
\hline
\end{tabular}

\subsubsection{Correções de esfericidade para $\mathrm{VO}_{2} / \mathrm{FC}$.}

Valores de $\boldsymbol{€}$ e $\boldsymbol{p}$ para a correção de Greenhouse-Geisser (GG) e de Huynh-Feldt (HF) (Tabela 21). As correções de esfericidade não alteraram as conclusões da análise inicial.

Tabela 21 - Correções de esfericidade para $\mathrm{VO}_{2} / \mathrm{FC}$.

\begin{tabular}{lcccc}
\hline \multicolumn{1}{c}{ Efeito } & GG & pGG & HF & pHF \\
\hline ESTAGIO & 0.68 & $<0.01$ & 0.74 & $<0.01$ \\
\hline ETIOLOGIA:ESTAGIO & 0.68 & 0.68 & 0.74 & 0.69 \\
\hline ESTAGIO:AMBIENTE & 0.83 & $<0.01$ & 0.91 & $<0.01$ \\
\hline ETIOLOGIA:ESTAGIO:AMBIENTE & 0.83 & 0.81 & 0.91 & 0.82 \\
\hline
\end{tabular}




\subsubsection{Perfis e boxplots de $\mathrm{VO}_{2} / \mathrm{FC}$.}
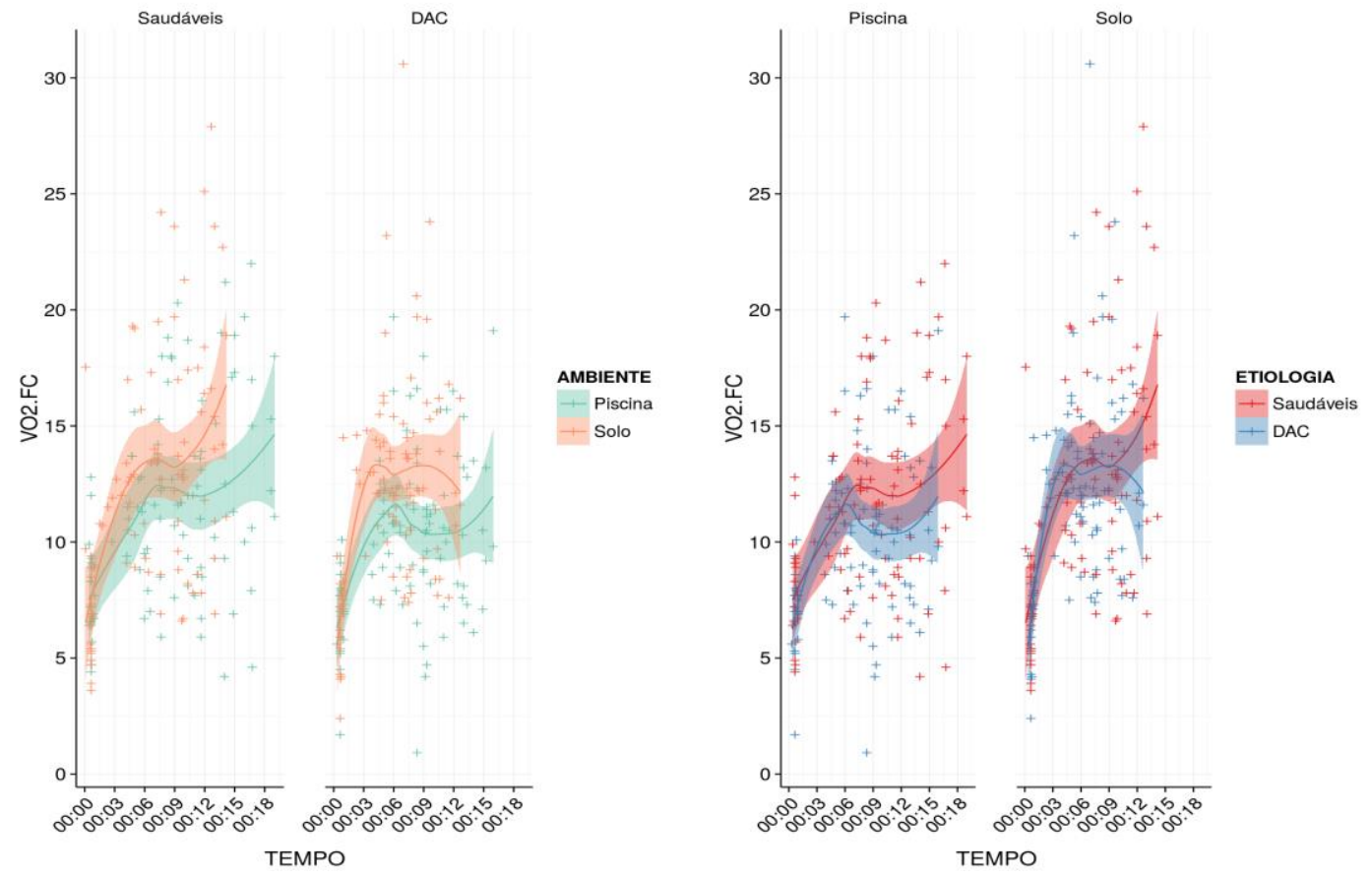

Figura 18 - Perfil da amostra para a variável $\mathrm{VO}_{2} / \mathrm{FC}$ por tempo de teste, medido em minutos e segundos.
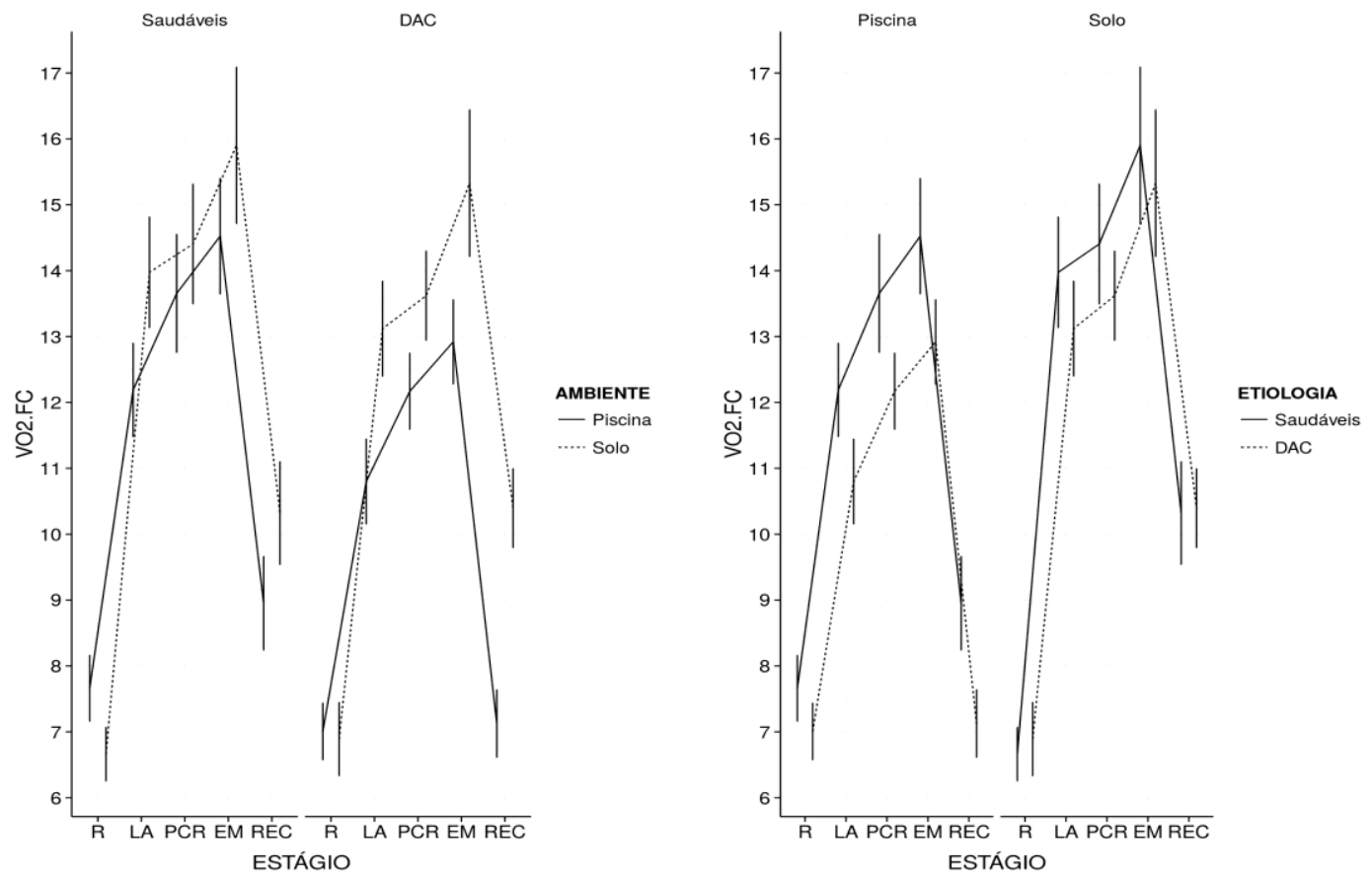

Figura 19 - Perfis médios da amostra para a variável $\mathrm{VO}_{2} / \mathrm{FC}$. 

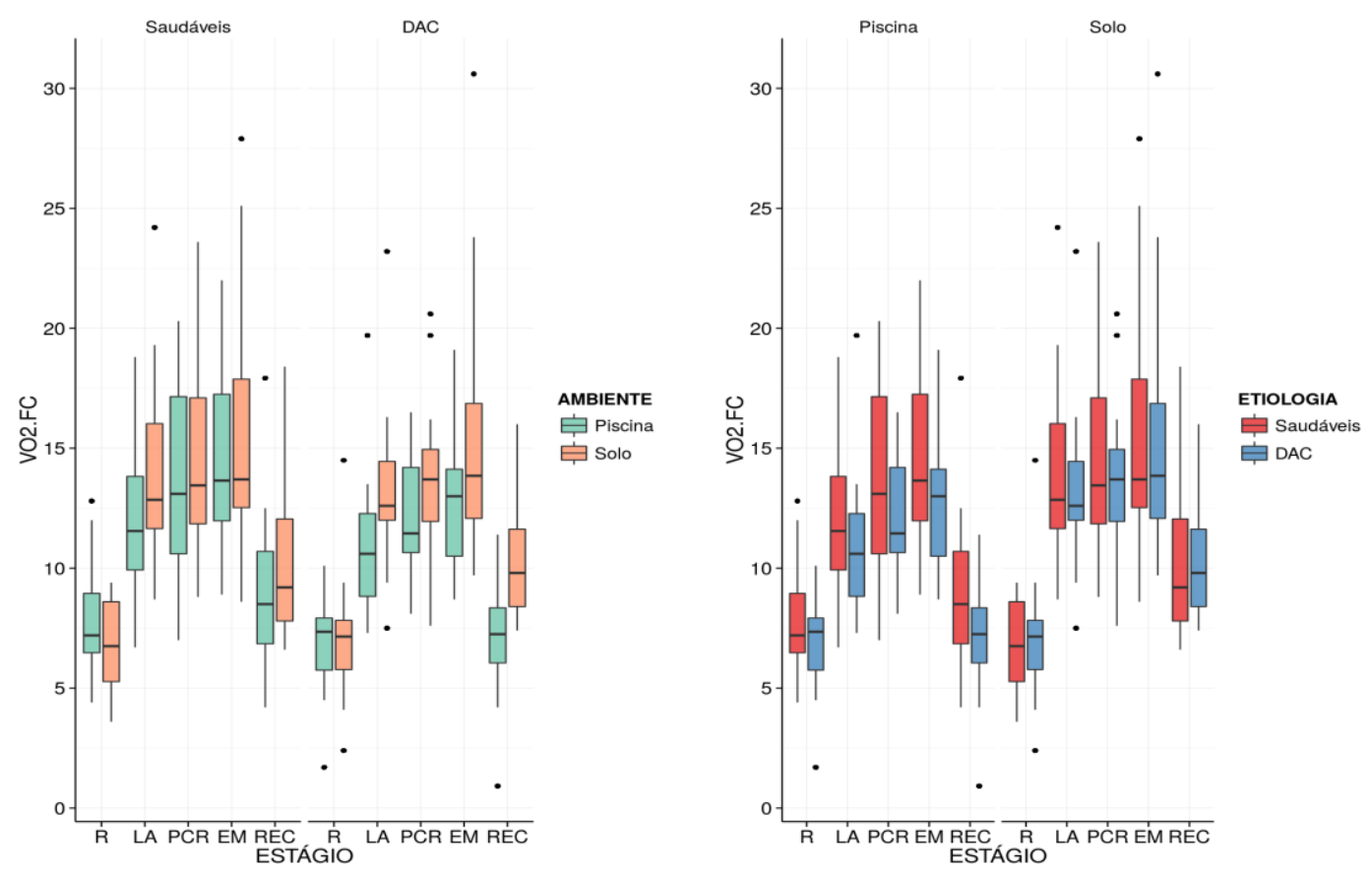

Figura 20 - Boxplot da amostra para a variável $\mathrm{VO}_{2} / \mathrm{FC}$.

\section{$5.6 \mathrm{VE} / \mathrm{NO}_{2}$}

\subsubsection{Analise de variância de $\mathrm{VE} / \mathrm{NO}_{2}$}

Os resultados mostram que há efeitos significantes em ETIOLOGIA, ESTAGIO e AMBIENTE, bem como interações significantes entre ETIOLOGIA e ESTAGIO e ESTAGIO e AMBIENTE em relação à variável VE/NO 2 (Tabela 22). 
Tabela 22 - Analise de variância de $\mathrm{VE} / \mathrm{VO}_{2}$

\begin{tabular}{lccccc}
\hline \multicolumn{1}{c}{ Efeito } & $\begin{array}{c}\text { DF } \\
\text { efeito }\end{array}$ & $\begin{array}{c}\text { DF } \\
\text { erro }\end{array}$ & $\mathbf{F}$ & $\mathbf{p}$ & $\boldsymbol{\eta}^{2}$ \\
\hline ETIOLOGIA & 1 & 38 & 0.45 & 0.51 & $<0.01$ \\
\hline ESTAGIO & 4 & 152 & 104.06 & $<0.01$ & 0.48 \\
\hline AMBIENTE & 1 & 38 & 1.51 & 0.23 & $<0.01$ \\
\hline ETIOLOGIA:ESTAGIO & 4 & 152 & 0.24 & 0.92 & $<0.01$ \\
\hline ETIOLOGIA:AMBIENTE & 1 & 38 & 1.13 & 0.30 & $<0.01$ \\
\hline ESTAGIO:AMBIENTE & 4 & 152 & 1.72 & 0.15 & $<0.01$ \\
\hline ETIOLOGIA:ESTAGIO:AMBIENTE & 4 & 152 & 0.57 & 0.69 & $<0.01$ \\
\hline
\end{tabular}

5.6.2 Teste de esfericidade de Mauchly para $\mathrm{VE} / \mathrm{NO}_{2}$

Houve desvio de esfericidade para o efeito principal ESTAGIO e a interação ETIOLOGIA e ESTAGIO (Tabela 23).

Tabela 23 - Teste de esfericidade de Mauchly para VE/ $/ \mathrm{O}_{2}$

\begin{tabular}{lcc}
\hline \multicolumn{1}{c}{ Efeito } & w & p \\
\hline ESTAGIO & 0.03 & $<0.01$ \\
\hline ETIOLOGIA:ESTAGIO & 0.03 & $<0.01$ \\
\hline ESTAGIO:AMBIENTE & 0.15 & $<0.01$ \\
\hline ETIOLOGIA:ESTAGIO:AMBIENTE & 0.15 & $<0.01$ \\
\hline
\end{tabular}




\subsubsection{Correções de esfericidade para $\mathrm{VE} / \mathrm{VO}_{2}$}

Valores de $€$ e $\boldsymbol{p}$ para a correção de Greenhouse-Geisser (GG) e de Huynh-Feldt (HF)( Tabela 24). As correções de esfericidade não alteraram as conclusões da análise inicial.

Tabela 24 - Correções de esfericidade para VE/ $\mathrm{VO}_{2}$

\begin{tabular}{lcccc}
\hline \multicolumn{1}{c}{ Efeito } & GG & pGG & HF & pHF \\
\hline ESTAGIO & 0.51 & $<0.01$ & 0.54 & $<0.01$ \\
\hline ETIOLOGIA:ESTAGIO & 0.51 & 0.79 & 0.54 & 0.81 \\
\hline ESTAGIO:AMBIENTE & 0.56 & 0.18 & 0.59 & 0.18 \\
\hline ETIOLOGIA:ESTAGIO:AMBIENTE & 0.56 & 0.59 & 0.59 & 0.60 \\
\hline
\end{tabular}

\subsubsection{Perfis e boxplots de $\mathrm{VE} / \mathrm{VO}_{2}$}
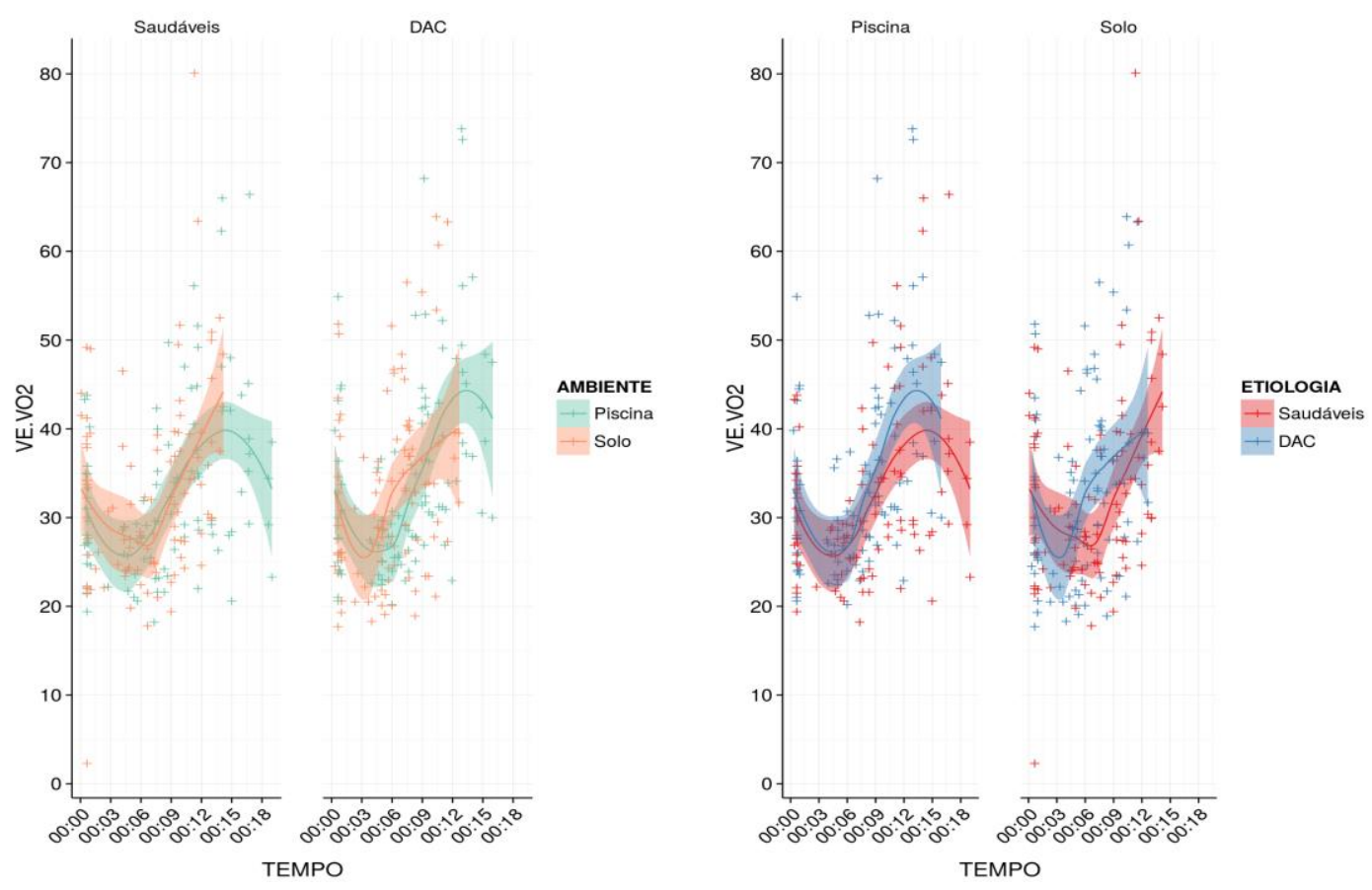

Figura 21 - Perfil da amostra para a variável $\mathrm{VE} / \mathrm{VO}_{2}$ por tempo de teste, medido em minutos e segundos. 

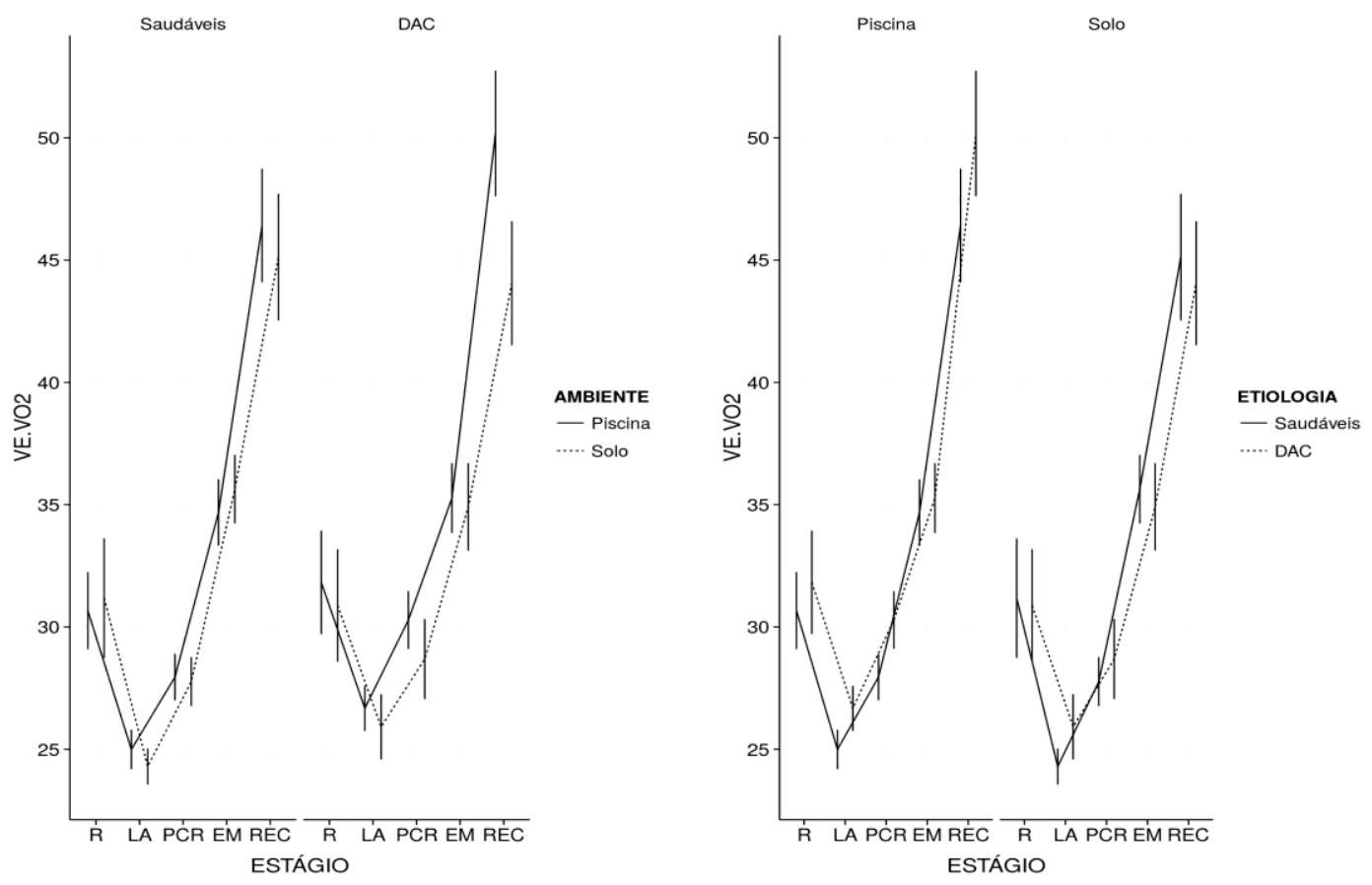

Figura 22 - Perfis médios da amostra para a variável $\mathrm{VE} / \mathrm{VO}_{2}$.
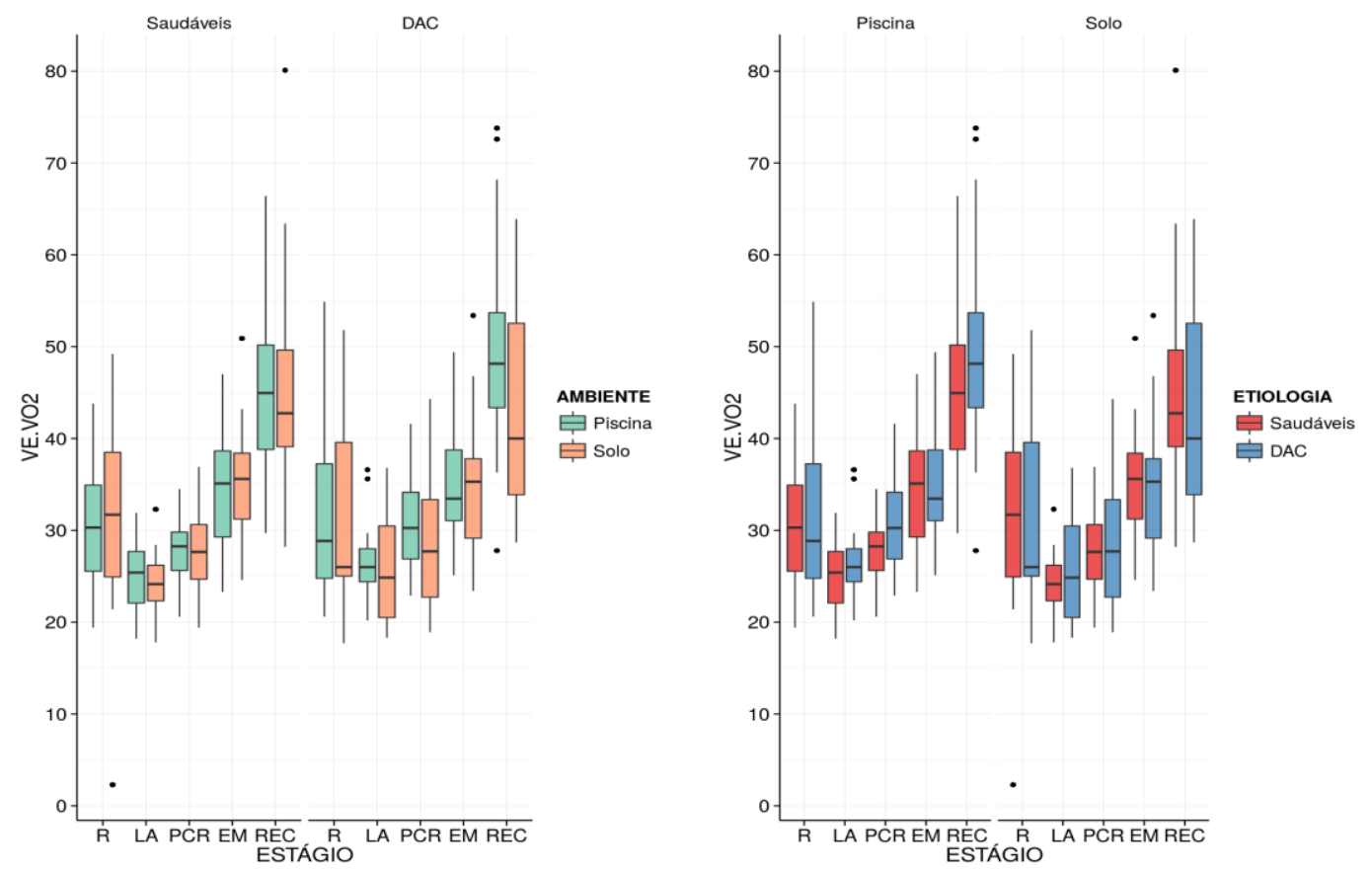

Figura 23 - Boxplot da amostra para a variável $\mathrm{VE} / \mathrm{VO}_{2}$. 


\section{$5.7 \mathrm{VE} / \mathrm{VCO}_{2}$}

\subsubsection{Analise de variância de $\mathrm{VE} / \mathrm{VCO}_{2}$}

Os resultados mostram que há efeitos significantes em ETIOLOGIA, ESTAGIO e AMBIENTE, bem como interações significantes entre ETIOLOGIA e ESTAGIO e ESTAGIO e AMBIENTE em relação à variável VE/VCO 2 (Tabela 25).

Tabela 25 - Analise de variância de $\mathrm{VE} / \mathrm{VCO}_{2}$

\begin{tabular}{lccccc}
\hline \multicolumn{1}{c}{ Efeito } & $\begin{array}{c}\text { DF } \\
\text { efeito }\end{array}$ & $\begin{array}{c}\text { DF } \\
\text { erro }\end{array}$ & $\mathbf{F}$ & $\mathbf{p}$ & $\boldsymbol{\eta}^{2}$ \\
\hline ETIOLOGIA & 1 & 38 & 1.35 & 0.25 & 0.02 \\
\hline ESTAGIO & 4 & 152 & 41.89 & $<0.01$ & 0.12 \\
\hline AMBIENTE & 1 & 38 & 1.76 & 0.19 & $<0.01$ \\
\hline ETIOLOGIA:ESTAGIO & 4 & 152 & 1.59 & 0.18 & $<0.01$ \\
\hline ETIOLOGIA:AMBIENTE & 1 & 38 & 0.02 & 0.89 & $<0.01$ \\
\hline ESTAGIO:AMBIENTE & 4 & 152 & 0.86 & 0.49 & $<0.01$ \\
\hline ETIOLOGIA:ESTAGIO:AMBIENTE & 4 & 152 & 0.35 & 0.84 & $<0.01$ \\
\hline
\end{tabular}

\subsubsection{Teste de esfericidade de Mauchly para $\mathrm{VE} / \mathrm{NCO}_{2}$}

Houve desvio de esfericidade para o efeito principal ESTAGIO e a interação ETIOLOGIA e ESTAGIO (Tabela 26). 
Tabela 26 - Teste de esfericidade de Mauchly para VE/ $/ \mathrm{CO}_{2}$

\begin{tabular}{lcc}
\hline \multicolumn{1}{c}{ Efeito } & W & p \\
\hline ESTAGIO & 0.10 & $<0.01$ \\
\hline ETIOLOGIA:ESTAGIO & 0.10 & $<0.01$ \\
\hline ESTAGIO:AMBIENTE & 0.06 & $<0.01$ \\
\hline ETIOLOGIA:ESTAGIO:AMBIENTE & 0.06 & $<0.01$ \\
\hline
\end{tabular}

\subsubsection{Correções de esfericidade para $\mathrm{VE} / \mathrm{NCO}_{2}$}

Valores de $€$ e $\boldsymbol{p}$ para a correção de Greenhouse-Geisser (GG) e de Huynh-Feldt (HF) (Tabela 27). As correções de esfericidade não alteraram as conclusões da análise inicial.

Tabela 27 - Correções de esfericidade para VE/VCO ${ }_{2}$

\begin{tabular}{lllll}
\hline \multicolumn{1}{c}{ Efeito } & GG & pGG & HF & pHF \\
\hline ESTAGIO & 0.51 & $<0.01$ & 0.53 & $<0.01$ \\
\hline ETIOLOGIA:ESTAGIO & 0.51 & 0.21 & 0.53 & 0.21 \\
\hline ESTAGIO:AMBIENTE & 0.42 & 0.41 & 0.44 & 0.42 \\
\hline ETIOLOGIA:ESTAGIO:AMBIENTE & 0.42 & 0.67 & 0.44 & 0.68 \\
\hline
\end{tabular}




\subsubsection{Perfis e boxplots de VE/VCO 2}
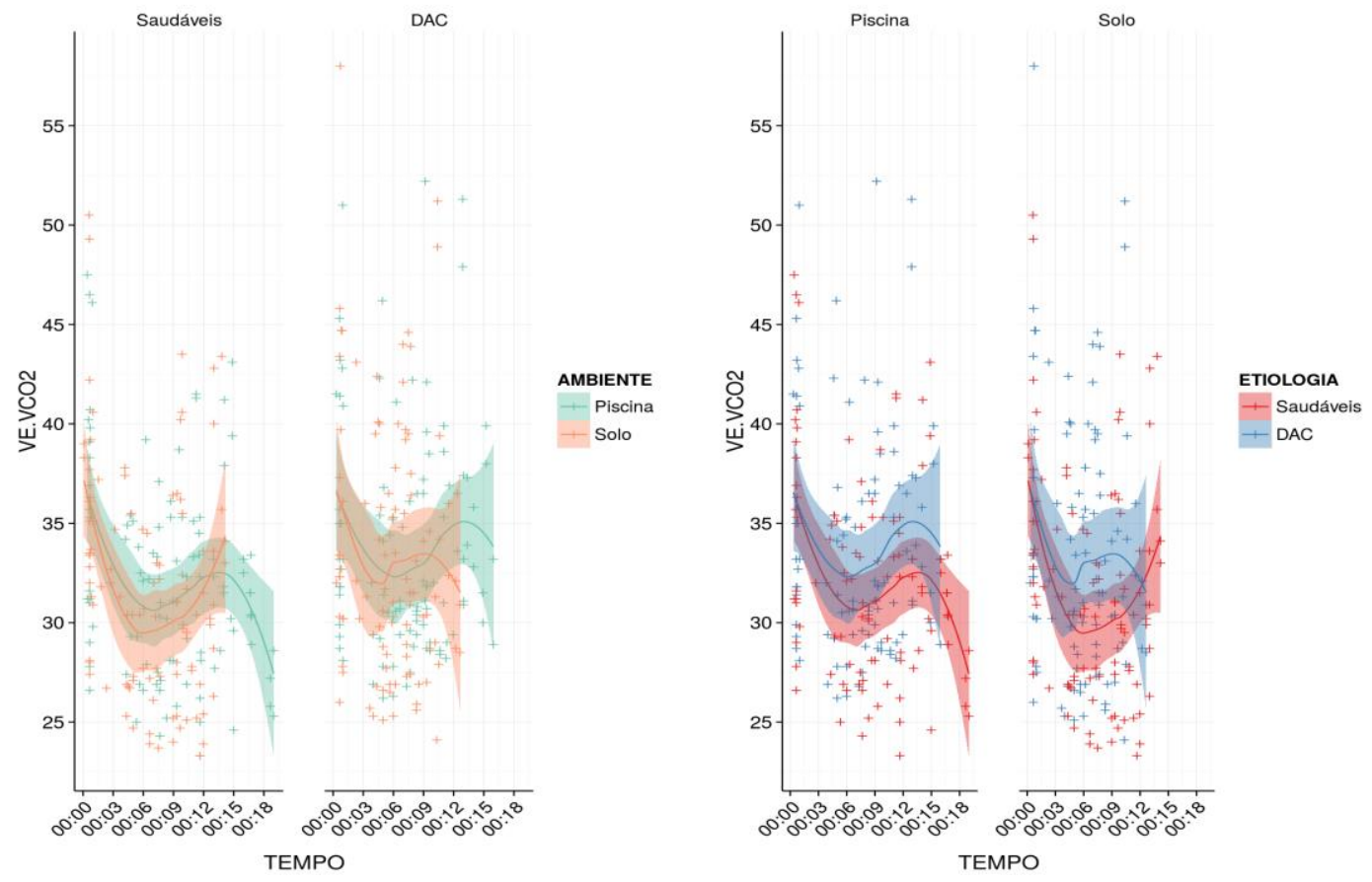

Figura 24 - Perfil da amostra para a variável $\mathrm{VE} / \mathrm{VCO}_{2}$ por tempo de teste, medido em minutos e segundos.
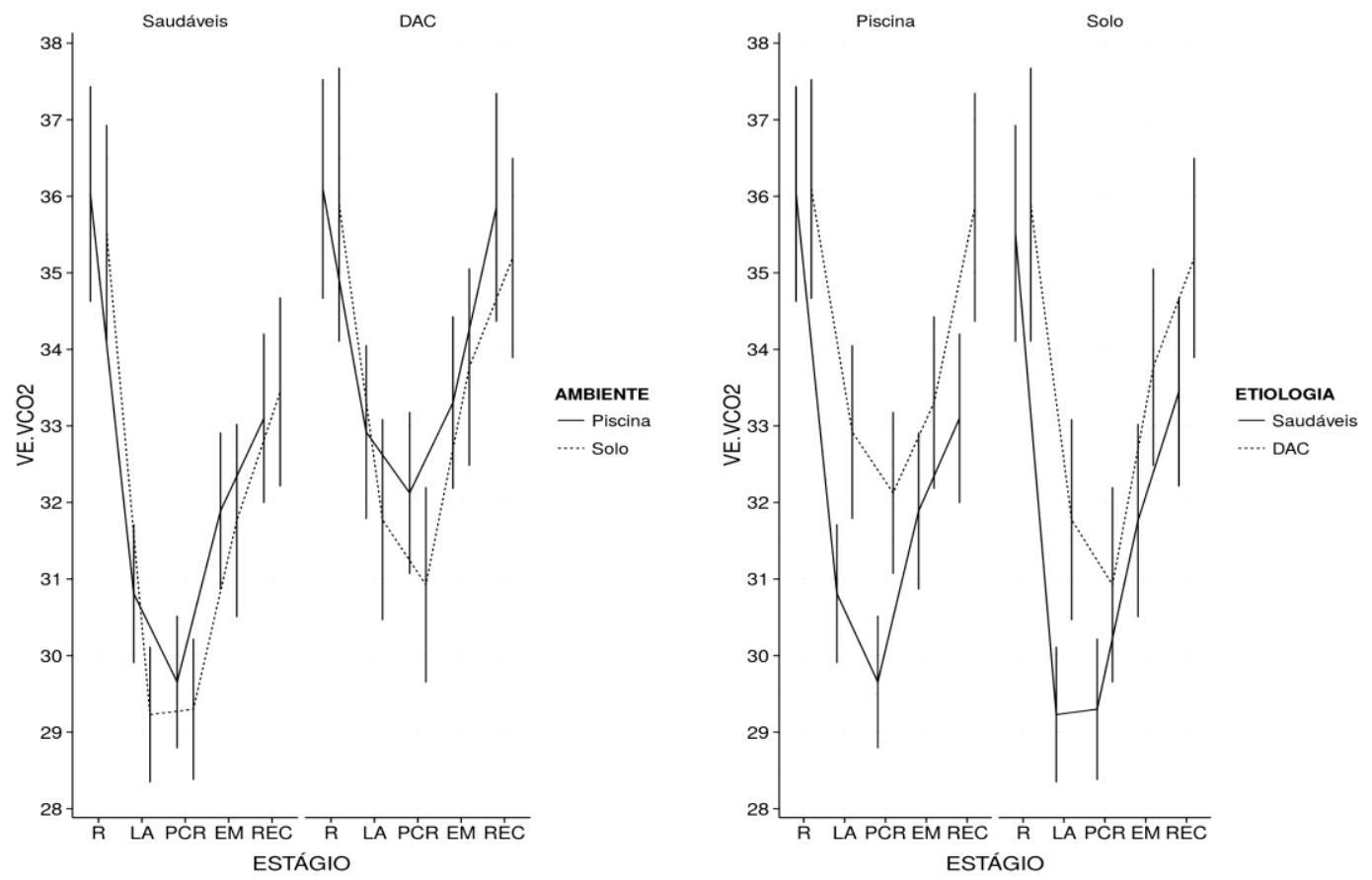

Figura 25 - Perfis médios da amostra para a variável VE/NCO ${ }_{2}$ 

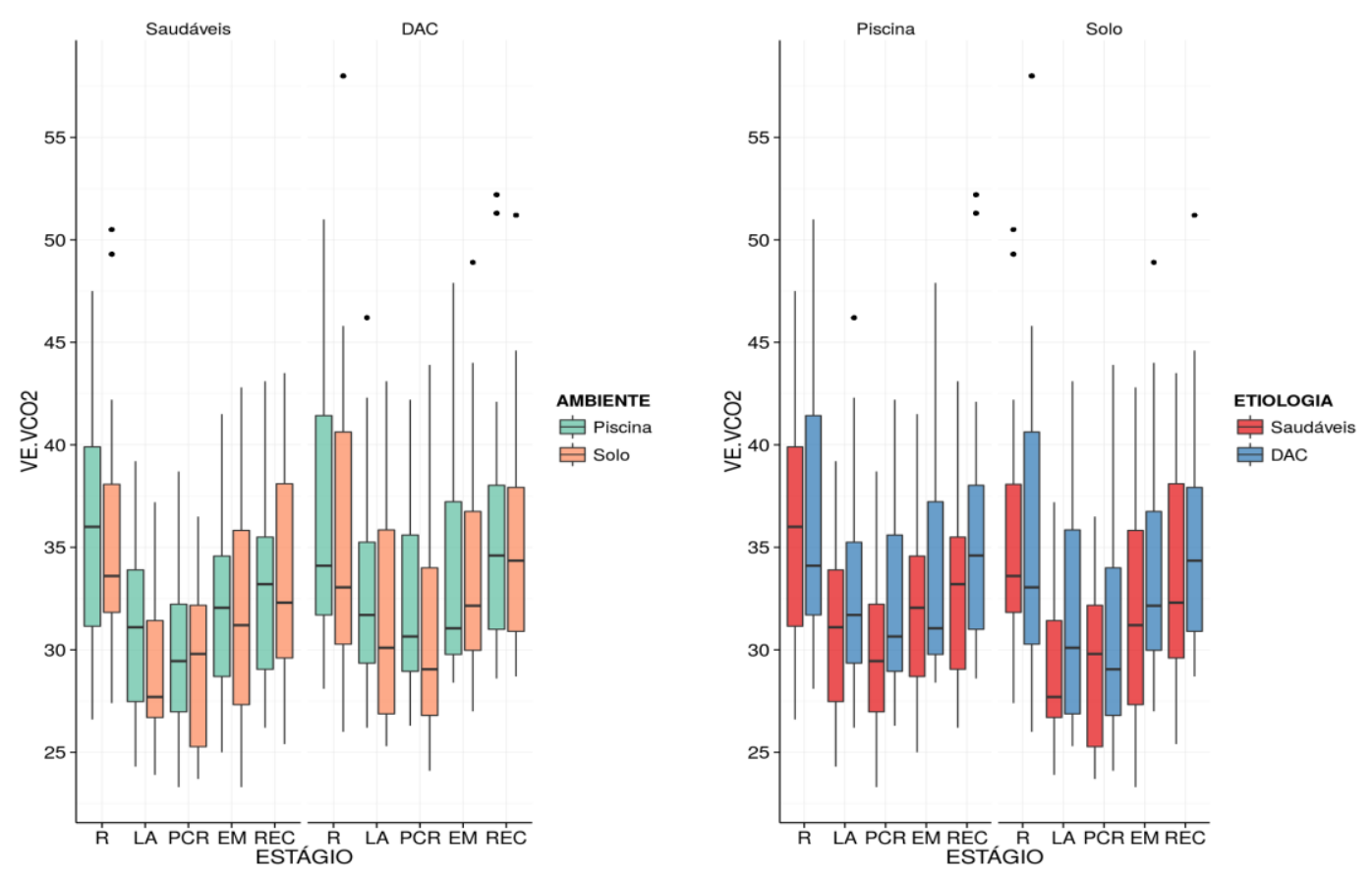

Figura 26 - Boxplot da amostra para a variável VE/VCO $\mathrm{CO}_{2}$

\section{$5.8 \mathrm{VCO}_{2} / \mathrm{VO}_{2}$}

\subsubsection{Analise de variância de $\mathrm{VCO}_{2} / \mathrm{VO}_{2}$}

Os resultados mostram que há efeitos significantes em ETIOLOGIA, ESTAGIO e AMBIENTE, bem como interações significantes entre ETIOLOGIA e ESTAGIO e ESTAGIO e AMBIENTE em relação à variável $\mathrm{VCO}_{2} / \mathrm{NO}_{2}$ (Tabela 28). 
Tabela 28 - Analise de variância de $\mathrm{VCO}_{2} \mathrm{NO}_{2}$

\begin{tabular}{lccccc}
\hline \multicolumn{1}{c}{ Efeito } & $\begin{array}{c}\text { DF } \\
\text { efeito }\end{array}$ & $\begin{array}{c}\text { DF } \\
\text { erro }\end{array}$ & $\mathbf{F}$ & $\mathbf{p}$ & $\boldsymbol{\eta}^{2}$ \\
\hline ETIOLOGIA & 1 & 38 & 1.91 & 0.17 & 0.01 \\
\hline ESTAGIO & 4 & 152 & 110.40 & $<0.01$ & 0.50 \\
\hline AMBIENTE & 1 & 38 & 1.17 & 0.29 & $<0.01$ \\
\hline ETIOLOGIA:ESTAGIO & 4 & 152 & 0.23 & 0.92 & $<0.01$ \\
\hline ETIOLOGIA:AMBIENTE & 1 & 38 & 0.51 & 0.48 & $<0.01$ \\
\hline ESTAGIO:AMBIENTE & 4 & 152 & 1.89 & 0.12 & 0.01 \\
\hline ETIOLOGIA:ESTAGIO:AMBIENTE & 4 & 152 & 1.25 & 0.29 & $<0.01$ \\
\hline
\end{tabular}

\subsubsection{Teste de esfericidade de Mauchly para $\mathrm{VCO}_{2} / \mathrm{VO}_{2}$}

Houve desvio de esfericidade para o efeito principal ESTAGIO e a interação ETIOLOGIA e ESTAGIO (Tabela 29).

Tabela 29 - Teste de esfericidade de Mauchly para $\mathrm{VCO}_{2} / \mathrm{VO}_{2}$

\begin{tabular}{lcc}
\multicolumn{1}{c}{ Efeito } & W & p \\
\hline ESTAGIO & 0.31 & $<0.01$ \\
\hline ETIOLOGIA:ESTAGIO & 0.31 & $<0.01$ \\
\hline ESTAGIO:AMBIENTE & 0.36 & $<0.01$ \\
\hline ETIOLOGIA:ESTAGIO:AMBIENTE & 0.36 & $<0.01$ \\
\hline
\end{tabular}




\subsubsection{Correções de esfericidade para $\mathrm{VCO}_{2} \mathrm{NO}_{2}$}

Valores de $€$ e $\boldsymbol{p}$ para a correção de Greenhouse-Geisser (GG) e de Huynh-Feldt (HF) (Tabela 30). As correções de esfericidade não alteraram as conclusões da análise inicial.

Tabela 30 - Correções de esfericidade para $\mathrm{VCO}_{2} / \mathrm{VO}_{2}$

\begin{tabular}{lllll}
\hline \multicolumn{1}{c}{ Efeito } & GG & pGG & HF & pHF \\
\hline ESTAGIO & 0.62 & $<0.01$ & 0.67 & $<0.01$ \\
\hline ETIOLOGIA:ESTAGIO & 0.62 & 0.84 & 0.67 & 0.86 \\
\hline ESTAGIO:AMBIENTE & 0.74 & 0.14 & 0.81 & 0.13 \\
\hline ETIOLOGIA:ESTAGIO:AMBIENTE & 0.74 & 0.30 & 0.81 & 0.30 \\
\hline
\end{tabular}

\subsubsection{Perfis e boxplots de $\mathrm{VCO}_{2} / \mathrm{NO}_{2}$}
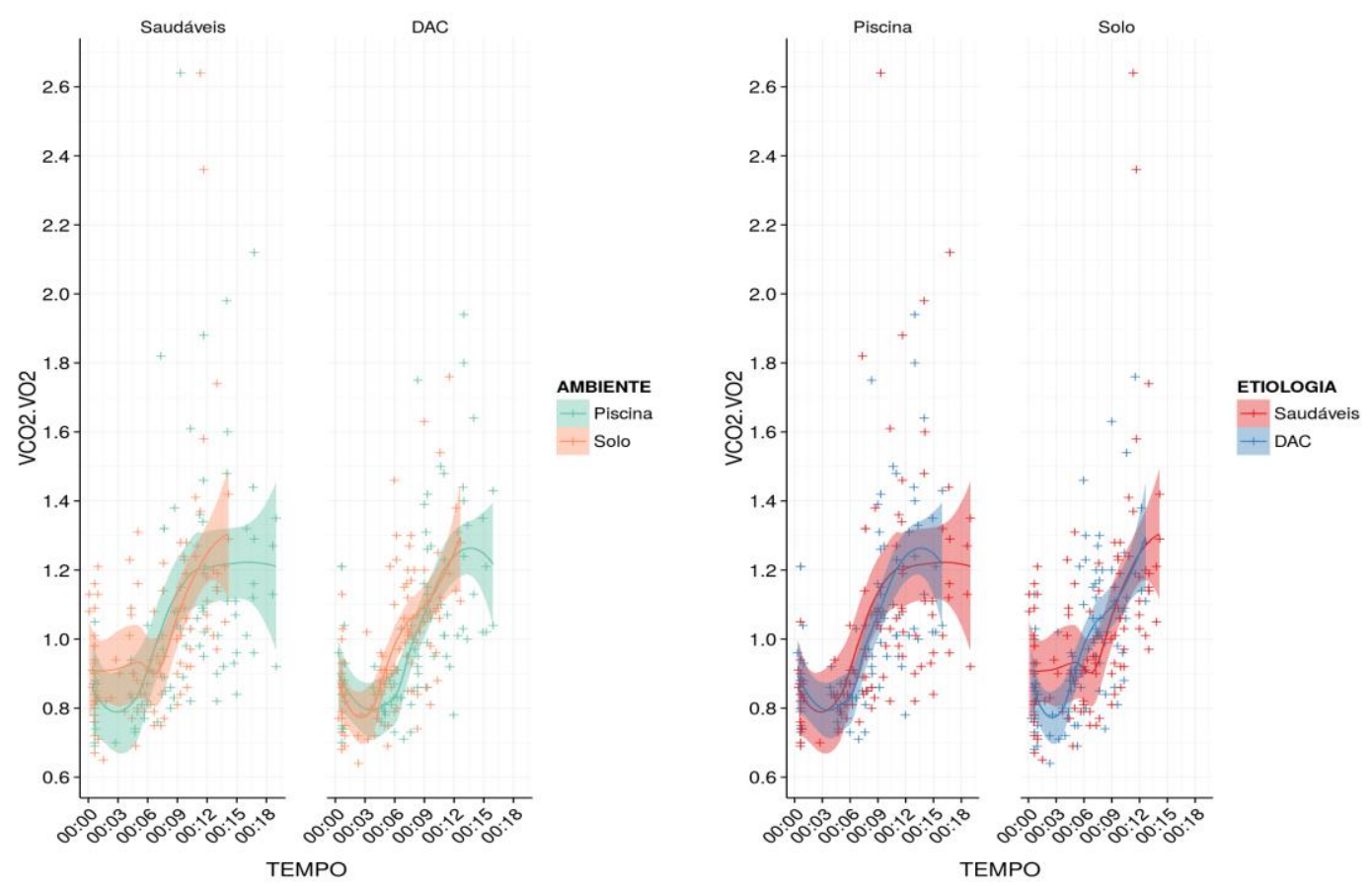

Figura 27 - Perfil da amostra para a variável $\mathrm{VCO}_{2} / \mathrm{VO}_{2}$ por tempo de teste, medido em minutos e segundos. 

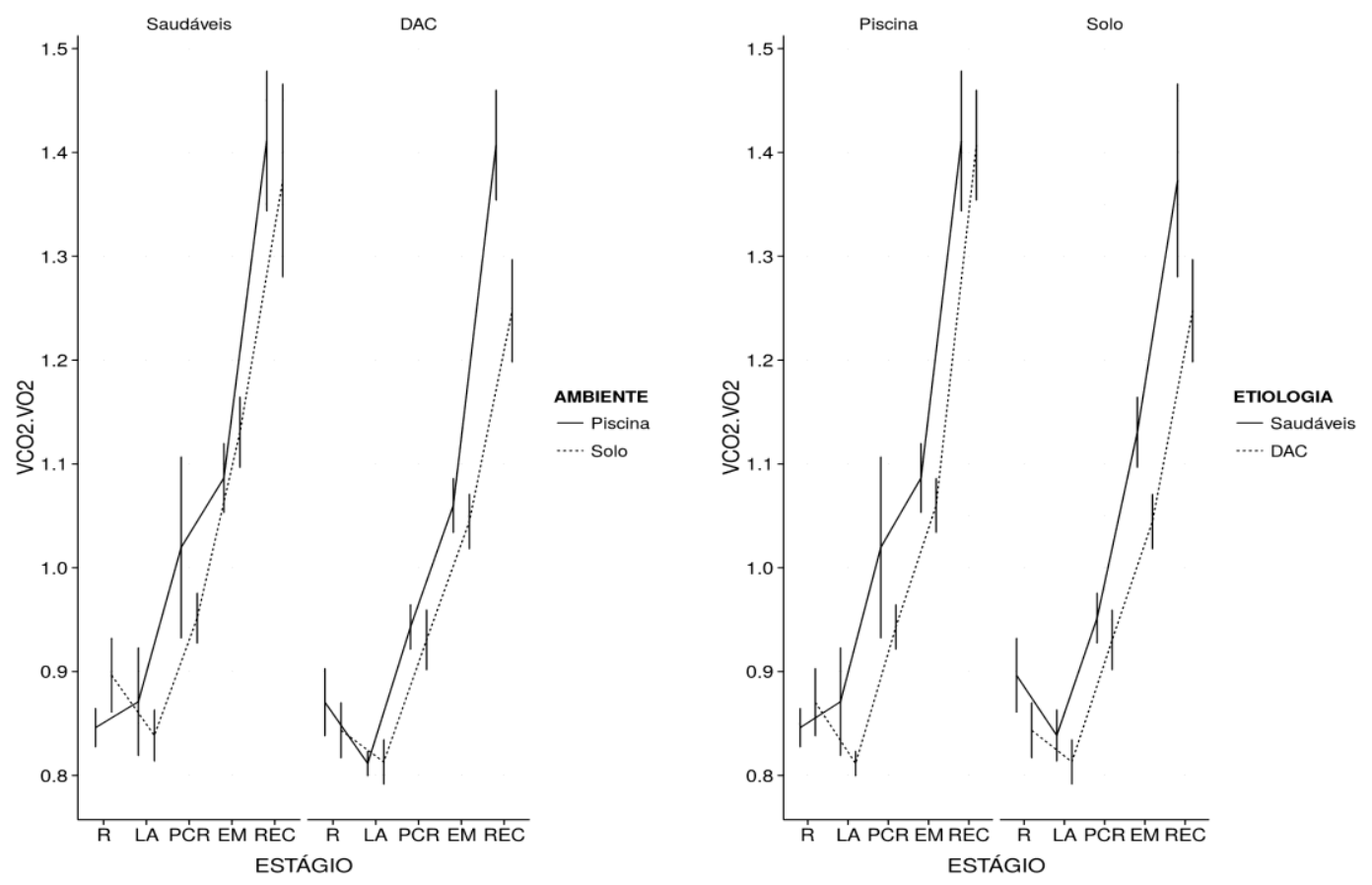

Figura 28 - Perfis médios da amostra para a variável $\mathrm{VCO}_{2} / \mathrm{VO}_{2}$.
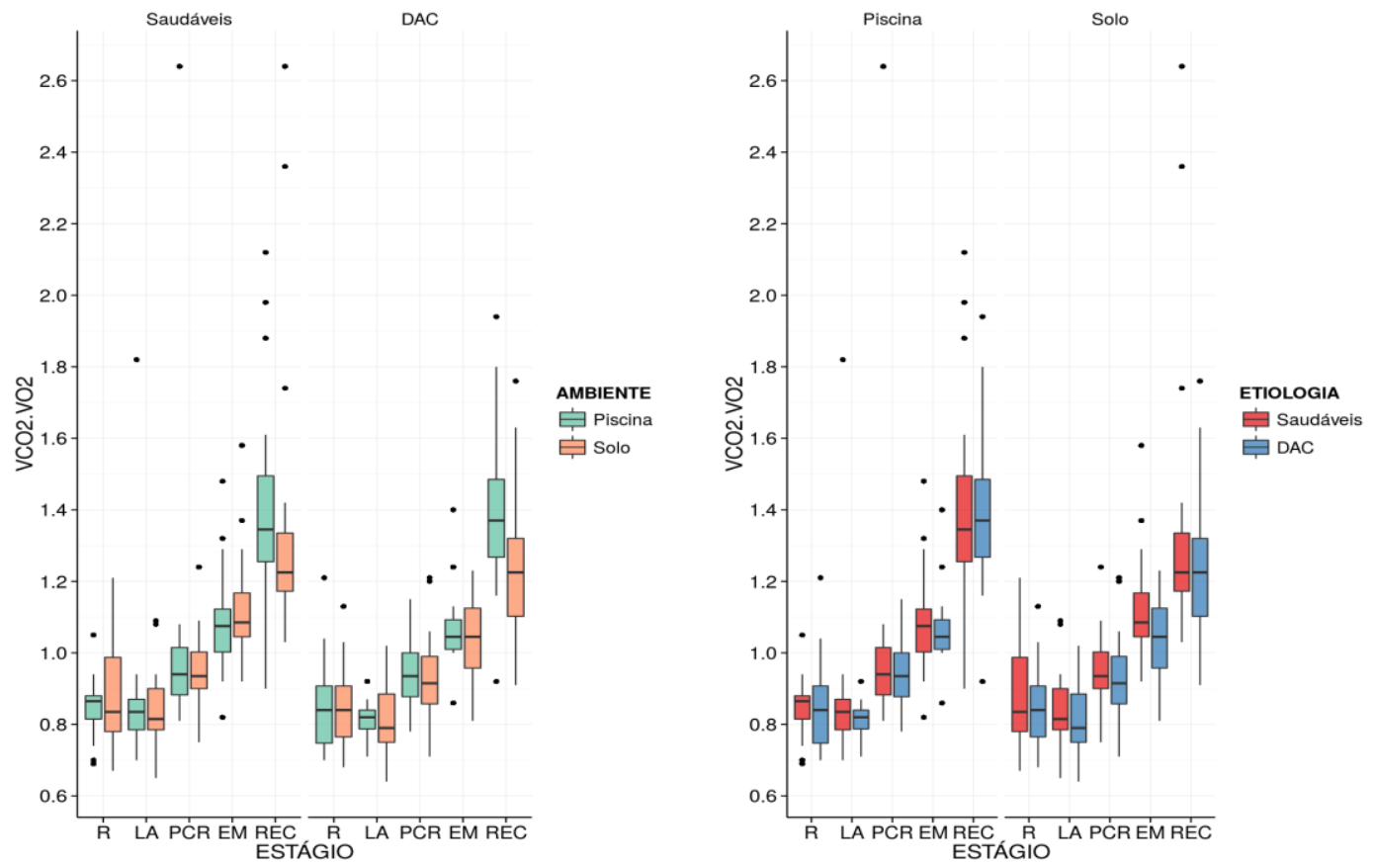

Figura 29 - Boxplot da amostra para a variável $\mathrm{VCO}_{2} / \mathrm{VO}_{2}$. 


\section{DISCUSSÃO}

Este estudo foi desenhado originalmente visando testar a hipótese de que a imersão e seus efeitos fisiológicos, associados ao exercício na piscina, não devem ser considerados como risco a pacientes com DAC e investigar as respostas cardiorrespiratórias durante O TECP em imersão, comparando-as ao solo, fornecendo dados reproduzíveis e confiáveis. O "Clinician's Guide to cardiopulmonary exercise testing in adults: a scientific statement from the American Heart Association" ${ }^{88}$ esclarece que O TECP realizado em solo é um teste extremamente seguro e versátil. Fornece informações para uma avaliação abrangente das respostas e das tolerâncias aos exercícios físicos, muito valiosa para o diagnóstico e prognostico de pacientes com doenças cardiovasculares. Em imersão, este teste é muito incomum, pois envolve instalações específicas e demanda procedimentos especiais para garantir a acurácia dos registros e a reprodutibilidade do teste para torná-lo tão confiável quanto os em solo. A preparação dos sujeitos para a captação dos sinais do ECG, sem interferência, com um cabo de 5 derivações e eletrodos recobertos com curativos oclusivos, possibilitaram a produção de dados com qualidade. A principal contribuição desta pesquisa foi demonstrar que o exercício em água aquecida é bem tolerado por pacientes com DAC e que o TECP submerso pode ser realizado. A caminhada ou a corrida em uma esteira subaquática com o corpo imerso ao nível do peito exige menor esforço cardiorrespiratório quando comparado com o solo. Os 
DACs toleraram bem o teste em imersão, tanto quanto o grupo controle, sem eventos adversos.

Questões relacionadas com a pré e pós-carga cardíaca durante a imersão surgiram devido ao deslocamento do sangue, principalmente dos membros inferiores, para a cavidade torácica, aumentando o volume de sangue nas quatro câmaras do coração. O volume cardíaco aumenta em 27 a $30 \%$ com imersão até o pescoço ${ }^{7}$. Mas o coração não é um receptáculo estático, a resposta cardíaca fisiológica ao aumento do volume é aumentar a força de contração, à medida que ocorre estiramento do miocárdio saudável. Segundo a Lei de Frank \& Starling ${ }^{89}$, o coração irá melhorar a eficiência de contração. Gabrielsen et al. ${ }^{13}$, em 1993, demonstraram que tanto o débito cardíaco quanto o volume sistólico aumentam na imersão em água a $30^{\circ} \mathrm{C}^{90}$, aumentando o volume sistólico e o Débito Cardíaco.

A imersão até o processo xifoide, diminui a carga sobre as articulações e os ossos em pelo menos $60 \%{ }^{46}$. O efeito do Empuxo, força vertical exercida pelo líquido de baixo para cima e de intensidade proporcional ao peso do volume do liquido deslocado pelo corpo, pode facilitar o exercício na água ao diminuir a força gravitacional. Entretanto, a resistência da água, de até 800 vezes maior que a do ar, exige mais esforço para caminhar e/ou correr neste meio. Neste aspecto, este estudo demonstra que, por estar andando ou correndo na esteira, mas não contra a resistência da água, o empuxo torna-se um facilitador ao demandar menor esforço da musculatura antigravitacional para a sustentação do peso e consequentemente, a percepção de esforço (Borg) apresentou diferença estatisticamente significativa entre a água e o solo $(p<0.01)$ para ambos os 
grupos. Christie et al. ${ }^{70}$, em 1990, demonstraram que a freqüência cardíaca em indivíduos saudáveis tem respostas semelhantes para o exercício em solo e em água até $\mathrm{o} \mathrm{VO}_{2}$ atingir $60 \%$ do $\mathrm{VO}_{2 \text { pico. Nossos achados }}$ demonstraram que na FC há efeitos significantes e interações significantes entre ETIOLOGIA e ESTÁGIO, ESTÁGIO e AMBIENTE $(p<0.01)$. Em todos os ESTÁGIOS, a FC foi maior no solo do que na água em ambos os grupos e os saudáveis apresentaram FC maior do que os DACs nos dois ambientes. $\mathrm{VO}_{2}$ é influenciado por vários fatores, mas a magnitude do consumo de oxigênio é um indicador muito confiável sobre a capacidade funcional cardiorrespiratória. Em 1989, Gleim \& Nicholas ${ }^{15}$ demonstraram que o consumo oxigênio $\left(\mathrm{VO}_{2}\right)$ durante a corrida na água foi três vezes maior do que no solo para uma mesma velocidade $(53 \mathrm{~m} / \mathrm{min})$. Portanto, durante a marcha ou corrida na água, apenas metade ou um terço da velocidade é necessária para atingir a mesma intensidade metabólica da atividade no solo. Como em nosso estudo, os sujeitos não corriam contra a resistência da água, isso pode ter determinado a impossibilidade de reproduzir resultados similares aos deste estudo. Contudo, nossos achados demonstraram efeitos e interações significantes entre ETIOLOGIA e ESTÁGIO, ESTÁGIO e AMBIENTE $(p<0.01) . \mathrm{O} \mathrm{VO}_{2}$ em solo foi maior em todos os ESTÁGIOS tanto para DAC como para saudáveis e ambos apresentaram $\mathrm{VO}_{2}$ menor na água em comparação ao solo. Craig \& Dvorak $^{90}$, em 1969, mostraram que, em repouso, o $\mathrm{VO}_{2}$ dos sujeitos saudáveis em solo ou imersos em água a $34^{\circ} \mathrm{C}$ era similar. Este achado não pode ser repetido em nosso experimento, o que sugere que nem a resistência da água ou a temperatura $\left(34^{\circ} \mathrm{C}\right)$ influenciaram no consumo de oxigênio. $A$ produção de $\mathrm{CO}_{2}$ tem uma relação de causa e 
efeito com o consumo de $\mathrm{O}_{2}$ e um aumento linear progressivo. Segundo Yasbek et al. ${ }^{31}$, em 1998, o Pulso de $\mathrm{O}_{2}\left(\mathrm{VO}_{2} / \mathrm{FC}\right)$ evidencia a quantidade de $\mathrm{O}_{2}$ que é transportada a cada sístole cardíaca. A diminuição do desempenho de VE pode ser detectada em uma prova de esforço crescente com observação do pulso de $\mathrm{O}_{2}$ e representa um índice indireto do transporte de oxigênio pelo sistema cardiopulmonar. Observamos efeito e interação significantes no ESTÁGIO e AMBIENTE ( $p<0.01)$, mas não em ETIOLOGIA e ESTÁGIO (P=0.75). De acordo com Hall et al. ${ }^{91}$, em 1990, um ambiente de gravidade reduzida requer menos atividade dos músculos antigravitacionais, o que pode explicar as diferenças significativa observada no $\mathrm{VO}_{2} / \mathrm{FC}$, menor na água do que em solo em ambos os grupos, mas não explica porque os pacientes com DAC apresentaram menor Pulso de $\mathrm{O}_{2}$ na água e no solo em relação ao grupo de saudáveis.

As relações $\mathrm{VE} / \mathrm{VO}_{2}$ e $\mathrm{VE} / \mathrm{VCO}_{2}$, com VE em condições de BTPS (Body Temperature Pressure Saturated) e $\mathrm{VO}_{2}$ e $\mathrm{VCO}_{2}$ em STPD (Standard Air Temperature and Air Pressure Dry), relacionam quantos litros de ar por minuto são necessários e devem ser ventilados para consumir $100 \mathrm{ml}$ de $\mathrm{O}_{2}$ e produzir $\mathrm{CO}_{2}$. Verificamos neste experimento que, mesmo diante de um esforço crescente e sob os efeitos fisiológicos da imersão, tanto os pacientes com DAC quanto os saudáveis não alteraram significativamente a VE, mantendo-se ajustada à demanda proporcional de $\mathrm{O}_{2}$ em cada momento. Em um estudo prévio, Craig \& Ware ${ }^{92}$, em 1967, e Hall et al. ${ }^{93}$, em 1990, demonstraram que, em sujeitos saudáveis, a VE diminui em imersão, este resultado não pudemos confirmar, acompanhando desta forma o estudo de 
Asa et al. ${ }^{87}$, em 2005. A eficiência ventilatória durante exercício em esteira no solo ou na água ocorreu de acordo com a demanda de $\mathrm{O}_{2}$.

A razão de troca respiratória ou $Q R$ é o resultado do quociente entre o $\mathrm{VCO}_{2}$ e o $\mathrm{VO}_{2}$. Em um esforço progressivo, como o de nosso estudo, o metabolismo gradativamente utiliza carboidratos como fonte de energia, chegando a $\geq 1,1$ no esforço máximo. Em ambos os teste, solo e água, os indivíduos atingiram $Q R>1$, e não houve efeito significativo entre ESTÁGIO e AMBIENTE e ETIOLOGIA e AMBIENTE.

As respostas hemodinâmicas ao exercício variam de acordo com o débito cardíaco e a resistência periférica, portanto esperávamos aumento na PAS pelo aumento do débito cardíaco em ambos os ambientes, principalmente em imersão. Em contraste, a PAD deveria manter-se, ou mesmo diminuir moderadamente com o exercício, porém nenhuma resposta significativa da PAS/D foi observada. Estudos sobre o comportamento da PAS/D durante a imersão de indivíduos saudáveis em repouso e em água termoneutra são divergentes e escassos na literatura (Gabrielsen et al. ${ }^{13}$, 1993).

No ECG, o cardiologista responsável pelo experimento, não observou nenhuma arritmia significativa, atividade ectópica ventricular e/ou depressão do segmento ST, na curva de avaliação.

O uso de uma esteira subaquática sem interface computadorizada, impossibilitou o controle da velocidade e da inclinação de forma automática, o que pode ter influenciado a coleta de dados no teste em imersão. Todavia, a metodologia utilizada nos dois testes foi idêntica e os sujeitos tinham que caminhar, ou correr, de acordo com Protocolo de Bruce ${ }^{86}$. 


\section{CONCLUSÕES}

Este estudo demonstrou que o Teste de Esforço Cardiopulmonar pode ser realizado com indivíduos imersos, com água na altura do manúbrio e que os dados obtidos pelos equipamentos, os mesmos utilizados em solo, tomando as devidas orientações descritas neste estudo, são confiáveis e podem ser reproduzidos de forma segura. As diferenças estatísticas observadas nos testes na água contra os de solo nos levam a entender que o exercício em imersão pode ser realizado por pacientes com Coronariopatias e que os efeitos fisiológicos da imersão, associados ao esforço, não produzem qualquer risco para este grupo, pois o esforço foi bem tolerado por todos os participantes. Conclui-se também que o teste em imersão não demanda equipamentos especiais, em relação ao solo e pode ser considerada uma opção de avaliação a ser utilizada pelo cardiologista para garantir, com mais segurança, um prognostico sobre as capacidades cardiopulmonares de Coronariopatas ao exercício dinâmico em piscina. Estudos mais aprofundados são necessários para compreender melhor os efeitos fisiológicos da imersão associados a exercícios em grupos de maior risco. 
8 ANEXOS

\section{Sumario Estatístico}

\section{Perfil da Amostra}

\begin{tabular}{llccccc}
\hline \multirow{2}{*}{ AMBIENTE } & ETIOLOGIA & Média (desvio) & Média (desvio) & Média (desvio) & $\begin{array}{c}\text { PAS(EM) } \\
\text { Média (desvio) }\end{array}$ & $\begin{array}{c}\text { PÁ } \\
\text { Média (desvio) }\end{array}$ \\
\hline Piscina & Saudáveis & $64.70(7.09)$ & $120.00(0.00)$ & $80.00(0.00)$ & $164.75(21.37)$ & $88.00(13.22)$ \\
& DAC & $63.65(8.89)$ & $120.50(6.86)$ & $80.00(5.62)$ & $153.00(15.84)$ & $84.50(6.86)$ \\
\multirow{2}{*}{ Solo } & Saudáveis & $64.70(7.09)$ & $123.50(8.13)$ & $81.00(3.08)$ & $174.00(14.92)$ & $89.75(9.52)$ \\
& DAC & $63.65(8.89)$ & $118.50(4.89)$ & $78.00(4.10)$ & $170.25(23.31)$ & $83.00(11.29)$ \\
\hline \multicolumn{7}{c}{ captionPerfil da amostra nos dois ambientes, por grupo em estudo. }
\end{tabular}

\section{Perfil do Experimento}

Perfil do experimento para os cincos estágios, por ambiente e grupo em estudo.

\begin{tabular}{|c|c|c|c|c|c|c|c|c|c|c|}
\hline ESTÁGIO & & & $\begin{array}{c}\text { PEB } \\
\text { Média (desvio) }\end{array}$ & $\begin{array}{c}F C \\
\text { Média (desvio) }\end{array}$ & $\begin{array}{c}\text { VO2 } \\
\text { Média (desvio) }\end{array}$ & $\begin{array}{c}\text { VCO2 } \\
\text { Média (desvio) }\end{array}$ & $\begin{array}{c}\text { VO2.FC } \\
\text { Média (desvio) }\end{array}$ & $\begin{array}{c}\text { VE.VO2 } \\
\text { Média (desvio) }\end{array}$ & $\begin{array}{c}\text { VE.VCO2 } \\
\text { Média (desvio) }\end{array}$ & $\begin{array}{c}\text { VCO2VO2 } \\
\text { Média (desvio) }\end{array}$ \\
\hline \multirow[t]{4}{*}{ PCR } & Piscina & Saudáveis & & & $1.69(0.53)$ & $1.58(0.49)$ & $13.65(4.00)$ & $27.95(4.17)$ & $29.66(3.84)$ & $1.02(0.39)$ \\
\hline & & DAC & $12.10(1.07)$ & $102.40(17.14)$ & $1.20(0.35)$ & $1.13(0.33)$ & $12.17(2.59)$ & $30.29(5.20)$ & $32.12(4.70)$ & $0.94(0.10)$ \\
\hline & Solo & Saudáveis & $11.25(1.62)$ & $127.65(8.63)$ & $1.83(0.50)$ & $1.71(0.40)$ & $14.40(4.06)$ & $27.77(4.41)$ & $29.30(4.10)$ & $0.95(0.11)$ \\
\hline & & DAC & $12.15(1.46)$ & $108.30(18.48)$ & $1.44(0.27)$ & $1.33(0.27)$ & $13.62(3.03)$ & $28.69(7.22)$ & $30.93(5.68)$ & $0.93(0.13)$ \\
\hline \multirow[t]{4}{*}{$\mathbf{R}$} & Piscina & Saudáveis & $7.15(0.49)$ & $85.90(12.56)$ & $0.64(0.16)$ & $0.54(0.14)$ & $7.66(2.23)$ & $30.67(6.97)$ & $36.03(6.28)$ & $0.85(0.08)$ \\
\hline & & DAC & $7.40(0.82)$ & $81.45(13.00)$ & $0.57(0.17)$ & $0.49(0.12)$ & $7.00(1.92)$ & $31.82(9.37)$ & $36.09(6.39)$ & $0.87(0.14)$ \\
\hline & Solo & Saudáveis & $7.10(0.45)$ & $88.60(11.49)$ & $0.59(0.17)$ & $0.53(0.19)$ & $6.66(1.82)$ & 31.18 (10.86) & $35.52(6.31)$ & $0.90(0.16)$ \\
\hline & & DAC & $7.30(0.73)$ & $81.30(15.62)$ & $0.56(0.19)$ & $0.46(0.14)$ & $6.89(2.49)$ & $30.88(10.21)$ & $35.89(7.97)$ & $0.84(0.12)$ \\
\hline \multirow[t]{4}{*}{ REC } & Piscina & Saudáveis & $15.05(2.72)$ & $99.85(12.76)$ & $0.85(0.26)$ & $1.15(0.35)$ & $8.95(3.17)$ & $46.41(10.30)$ & $33.10(4.93)$ & $1.41(0.30)$ \\
\hline & & DAC & $15.60(0.88)$ & $89.30(14.12)$ & $0.68(0.21)$ & $0.93(0.22)$ & $7.13(2.29)$ & $50.17(11.41)$ & $35.85(6.66)$ & $1.41(0.24)$ \\
\hline & Solo & Saudáveis & $16.10(1.17)$ & 109.15 (11.39) & $1.13(0.41)$ & $1.51(0.53)$ & $10.32(3.48)$ & $45.12(11.49)$ & $33.45(5.49)$ & $1.37(0.42)$ \\
\hline & & DAC & $16.45(0.83)$ & $89.95(22.62)$ & $0.91(0.24)$ & $1.11(0.29)$ & $10.39(2.67)$ & $44.05(11.26)$ & $35.20(5.82)$ & $1.25(0.22)$ \\
\hline \multirow[t]{4}{*}{ LA } & Piscina & Saudáveis & $9.95(1.05)$ & $103.95(13.80)$ & $1.26(0.37)$ & $1.02(0.31)$ & $12.19(3.16)$ & $25.00(3.52)$ & $30.81(4.03)$ & $0.87(0.23)$ \\
\hline & & DAC & $10.30(1.22)$ & $90.00(15.45)$ & $0.97(0.33)$ & $0.78(0.24)$ & $10.80(2.88)$ & $26.68(4.05)$ & $32.92(5.05)$ & $0.81(0.05)$ \\
\hline & Solo & Saudáveis & $9.25(1.37)$ & $109.10(9.79)$ & $1.53(0.40)$ & $1.28(0.35)$ & $13.97(3.75)$ & $24.30(3.21)$ & $29.23(3.94)$ & $0.84(0.11)$ \\
\hline & & DAC & $9.85(1.60)$ & $95.40(17.82)$ & $1.22(0.23)$ & $0.99(0.20)$ & $13.12(3.21)$ & $25.92(5.90)$ & $31.77(5.85)$ & $0.81(0.10)$ \\
\hline \multirow[t]{4}{*}{ EM } & Piscina & Saudáveis & $14.85(1.31)$ & 139.35 (13.29) & $1.96(0.66)$ & $2.17(0.71)$ & $14.52(3.92)$ & $34.69(5.99)$ & $31.89(4.56)$ & $1.09(0.15)$ \\
\hline & & DAC & $14.85(1.35)$ & $118.60(20.63)$ & $1.51(0.33)$ & $1.60(0.38)$ & $12.92(2.86)$ & $35.27(6.31)$ & $33.30(5.02)$ & $1.06(0.12)$ \\
\hline & Solo & Saudáveis & $15.00(1.62)$ & $149.65(12.77)$ & $2.35(0.85)$ & $2.61(0.94)$ & $15.90(5.31)$ & $35.63(6.20)$ & $31.77(5.62)$ & $1.13(0.15)$ \\
\hline & & DAC & $15.20(1.01)$ & $126.50(17.82)$ & $1.72(0.36)$ & $1.78(0.31)$ & $15.33(4.98)$ & 34.91 (7.92) & $33.77(5.74)$ & $1.04(0.12)$ \\
\hline
\end{tabular}




\section{PEB}

\section{Localização das diferenças significativas}

Tabela de Matriz de valores $p$ dos testes t pareados usados para determinar a localização das diferenças por ESTAGIO, ETIOLOGIA e AMBIENTE

\begin{tabular}{|c|c|c|c|c|c|c|c|c|c|c|c|c|c|c|c|c|c|c|c|}
\hline 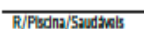 & & & & & & & & & & & & & & & & & & & \\
\hline 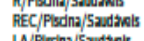 & $<0.1$ & $<0.01$ & $\therefore$ & : & : & : & : & : & : & $\therefore$ & $\therefore$ & : & $\therefore$ & : & : & : & : & : & : \\
\hline 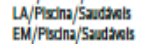 & $\begin{array}{lll}<0.01 \\
<0.1\end{array}$ & $\begin{array}{l}<0.01 \\
<0.01\end{array}$ & $\begin{array}{r}<0.01 \\
1.00\end{array}$ & $<0.01$ & . & . & : & : & : & : & : & : & : & : & : & : & : & : & \\
\hline 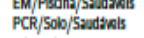 & $\begin{array}{r}0.01 \\
0.23\end{array}$ & $\begin{array}{l}<0.01 \\
<0.1\end{array}$ & $<0.01$ & $\begin{aligned}<0.08 \\
0.08\end{aligned}$ & $<0.01$ & 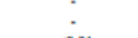 & : & : & : & : & : & : & & : & . & . & . & & . \\
\hline 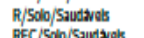 & $<0.01$ & 1.00 & $<0.01$ & $<0.01$ & $<0.01$ & $<0.01$ & & 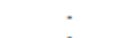 & - & : & & - & & - & 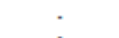 & 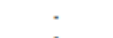 & - & & - \\
\hline 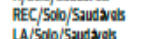 & $<0.01$ & $<0.01$ & 0.4 & $<0.01$ & 0.12 & $<0.01$ & $<0.01$ & $\therefore$ & : & - & : & : & & : & 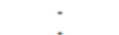 & 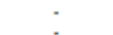 & - & & : \\
\hline 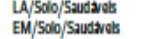 & $\begin{array}{l}<0.01 \\
<0.1\end{array}$ & $\begin{array}{c}<0.01 \\
<0.1\end{array}$ & $\begin{array}{c}<.0 .1 \\
1.00\end{array}$ & $\begin{array}{l}1.00 \\
<0.01\end{array}$ & $\begin{array}{c}<0.01 \\
1.00\end{array}$ & $\begin{array}{l}<0.01 \\
<0.01\end{array}$ & $\begin{array}{l}<0.01 \\
<0.1\end{array}$ & $\begin{array}{c}<0.12 \\
0.28\end{array}$ & $<0.01$ & $:$ & : & : & : & : & : & : & & & : \\
\hline & 1.00 & $<0.01$ & $<0.01$ & $<0.01$ & $<0.01$ & <.o.1. & $<0.01$ & $<0.012$ & $<0.01$ & $<0.01$ & • & . & : & : & : & : & & & : \\
\hline 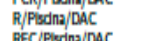 & $<0.01$ & 1.00 & $<0.01$ & $<0.01$ & $<0.01$ & $<0.01$ & 1.00 & $<0.01$ & $<0.01$ & $<0.01$ & $<0.01$ & & & . & . & . & & & : \\
\hline 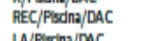 & $<0.01$ & $<0.01$ & $\begin{aligned} 1.00 \\
<0.1\end{aligned}$ & $<0.01$ & 1.00 & $<0.01$ & $<0.01$ & 1.00 & $<0.01$ & 1.00 & $<0.01$ & $<0.01$ & & - & - & - & - & & : \\
\hline 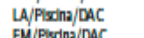 & $<001$ & $<0.01$ & $<0.01$ & 1.00 & $<0.01$ & 0.50 & $<0.01$ & $<0.01$ & 0.4 & $<0.01$ & $<0.01$ & $<0.01$ & $<0.01$ & & - & - & . & & : \\
\hline 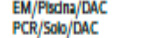 & $\begin{array}{l}<.00 \\
1.00\end{array}$ & $<0.01$ & $<0.01$ & $<0.01$ & $\begin{array}{l}1.00 \\
<0.01\end{array}$ & $\begin{array}{c}<0.01 \\
100\end{array}$ & $<0.01$ & $\begin{array}{l}0.12 \\
<012\end{array}$ & $<0.01$ & $\begin{array}{l}1.00 \\
<0.01\end{array}$ & $<0.01$ & $<0.01$ & $\begin{array}{l}1.0 .01 \\
<0.01\end{array}$ & $<0.01$ & $<0.01$ & & . & . & : \\
\hline $\mathrm{R} / \mathrm{Scol} / \mathrm{DAC}$ & $<0.01$ & L.1.00 & $<0.01$ & $<0.01$ & $<0.01$ & $<0.01$ & $\underbrace{}_{1.00}$ & $<0.01$ & $<0.01$ & $<0.01$ & $<0.01$ & s.out & $<0.01$ & $<0.01$ & $<0.01$ & $<0.01$ & & & . \\
\hline 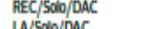 & $<0.01$ & $<0.01$ & 0.04 & $<0.01$ & $<0.01$ & $<0.01$ & $<0.01$ & 1.00 & $<0.01$ & 0.02 & & $<0.01$ & & $<0.04$ & $<0.01$ & $<0.01$ & $<0.01$ & $x$ & - \\
\hline 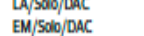 & $<0.01$ & $\begin{array}{l}<0.01 \\
<0.14\end{array}$ & $\begin{array}{r}<0.01 \\
1.00\end{array}$ & $\begin{array}{l}1.000 \\
<0.01\end{array}$ & $\begin{array}{c}<0.01 \\
1.00\end{array}$ & $\begin{array}{c}0.04 \\
<0.01\end{array}$ & $<0.011$ & $\begin{aligned}<0.01 \\
1.00\end{aligned}$ & $\begin{array}{r}1.00 \\
\langle 0.01\end{array}$ & $\begin{aligned}<0.01 \\
1.00\end{aligned}$ & $<0.01$ & $\begin{array}{c}<0.01 \\
<0.01\end{array}$ & $\begin{array}{r}<0.01 \\
1.00\end{array}$ & $\begin{array}{r}1.00 \\
<0.01\end{array}$ & $\begin{array}{r}<0.01 \\
1.00 \\
1.00\end{array}$ & $\begin{array}{l}<0.01 \\
<0.01\end{array}$ & $\begin{array}{l}<0.01 \\
<0.01\end{array}$ & $<0.012$ & $<0.01$ \\
\hline
\end{tabular}

FC

Localização das diferenças significativas

Tabela de Matriz de valores $p$ dos testes t pareados usados para determinar a localização das diferenças por ESTAGIO, ETIOLOGIA e AMBIENTE 


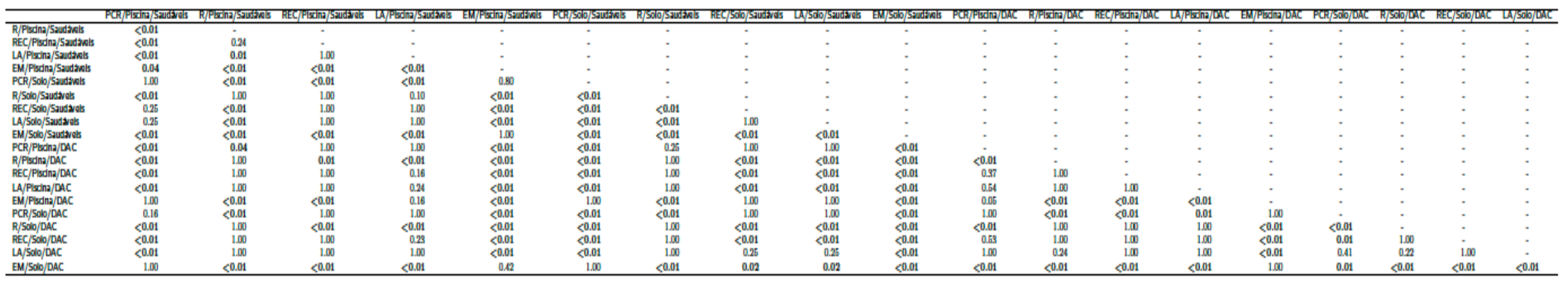

$\mathrm{VO}_{2}$

\section{Localização das diferenças significativas}

Tabela de Matriz de valores $p$ dos testes t pareados usados para determinar a localização das diferenças por ESTAGIO, ETIOLOGIA e AMBIENTE

\begin{tabular}{|c|c|c|c|c|c|c|c|c|c|c|c|c|c|c|c|c|c|c|c|}
\hline 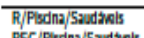 & $<0.01$ & $1 \mathrm{~m}$ & 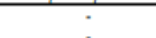 & $\cdot$ & $\cdot$ & $\cdot$ & . & . & t. & - & - & 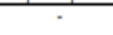 & 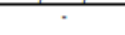 & - & • & 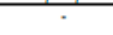 & 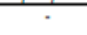 & - & \\
\hline 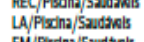 & $\begin{array}{l}50.4 \\
0.04\end{array}$ & $<0.01$ & 0.088 & & : & : & : & $:$ & : & : & : & : & : & : & : & : & : & : & : \\
\hline 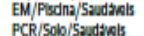 & 1.00 & $<0.01$ & $<0.01$ & $<0.01$ & in & - & - & - & - & - & - & - & - & - & - & - & - & - & - \\
\hline 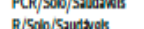 & & $\begin{aligned}<0.01 \\
100\end{aligned}$ & $\begin{array}{l}<0.01 \\
100\end{array}$ & & & & & & & & & & & & & & & & \\
\hline 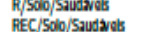 & $<001$ & $<0.01$ & 1.00 & 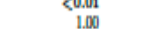 & $<0.01$ & $<0.01$ & $<01$ & $\therefore$ & $\therefore$ & $\therefore$ & $\therefore$ & $\therefore$ & $\therefore$ & : & $:$ & : & : & $\therefore$ & $\therefore$ \\
\hline 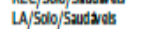 & 1.000 & $<0.01$ & $<0.01$ & 1.00 & 0.04 & 0 & & 0.08 & . & . & & . & & . & . & & & . & : \\
\hline EM/5olo/saudavos & $<0.01$ & $<0.01$ & $<0.01$ & $<0.01$ & 0.13 & $<0.01$ & $<0.01$ & $<0.01$ & $<0.01$ & . & . & . & . & . & . & . & . & . & . \\
\hline PCR/Psina/DAC & $<0.01$ & $<0.01$ & 0.38 & 1.00 & $<0.01$ & $<0.01$ & $<0.01$ & 1.00 & 0.48 & $<0.01$ & & 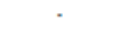 & - & 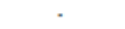 & & 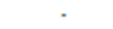 & & - & - \\
\hline 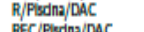 & $<0.01$ & 1.00 & 1.00 & $<0.01$ & $<0.01$ & $<0.01$ & 100 & $<0.01$ & $<0.01$ & $<0.01$ & $<0.01$ & 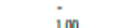 & • & 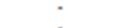 & & - & & - & - \\
\hline 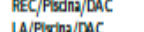 & $s 001$ & $\begin{array}{l}1.000 \\
0.52\end{array}$ & .1.00 & $<0.01$ & $<0.01$ & 80.01 & 100 & 0.013 & $<0.01$ & $<001$ & 8.014 & $\begin{array}{l}1.100 \\
0.99\end{array}$ & ieg & : & • & - & - & - & - \\
\hline 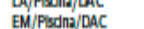 & $\begin{array}{l}<0.01 \\
100\end{array}$ & $\begin{aligned} 0.02 \\
<0.1\end{aligned}$ & $<0.01$ & $\begin{array}{l}0.98 \\
1.00\end{array}$ & $\begin{aligned}<0.02 \\
0.02\end{aligned}$ & $<_{0.06}^{0.04}$ & $<0.01$ & 0.13 & s.u. & $<0.1$ & 0.06 & $<0.01$ & $<0.01$ & $<0.01$ & & : & & $\cdot$ & : \\
\hline 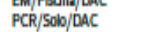 & 1.00 & $<0.01$ & $<0.01$ & $\begin{array}{l}1.00 \\
1.00\end{array}$ & $<0.01$ & 0.0 .14 & $<0.1$ & 0.61 & 1.00 & $<0.01$ & 1.000 & $<0.01$ & $<0.01$ & 0.01 & & & & & . \\
\hline R/SDilojoAC & $<0.01$ & 1.00 & 0.88 & $<0.01$ & $<0.01$ & $<0.01$ & 100 & $<0.01$ & $<0.01$ & $<0.01$ & $<0.01$ & 1.00 & 100 & 0.07 & $<0.01$ & $<0.01$ & & . & . \\
\hline REC/ $/ 500 /$ DAC & $<0.01$ & 1.00 & 1.00 & 0.30 & $<0.01$ & $<0.01$ & 0.58 & 1.00 & $<0.01$ & $<0.01$ & 0.97 & 0.42 & 1.00 & 1.000 & $<0.01$ & $<0.01$ & 0.30 & & . \\
\hline 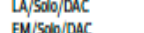 & 0.01 & $<0.01$ & 0.22 & 1.00 & $<0.01$ & $<0.01$ & $<0.01$ & $\begin{aligned} 1.00 \\
609\end{aligned}$ & 0.71 & $<0.01$ & $\begin{array}{r}1.00 \\
0.09\end{array}$ & $<0.01$ & $<0.01$ & $\begin{array}{r}1,00 \\
<001\end{array}$ & 0.096 & 1.00 & $<0.01$ & 0.08 & 0.1 \\
\hline & & & & & & & $<0.01$ & $\leq 0.01$ & 1.00 & $<0.01$ & $\zeta 0.01$ & $<0.01$ & $\langle 0.01$ & $<0.01$ & 1.50 & 1.00 & $\measuredangle 0.01$ & $<0.01$ & 0.01 \\
\hline
\end{tabular}


$\mathrm{VCO}_{2}$

\section{Localização das diferenças significativas}

Tabela de Matriz de valores $p$ dos testes $t$ pareados usados para determinar a localização das diferenças por ESTAGIO, ETIOLOGIA e AMBIENTE

\begin{tabular}{|c|c|c|c|c|c|c|c|c|c|c|c|c|c|c|c|c|c|c|c|}
\hline 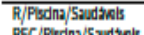 & $<0.01$ & & ${ }^{*}$ & $\cdot$ & - & - & $\cdot$ & - & - & $\cdot$ & - & $\cdot$ & $\cdot$ & - & - & $\cdot$ & $\cdot$ & $\cdot$ & ${ }^{\circ}$ \\
\hline 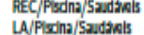 & $<0.00$ & $<0.01$ & ino & . & : & : & . & . & $:$ & $:$ & . & - & : & - & : & - & - & : & : \\
\hline 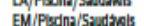 & $<01$ & $<00$ & $<001$ & $<00$ & - & $\therefore$ & $\therefore$ & & & & & & & & & & & & \\
\hline 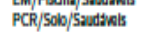 & 1.00 & $<0.01$ & $<0.01$ & $<0.01$ & 0.03 & . & . & . & . & : & . & . & : & . & . & . & . & . & : \\
\hline R/Sdo/Saudaves & $<0.01$ & 1.00 & $<0.01$ & $<0.01$ & $<0.01$ & $<0.01$ & & 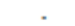 & . & 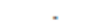 & . & 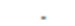 & . & . & 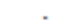 & . & . & . & . \\
\hline 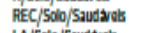 & 1.00 & $<0.01$ & 0.91 & 0.01 & $<0.01$ & 1.00 & $<0.01$ & i & - & - & . & - & & - & - & - & - & - & . \\
\hline 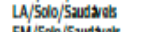 & 0.76 & $<0.01$ & 1.00 & 1.00 & $<0.01$ & 0.04 & $<0.01$ & 1.00 & & - & • & $\therefore$ & - & - & - & - & - & - & - \\
\hline 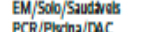 & $<0.01$ & $<0.01$ & $<0.01$ & $<0.01$ & ${ }_{60.04}^{0.04}$ & $<0.01$ & $<0.01$ & $<0.01$ & $<0.01$ & sin & : & : & $:$ & $:$ & 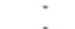 & $:$ & : & : & - \\
\hline 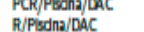 & $<0.01$ & $\stackrel{<0.01}{1.00}$ & $<0.01$ & $<0.01$ & $\begin{array}{c}<0.01 \\
<0.01\end{array}$ & $<0.01$ & $\begin{array}{c}<0.01 \\
1.00\end{array}$ & $<0.17$ & $<0.01$ & $<0.01$ & $<0.01$ & $:$ & . & . & : & : & : & $\therefore$ & : \\
\hline REC/PSOSOAz/DAC & $<0.01$ & 0.13 & 1.00 & $\begin{array}{l}3.00 \\
1.00\end{array}$ & $<0.01$ & $<0.01$ & 0.09 & $<0.1$ & 0.88 & $<0.01$ & $\begin{array}{l}<.00 \\
1.00\end{array}$ & 0.03 & : & : & : & : & : & : & : \\
\hline$L A / P \sin 3 / \not A C$ & $<0.01$ & 1.00 & 0.19 & 1.00 & $<0.01$ & $<0.01$ & 1.00 & $<0.01$ & $<0.01$ & $<0.01$ & 0.38 & 0.97 & $1 . \omega$ & & . & - & . & . & . \\
\hline EM/PFscha/PAC & 1.00 & $<0.01$ & 0.08 & $<0.01$ & $<0.01$ & 1.00 & $<0.01$ & 1.00 & 0.50 & $<0.01$ & 0.01 & $<0.01$ & $<0.01$ & $<0.01$ & & . & . & . & . \\
\hline PCR/Job//AC & 1.00 & $<0.01$ & 1.00 & & $<0.01$ & 0.14 & $<0.01$ & 1.00 & 1.00 & Suan & 1.00 & $<0.01$ & 0.12 & $<0.01$ & 1.00 & & . & . & - \\
\hline 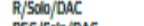 & $<0.01$ & 1.00 & $<0.01$ & $<0.01$ & $<0.01$ & $<0.01$ & 1.00 & $<0.01$ & $<0.01$ & $<0.01$ & $<0.01$ & 1.00 & 0.01 & 0.038 & $<0.01$ & $<0.01$ & & - & . \\
\hline 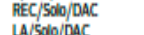 & 0.02 & $<0.01$ & 1.00 & 1.00 & $<0.01$ & $<0.01$ & $<0.01$ & 0.12 & 1.00 & $<0.01$ & 1.00 & $<0.01$ & 20 & ${ }_{10,7}^{0.78}$ & $<0.01$ & 1.00 & $\angle 0.01$ & in & : \\
\hline 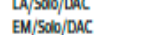 & 1.00 & $<0.01$ & $<0.01$ & $<0.01$ & 0.13 & 1.00 & $<0.01$ & 1.00 & $<0.01$ & $<0.01$ & $<0.01$ & $<0.01$ & $<0.01$ & $<0.1$ & $\begin{array}{l}80,01 \\
100\end{array}$ & 0.08 & $<0.01$ & $<0.01$ & $<0.11$ \\
\hline
\end{tabular}

$\mathrm{VO}_{2}$.FC

Localização das diferenças significativas

Tabela de Valores de $\varepsilon$ e p para a correção de Greenhouse-Geisser (GG ) e de Huynh-Feldt (HF ). As correções de esfericidade não alteraram as conclusões da analise inicial. 


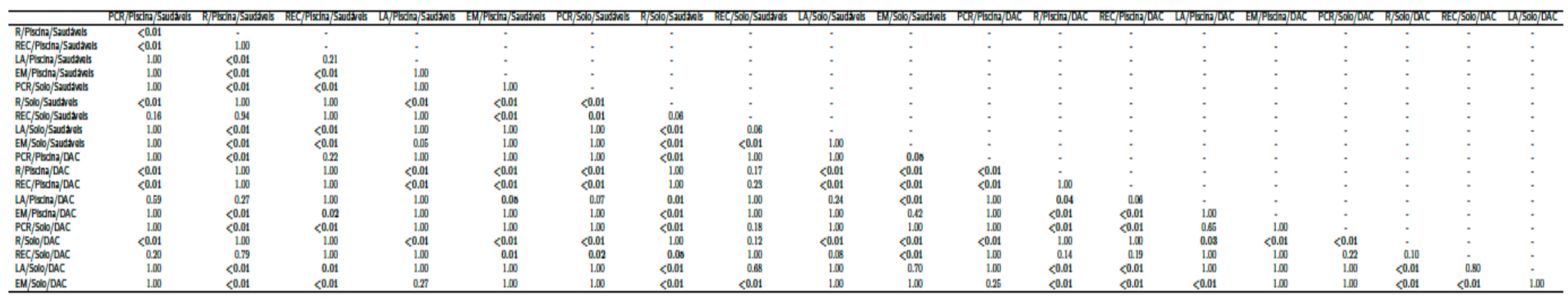

VE/ $/ \mathrm{NO}_{2}$

\section{Localização das diferenças significativas}

Tabela de Valores de $\varepsilon$ e p para a correção de Greenhouse-Geisser (GG ) e de Huynh-Feldt (HF ). As correções de esfericidade não alteraram as conclusões da analise inicial.

\begin{tabular}{|c|c|c|c|c|c|c|c|c|c|c|c|c|c|c|c|c|c|c|c|}
\hline $\mathrm{R} / \mathrm{Fs}$ sona/52adinols & 1.00 & & 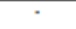 & . & & & . & r. & $\because$ & & & & & & & & & & \\
\hline 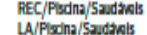 & $<0.010$ & $<0.010$ & & & & : & & & & & - & - & & & - & & - & - & - \\
\hline 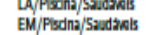 & 0.06 & 1.00 & $<0.01$ & 0.01 & : & - & : & : & : & : & $:$ & : & : & $:$ & & : & $:$ & $:$ & : \\
\hline 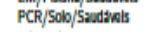 & 1.00 & 1.00 & $<0.01$ & 1.00 & 0.55 & . & 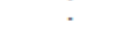 & . & . & . & . & . & . & . & & . & . & . & \\
\hline 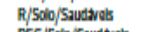 & 1.00 & 1.00 & $<0.01$ & 1.00 & 1.00 & 1.00 & & . & & - & - & - & - & & - & - & - & - & - \\
\hline 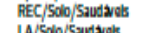 & $<0.01$ & $<0.01$ & 1.00 & $<0.01$ & $<0.01$ & $<0.01$ & $<0.01$ & & - & : & - & - & : & : & & - & - & - & - \\
\hline 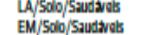 & $l_{0.20}^{1.00}$ & $\begin{array}{l}0.088 \\
1.00\end{array}$ & $\begin{array}{l}<0.01 \\
<0.01\end{array}$ & $\begin{array}{l}1.000 \\
<0.01\end{array}$ & $\begin{array}{c}<0.01 \\
1.00\end{array}$ & $\begin{array}{l}1.00 \\
0.17\end{array}$ & $\begin{array}{l}0.58 \\
1.00\end{array}$ & $\begin{array}{c}<0.01 \\
0.02\end{array}$ & $<0$ & $:$ & $:$ & $:$ & : & : & & : & $:$ & : & : \\
\hline 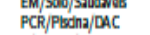 & $\begin{array}{l}.027 \\
1.00\end{array}$ & 1.00 & $<0.01$ & $\begin{array}{r}80.01 \\
1.00 \\
2\end{array}$ & ${ }_{1.00}^{1.0}$ & $\begin{array}{l}0.17 \\
1.00\end{array}$ & 1.00 & $<0.01$ & $\sum_{1 . \infty}^{0.01}$ & 1.00 & : & : & : & : & : & : & : & : & : \\
\hline $\mathrm{R} / \mathrm{Pscm} / \mathrm{DaC}$ & 1.00 & 1.00 & $<0.01$ & 0.00 & 1.00 & 1.0 & 100 & $<0.1$ & 0.27 & 1.00 & 1.00 & - & . & . & . & . & . & . & . \\
\hline REC/PBSDin/DAC & $<0.01$ & $<0.01$ & 1.00 & $<0.01$ & $<0.01$ & $<0.01$ & $<0.01$ & 1.00 & $<0.01$ & $<0.01$ & $<0.11$ & $<0.01$ & & - & & - & - & - & - \\
\hline 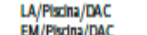 & 1.00 & 1.00 & $<0.01$ & 1.00 & 0.14 & 1.00 & 100 & $<0.01$ & 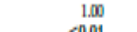 & 0.04 & 1.00 & 1.00 & $<0.01$ & 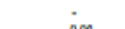 & $\cdot$ & & - & • & - \\
\hline 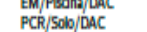 & $\begin{array}{l}0.34 \\
100\end{array}$ & $\begin{array}{l}1.100 \\
1.00\end{array}$ & $\begin{array}{l}<0.01 \\
<0.01\end{array}$ & $\begin{array}{r}<0.01 \\
1.00\end{array}$ & ${ }_{1.00}^{1.00}$ & 0.10 & 1000 & $<0.01$ & $\begin{array}{l}<0.01 \\
100\end{array}$ & $\begin{array}{l}1.00 \\
0.58\end{array}$ & 100 & 1.000 & $<0.01$ & 100 & & & : & $:$ & : \\
\hline 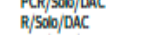 & 1.00 & $\int_{1.00}^{1.00}$ & $\begin{array}{l}<0.01 \\
<0.01\end{array}$ & 1.000 & ${ }_{1.00}^{1.00}$ & ${ }_{1.00}^{1.0}$ & 100 & $<001$ & $\int_{0,7}^{2.0}$ & $\frac{0.08}{100}$ & 100 & 1000 & $<0.1$ & 100 & 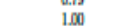 & ino & * & : & - \\
\hline 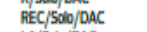 & $<0.01$ & $<0.01$ & 1.00 & $<0.01$ & 0.02 & $<0.01$ & $<0.01$ & 1.00 & $<0.01$ & 0.05 & $<0.01$ & $<0.01$ & 1.0 & $<0.01$ & 0.00 & $<0.01$ & $<0.01$ & & : \\
\hline La/SBdo/DACC & 1.00 & 1.00 & $<0.01$ & 1.00 & 0.05 & 1.00 & 1.00 & $<0.01$ & 1.00 & 0.01 & 1.00 & 1.00 & $<0.01$ & 1.00 & 0.02 & 1.00 & 1.00 & $<0.01$ & \\
\hline & & & & & & & & & & & & & & & & & & & \\
\hline
\end{tabular}




\section{$\mathrm{VE} / \mathrm{VCO}_{2}$}

\section{Localizacao das diferencas signicativas}

Tabela de Valores de $\varepsilon$ e p para a correção de Greenhouse-Geisser (GG ) e de Huynh-Feldt (HF ). As correções de esfericidade não alteraram as conclusões da analise inicial

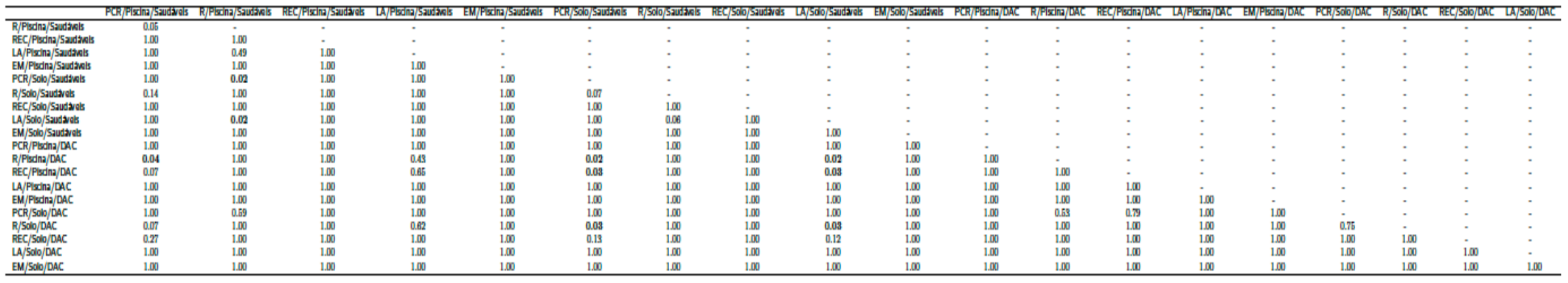

\section{VC02.V02}

\section{Localização das diferenças significativas}

Tabela de Valores de $\varepsilon$ e p para a correção de Greenhouse-Geisser (GG ) e de Huynh-Feldt (HF ). As correções de esfericidade não alteraram as conclusões da analise inicial. 


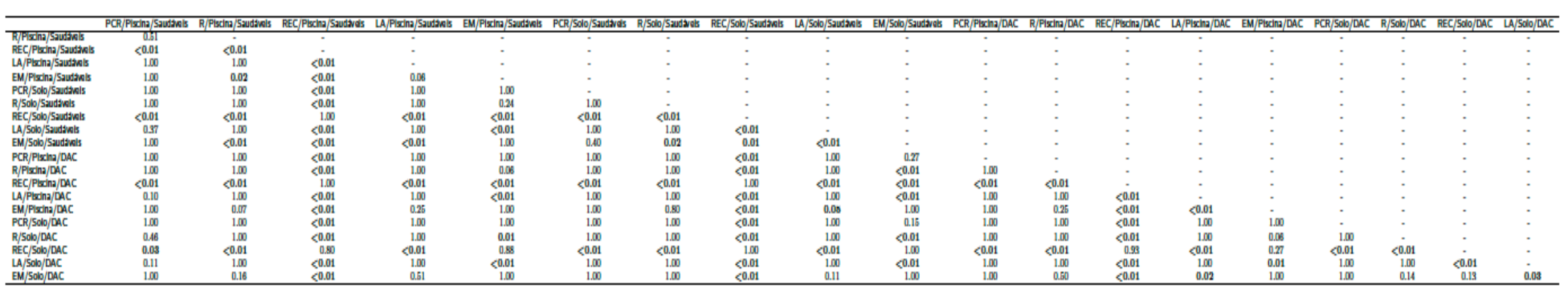




\section{REFERÊNCIAS*}

1. Becker BE, Cole AJ. Terapia Aquática Moderna 2000, $1^{\text {a }}$ ed. Brasileira.

2. Schmid JP, Noveanu M, Morger C, Gaillet R, Capoferri M, Anderegg M, Saner $\mathrm{H}$. Influence of water immersion, water gymnastics and swimming on cardiac output in patients with heart failure. Heart 2007; 93: 722-727.

3. DeLisa. Physical Medicine and Rehabilitation 2005, $4^{\text {th }}$ ed. Aquatic Rehabilitation: 479-492.

4. Arborelius M Jr, Ballidin UI, Lilja B, Lundgren CEG. Hemodynamic changes in man during immersion with the head above water. Aerosp Med 1972; 43: $592-598$.

5. Risch WD, Koubenec HJ, Beckmann U, Lange S, Gauer OH. The effect of graded immersion on heart volume, central venous pressure, pulmonary blood distribution, and heart rate in man. Pflügers Arch 1978; 374: 115-118.

6. Lange L, Lange S, Echt $\mathrm{M}$, Gauer $\mathrm{OH}$. Heart volume in relation to body posture and immersion in a thermo-neutral bath: a roentgenometric study. Pflügers Arch 1974; 352: 219-226.

7. Weston CF, O'Hare JP, Evans JM, Corrall RJ. Haemodynamic changes in man during immersion in water at different temperatures. Clin Sci (Lond) 1987; 73(6):613-6.

\footnotetext{
* De acordo com:

Adaptado de International Committee of Medical Journals Editors (Vancouver).

Universidade de São Paulo. Faculdade de Medicina. Serviço de Biblioteca e Documentação. Guia de

apresentação de dissertações, teses e monografias da FMUSP. Elaborado por Anneliese Carneiro da Cunha,

Maria Julia A.L. Freddi, Maria F. Crestana, Marinalva de S. Aragão, Suely C. Cardoso, Valéria Vilhena. 3a ed.

São Paulo: Divisão de Biblioteca e Documentação; 2011.

Abreviaturas dos títulos dos periódicos de acordo com List of Journals Indexed in Index Medicus.
} 
8. Gianuzzi P, Tavazzi L, Meyer K, Perk J, Drexler H, Dubach P, Myers J, Opasich C, Meyers J. Recommendations for exercise training in chronic heart failure patients. Eur Heart J 2001; 22: 125-135.

9. Meyer K. Exercise training in heart failure: recommendations based on current research. Med Sci Sports Exerc 2001; 33; no4: 525-531.

10.Yazbek P Jr, Sabbag LMS, Bocchi E, Guimarães GV, Cardoso CV, Ferraz AS, Battistella LR. Insuficiência cardíaca: importância da atividade física. Rev Soc Cardiol Estado de São Paulo 2005; 2: 143-151.

11.Coruzzi P, Novarini A, Biggi A, Lazzeroni E, Musiari L, Ravanetti C, Tagliavini S, Borghetti A. Low-pressure receptor activity and exaggerated natriuresis in essential hypertension. Nephron 1985; 40: 309-315.

12.Epstein M. Renal effects of head-out water immersion in humans: a 15-year update. Physiol Rev 1992; 72:563-621.

13.Gabrielsen A, Johansen LB, Norsk P. Central cardiovascular pressures during graded water immersion in humans. J Appl Physiol 1993; 75:581-585.

14.Norsk P, Ellegaard P, Videbaek R, Stadeager C, Jessen F, Johansen LB, Kristensen MS, Kamegai M, Warberg J, Christensen NJ. Arterial pulse pressure and vasopressin release in humans during lower body negative pressure. Am J Physiol 1993;264:R1024-1030.

15.Gleim GW, Nicholas JA. Metabolic costs and heart rate responses to treadmill walking in water at different depths and temperatures. Am J Sports Med 1989; 17: 248-252. 
16.Guimarães J.I, Normatização de Técnicas e Equipamentos para Realização de Exames em Ergometria e Ergoespirometria. Arquivo Brasileiro de Cardiologia 2003; 80: 458-64.

17.Costa CAC, Ferraz AS. I Consenso Nacional de Reabilitação Cardiovascular. Revista do arquivo Brasileiro de Cardiologia 1997;V. 69: Nr4.

18.Barretto ACP, Albanese FM. Teste esforço e Insuficiência Cardíaca in Insuficiência Cardíaca. Santo André: ABC Artes Gráficas, 1996.

19.Alfieri RG. I Consenso Nacional de Reabilitação Cardiovascular. Revista do arquivo Brasileiro de Cardiologia V. 69 Nr 4 - Out. 1997.

20. Bittencourt M, Oliveira ALV, Gowdak LHW. Capítulo 11: Doença arterial coronária crônica: diagnóstico, classificação e estratificação de risco. In: José Carlos Nicolau, Flávio Tarasoutchi, Leonardo Vieira da Rosa. (Org.). Condutas práticas em Cardiologia. 1 ed. Barueri: Manole, 2009, v. 1, p. 9397.

21.Barretto ACP. Insuficiência Cardíaca no Terceiro Milênio. São Paulo: Lemos Editorial, 2000.

22. Claussell N. Fisiopatologia da Insuficiência Cardíaca In Barretto ACP, Bocchi EA. Insuficiência Cardíaca. São Paulo: Editora Segmento, 2003.

23.Barretto ACP, Bocchi EA. Insuficiência Cardíaca. São Paulo: Editora Segmento, 2003.

24.Ho KKL, Pinsk JL, Kannel WB et al. Part II: New insights into the epidemiology and pathophisiology of heart failure. The Framingham Study. J Am Coll Cardiol 1993; 22 (suppl A): 6 A- 13 A. 
25. Andrade JP, Mattos LAP, Carvalho AC, Machado CA, Oliveira GMM. Programa nacional de qualificação de médicos na prevenção e atenção integral às doenças cardiovasculares. Arquivos Brasileiros de Cardiologia volume 100 numero 3. São Paulo Março 2013.

26. Barreto ACP, Nobre MRC, Wajngarten M, Canesin MF, Azul JBS, Insuficiência Cardíaca em Grande Hospital Terciário de São Paulo. Arquivo Brasileiro de Cardiologia, volume 71 ( $n^{\circ}$ 1), 15-20, 1998.

27.Albanesi Filho, FM. O que vem ocorrendo com a insuficiência cardíaca no Brasil? Arq Bras Cardiol 2005;85:155-6.

28. Alfieri, RG et al. Prognostic significance of silent myocardial ischemia after a first uncomplicated myocardial infarction. International Journal of Cardiology Volume 38, Issue 1, January 1993, Pages 41-47.

29. Yazbek P, Sabbag LMF, Bocchi E, Guimaraes GV, Cardoso CV, Ferraz AS, Battistella LR. Insuficiência cardíaca: importância da atividade física. 2003; 2:143-151.

30.Leite JJ, Mansur AJ, Freitas HFG, Chizzola PR, Bocchi EA, Terra-Filho M, et al. Periodic breathing during incremental exercise predicts mortality in patients with chronic heart failure evaluated for cardiac transplantation. J Am Coll Cardiol 2003;41:2175-81.

31. Yazbek Jr. Ergoespirometria metodologia e interpretação. Arquivo Brasileiro de Cardiologia 1998; 71 (5): 719-723.

32. Weber K, Janicki JS - Cardiopulmonary exercise testing for evaluation of chronic heart failure. Am J. Cardiol. 1985; 55: 22A$31 \mathrm{~A}$. 
33. Cole AJ, Morris DM, Ruoti RG. Aquatic Rehabilitation. Nova lorque, EUA: Lippincott, 1997.

34.Skinner AT, Thomson AM. Exercícios na água._São Paulo: Manole, 1983.

35.Campion MR. Hidroterapia: Princípios e Prática. São Paulo: Manole, 2000.

36. Candeloro JM, Caromano FA. Graduação da resistência ao movimento durante imersão na água. Fisioterapia Brasil 2004; 5; 73-76.

37.Froude W, Abell, Sir W, Gawn, RWL, Duckworth, AD. Institution of Naval Architects. The Papers of William Froude, 1810-1879: With a Memoir by Sir Westcott Abell and an Evaluation of William Froude's Work by R.W.L. Gawn: Collected Into One Volume. Institution of Naval Architects, 1955.

38.Zahm (1862-1945) In: Campion MR. Hidroterapia: Princípios e Prática. São Paulo: Manole, 2000.

39.Craig $A B \mathrm{Jr}$, Dvorak M. Thermal regulation of man exercising during water immersion. J Appl Physiol 1968;25(1):28-35.

40.Agostini E. Respiratory mechanics during submersion and negative-pressure breathing. J Appl Physiol 1966; 21:251-258

41.Hong SK, Cerretelli P, Cruz JC, Rahn H. Mechanics of respiration during submersion in water. J Appl Physiol 1969;27(4):535-538.

42.Taylor NA, Morrison JB. Static and dynamic pulmonary compliance during upright immersion. Acta Physiol Scand. 1993;149(4):413-7.

43. Gabrielsen A, Bie P, Holstein-Rathlou NH, Christensen NJ, Warberg J, DigePetersen H, Frandsen E, Galatius S, Pump B, Sorensen VB, Kastrup J, Norsk P. Neuroendocrine and renal effects of intravascular volume 
expansion in compensated heart failure. Am J Physiol Regul Integr Comp Physiol 2001;281(2):R459-67.

44.Grossman E, Goldstein DS, Hoffman A, Wacks IR, Epstein M. Effects of water immersion on sympathoadrenal and dopa-dopamine systems in humans. Am J Physiol 1992;262(6 Pt 2):R993-999.

45.Krishna GG, Danovitch GM. Renal response to central volume expansion in humans is attenuated at night. Am J Physiol 1983;244(4):R481-486.

46. Harrison RA, Bulstrode S. Loading of the lower limb when walking partially immersed. Physiotherapy 1992; 78:165.

47.Freitas, GC. A Cura Pela Água: Hidrocinesioterapia - Teoria e Prática. Rio de Janeiro: Rio, 2005.

48.Frangolias DD, Rhodes EC. Maximal and ventilatory threshold responses treadmill and water immersion running. Med Sci Sports Exerc 1995;27(7):1007-13.

49.Sullivan MJ, Higginbotham MB, Cobb FR. Exercise training in patients with severe left ventricular dysfunction. Hemodynamic and metabolic effects. Circulation 1988;78(3):506-15.

50.Coats AJ, Adamopoulos S, Radaelli A, McCance A, Meyer TE, Bernardi L, Solda PL, Davey P, Ormerod O, Forfar C, et al. Controlled trial of physical training in chronic heart failure. Exercise performance, hemodynamics, ventilation, and autonomic function. Circulation 1992;85(6):2119-31.

51.Belardinelli R, Georgiou D, Cianci G, Purcaro A. Randomized, controlled trial of long-term moderate exercise training in chronic heart failure: effects on 
functional capacity, quality of life, and clinical outcome. Circulation. 1999;99(9):1173-82.

52.Piepoli MF, Davos C, Francis DP, Coats AJ; ExTraMATCH Collaborative. Exercise training meta-analysis of trials in patients with chronic heart failure (ExTraMATCH). BMJ 2004;328(7433):189.

53.Wilson JR, Martin JL, Schwartz D, Ferraro N. Exercise intolerance in patients with chronic heart failure: role of impaired nutritive flow to skeletal muscle. Circulation 1984;69(6):1079-87.

54.Mancini DM, Walter G, Reichek N, Lenkinski R, McCully KK, Mullen JL, Wilson JR. Contribution of skeletal muscle atrophy to exercise intolerance and altered muscle metabolism in heart failure. Circulation 1992;85(4):136473.

55.Wilson JR, Mancini DM. Factors contributing to the exercise limitation of heart failure. J Am Coll Cardiol 1993;22(4 Suppl A):93A-98A.

56.Wilson JR, Mancini DM, Dunkman WB. Exertional fatigue due to skeletal muscle dysfunction in patients with heart failure. Circulation 1993;87(2):4705.

57.Hulsmann M, Quittan M, Berger R, Crevenna R, Springer C, Nuhr M, Mrtl D, Moser P, Pacher R. Muscle strength as a predictor of long-term survival in severe congestive heart failure. Eur J Heart Fail 2004;6(1):101-7.

58.Pina IL, Apstein CS, Balady GJ, Belardinelli R, Chaitman BR, Duscha BD, Fletcher BJ, Fleg JL, Myers JN, Sullivan MJ. Exercise and heart failure: A statement from the American Heart Association Committee on exercise, rehabilitation, and prevention. Circulation 2003;107(8):1210-25. 
59.Yazbek P, Battistella LR, Wajngarten M, Barreto ACP. Aplicação do exercício físico em portadores de insuficiência cardíaca congestiva. Revista da Sociedade de Cardiologia do Estado de SP 1996; Vol 6: $\mathrm{N}^{\circ} 1$.

60.Municinó A, Nicolino A, Milanese M, Gronda E, Andreuzzi B, Oliva F, Chiarella F. Hydrotherapy in advanced heart failure: the cardio-HKT pilot study. Monaldi Arch Chest Dis 2006;66(4):247-54.

61.Jondeau G, Katz SD, Toussaint JF, Dubourg O, Monrad ES, Bourdarias JP, LeJemtel TH. Regional specificity of peak hyperemic response in patients with congestive heart failure: correlation with peak aerobic capacity. J Am Coll Cardiol 1993;22(5):1399-402.

62.Cider A, Sveälv BG, Täng MS, Schaufelberger M, Andersson B. Immersion in water induces improvement in cardiac function in patients with chronic heart failure. Eur J Heart Failure 2006; 8: 308-313.

63.Cider A, Schaufelberger M, Sunnerhagen KS, Andersson B. Hydrotherapy-a new approach to improve function in the older patient with chronic heart failure. Eur J Heart Failure 2003; 5: 527-535.

64.Petersen AM, Pedersen BK. The anti-inflammatory effect of exercise. J Appl Physiol 2005;98(4):1154-62.

65.Hunt SA, Abraham WT, Chin MH, Feldman AM, Francis GS, Ganiats TG, Jessup M, Konstam MA, Mancini DM, Michl K, Oates JA, Rahko PS, Silver MA, Stevenson LW, Yancy CW, Antman EM, Smith SC Jr, Adams CD, Anderson JL, Faxon DP, Fuster V, Halperin JL, Hiratzka LF, Jacobs AK, Nishimura R, Ornato JP, Page RL, Riegel B. ACC/AHA 2005 Guideline Update for the Diagnosis and Management of Chronic Heart Failure in the 
Adult: a report of the American College of Cardiology/American Heart Association Task Force on Practice Guidelines. Circulation 2005;112(12):e154-235.

66.Briffa TG, Maiorana A, Sheerin NJ, Stubbs AG, Oldenburg BF, Sammel NL, Allan RM. Physical activity for people with cardiovascular disease: recommendations of the National Heart Foundation of Australia. Med J Aust $2006 ; 184(2): 71-5$.

67.Joshi SB. Exercise training in the management of cardiac failure and ischaemic heart disease. Heart Lung Circulation 2007, doi: 10.1016/j.hlc.2007.03.013.

68.DeLisa. Physical Medicine and Rehabilitation 2005, $4^{\text {th }}$ ed. Cardiac Rehabilitation: 1811-1841.

69.Sheldahl LM, Tristani FE, Clifford PS, Hughes CV, Sobocinski KA, Morris RD. Effect of head-out water immersion on cardiorespiratory response to dynamic exercise. J Am Coll Cardiol 1987;10(6):1254-8.

70.Christie JL, Sheldahl LM, Tristani FE, Wann LS, Sagar KB, Levandoski SG, Ptacin MJ, Sobocinski KA, Morris RD. Cardiovascular regulation during head-out water immersion exercise. J Appl Physiol 1990;69(2):657-64.

71. Hanna RD, Sheldahl LM, Tristani FE. Effect of enhanced preload with headout water immersion on exercise response in men with healed myocardial infarction. Am J Cardiol 1993;71(12):1041-4.

72.Gabrielsen A, Sorensen VB, Pump B, Galatius S, Videbaek R, Bie P, Warberg J, Christensen NJ, Wroblewski H, Kastrup J, Norsk P. Cardiovascular and neuroendocrine responses to water immersion in 
compensated heart failure. Am $J$ Physiol Heart Circ Physiol 2000;279(4):H1931-40.

73.Cider A, Sunnerhagen KS, Schaufelberger M, Andersson B. Cardiorespiratory effects of warm water immersion in elderly patients with chronic heart failure. Clin Physiol Funct Imaging 2005;25(6):313-7.

74.Allison TG, Reger WE. Comparison of responses of men to immersion in circulating water at 40.0 and 41.5 degrees C. Aviat Space Environ Med 1998;69(9):845-50.

75.Shimizu T, Kosaka M, Fujishima K. Human thermoregulatory responses during prolonged walking in water at 25, 30 and 35 degrees C. Eur J Appl Physiol Occup Physiol 1998;78(6):473-8.

76.Park KS, Choi JK, Park YS. Cardiovascular regulation during water immersion. Appl Human Sci 1999;18(6):233-41.

77.Srámek P, Simecková M, Janský L, Savlíková J, Vybíral S. Human physiological responses to immersion into water of different temperatures. Eur J Appl Physiol 2000; 81: 436-442.

78.Meyer K, Bucking J. Exercise in heart failure: should aqua therapy and swimming be allowed? Med Sci Sports Exerc 2004;36(12):2017-23.

79.Wilder RP, Brennan DK. Physiological responses to deep water running in athletes. Sports Med 1993;16(6):374-80.

80.Biro S, Masuda A, Kihara T, Tei C. Clinical implications of thermal therapy in lifestyle-related diseases. Exp Biol Med 2003; 228(10):1245-249.

81.Lund KL, Mahon RT, Tanen DA, Bakhda S. Swimming-induced pulmonary edema. Ann Emerg Med 2003;41(2):251-6. 
82.Adir Y, Shupak A, Gil A, Peled N, Keynan Y, Domachevsky L, Weiler-Ravell D. Swimming-induced pulmonary edema: clinical presentation and serial lung function. Chest 2004;126(2):394-9.

83. Yoder JA, Viera AJ. Management of swimming-induced pulmonary edema. Am Fam Physician 2004;69(5):1046, 1048-9.

84.Pons M, Blickenstorfer D, Oechslin E, Hold G, Greminger P, Franzeck UK, Russi EW. Pulmonary oedema in healthy persons during scuba-diving and swimming. Eur Respir J 1995;8(5):762-7.

85.Biswas R, Shibu PK, James CM. Pulmonary oedema precipitated by cold water swimming. Br J Sports Med 2004;38(6):e36.

86. Bruce RA, Pearson R, Lovejoy Jr. FW, Yu PNG, Brothers GB. Variability of respiratory and circulatory performance during standardized exercise. J Clin Invest. 1949;28(6, Pt. 2):1431-8.

87.Asa C, Sunnerhagen KS, Schaufekberger M, Anderson B. Cardiorespiratory effects of warm water immersion in elderly patients with chronic heart failure. Clin Physiol Funct Imaging. 2005; 25: 313-317.

88.Balady GJ, Arena R, Sietsema K, Myers J, Coke L, Fletcher GF, et al. Clinician's Guide to cardiopulmonary exercise testing in adults: a scientific statement from the American Heart Association. Circulation. 2010;122(2):191-225.

89.Becker BE, Cole AJ. Aquatic rehabilitation. In: DeLisa JA (eds). Physical Medicine and rehabilitation: principles and practice. $4^{\text {th }}$ ed. Philadelphia: Lippincott; 2005. p. 479-92. 
90.Craig A, Dvorak M. Comparison of exercise in air and in water of different temperatures. Med Sci Sports (1969); 1: 124-130.

91.Hall J, Macdonald IA, MaddisonPJ, O’Hare JP. Cardiorespiratory responses to underwater treadmill walking in healthy females. J ApplPhysiol 1998; 77 : 278-284.

92.Craig $A B$ Jr, Ware DE. Effect of immersion in water on vital capacity and residual volume of the lungs. J Appl Physiol. 1967;23(4):423-5.

93. Hall J, Bisson D, O'Hare P. The physiology of immersion. Physiotherapy (1990); 76: 517-521. 


\section{APÊNDICES}

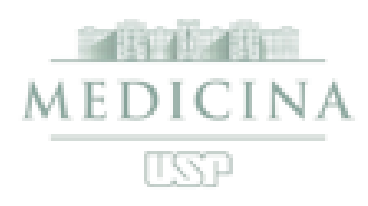

\section{ESTUDO COMPARATIVO DAS RESPOSTAS ERGOESPIROMÉTRICAS EM ESTEIRA DE SOLO VERSUS SUBAQUÁTICA}

Prezados Senhores (as).

Estamos convidando o senhor(a) a participar de um estudo que está sendo realizado no Instituto de Medicina Fisica e Reabiiltaçẳo do Hospital das Clinicas FMUSP. Sendo eleito, você fará um teste de esforço cardiopulmonar em uma esteira no solo e depois, o mesmo teste, na esteira subaquática. 0 exame é rico em detalhes e determina, de maneira individualizada, sua capacidade cardiorrespiratória, frequência cardiaca, equillbrio respiratório e carga de trabalho.

Este conhecimento poderá contribuir sobremaneira no entendimento da fisiologia da imersăo e suas possibilidades em programas de reabilitação cardiovascular. Serăo considerados eleitos homens com idade entre 50 a 75 anos com e sem diagnostico de cardiopatia. Garantimos atendimento gratuito e avaliaçāo sob condiçōes controladas e supervisāo médica especializada.

\section{Faça sua inscrição pelos e-mails ou telefones abaixo}

Local Instituto de Medicina Fisica e Reabilitaçăo

Periodo: de 1 de Fevereiro a 31 de Março de 2012

End.: Rua Domingo de Soto 100 - Vila Mariana - SP (Travessa da Rua Vergueiro - próximo da estaçăo

Chácara Klabin do Metro)

Fone: (11) 5549-0111- ramal 266 - Mauricio ou Fabiola

e-mail: mauriciokq@usp.br

Agradecemos sua participação

Mauricio Koprowski Garcia

Pesquisador responsável 


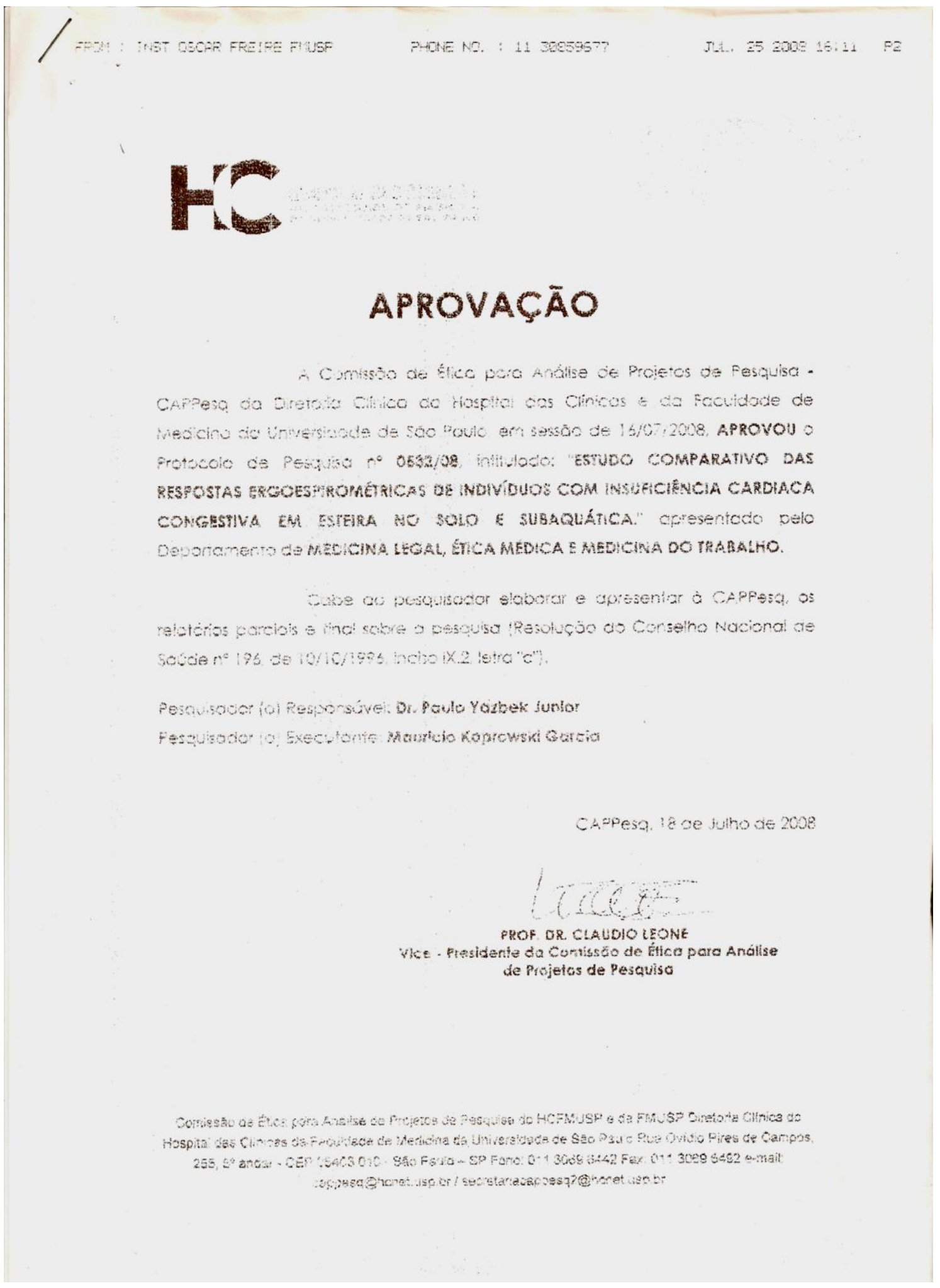




\title{
ClinicalTrials.gov Protocol Registration System
}

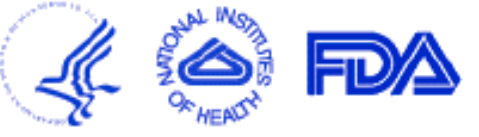

\author{
Protocol Registration Receipt \\ $10 / 02 / 2009$
}

\section{Comparative Study of the Ergospirometry Responses in Patients With Congestive Heart Failure in a Treadmill (CHF)}

This study is currently recruiting participants.

Verified by University of Sao Paulo General Hospital, October 2009

\begin{tabular}{|r|l|}
\hline Sponsored by: & $\begin{array}{l}\text { University of Sao Paulo General Hospital } \\
\text { Instituto Dante Pazzanese de Cardiologia }\end{array}$ \\
\hline Information provided by: & University of Sao Paulo General Hospital \\
\hline ClinicalTrials.gov Identifier: & NCT00989248 \\
\hline
\end{tabular}

\section{Purpose}

Researchers point important alterations in the cardio, respiratory, and circulatory system in individuals when submitted to immersion in heated water $\left(34^{\circ} \mathrm{C}\right)$. This study aimed at comparing the ergospirometric answers for a group of patients with Congestive Heart Failure, age 55 to 75 years, when submitted to an effort in land and underwater on a treadmill at one depth, water on the breast level - nipples.

\begin{tabular}{|l|l|l|}
\hline Condition & Intervention & Phase \\
\hline Congestive Heart Failure & $\begin{array}{l}\text { Aerobic and anaerobic capacity use } \\
\text { aquatic exercises }\end{array}$ & Phase 1 \\
\hline
\end{tabular}

Study Type: Interventional

Study Design: Treatment, Single Group Assignment, Open Label, N/A, Active Control, Safety Study Official Title: Comparative Study of the Ergospirometry Responses in Patients With Congestive Heart Failure in a Treadmill on Land and Underwater

Further study details as provided by University of Sao Paulo General Hospital:

Primary Outcome Measure:

- The following variables will be compare: VO2 max, VO2/FC, VE, AP max, difference of time among

$$
\text { - Page } 1 \text { of } 3 \text { - }
$$


compensation point and anaerobic threshold, VE/VO2 and VENCO2 obtained in land versus in water at breast levels. [Time Frame: one year] [Designated as safety issue: Yes]

Secondary Outcome Measures:

- The treatment program can improves quality of life, rate response to exercise in patients with Congestive Heart Failure (CHF). The authors expect a beneficial adaptive response to the exercise in water comparing exercise on land. [Time Frame: one year] [Designated as safety issue: Yes]

Estimated Enrollment: 90

Study Start Date: September 2009

Estimated Study Completion Date: July 2011

Estimated Primary Completion Date: July 2010

\begin{tabular}{|l|l|}
\hline Arms & Assigned Interventions \\
\hline $\begin{array}{l}\text { Experimental: comparation VENO2 and } \\
\text { VENCO2 }\end{array}$ & $\begin{array}{r}\text { Aerobic and anaerobic capacity use aquatic exercises } \\
\text { Improve aerobic capacity use aquatic exercises in } \\
\text { patients with Congestive Heart Failure }\end{array}$ \\
\hline
\end{tabular}

In the human body immersed, the water exerts a pressure on the surface; consequently there is a blood volume shift from the periphery to the central circulation, resulting in marked volume loading of the thorax and heart. Exercise in warm water, as a rehabilitation program has been considered potentially dangerous in patients with heart failure due to the increased venous return caused by the hydrostatic pressure. However, exercise in water has advantages compared to conventional training if the water temperature is controlled, specific reference to exercise capacity, muscle function, quality of life and safety.

This study is about to compare the responses of one effort in two different environment. A group of 90 men, age between 55 to 75 years old recruited after a medical consultation, with the diagnostic of Congestive Heart Failure (CHF), under treatment at the Institute of Medicine and Rehabilitation and Institute Dante Pazzanesi, and considered clinically stable (no cardiac symptoms or changes in medication for at least 30 days).

Experimental Design: Patients will perform an Ergospirometry test first in a treadmill on land and than in the water. The following variables will be comparing: VO2 max, VO2/FC, VE, AP max, difference of time among compensation point and anaerobic threshold, VEVO2 and VENCO2 obtained in land versus swimming pool at breast levels. A group of 45 patients will be submitted to a aquatic exercises (3) tree times a week (30 minutes) during six month, another group will be training at the same frequency and time on thought land exercises.

Before and after the intervention, patients will perform pulmonary function test and cardiopulmonary exercise testing. The exercises will be control by the sub-maximal heart rates.

\section{Eligibility}

Ages Eligible for Study: 55 Years to 75 Years

Genders Eligible for Study: Male

Inclusion Criteria: 55 - 75 year old with the diagnostic of Congestive Heart Failure (CHF)

\footnotetext{
- Page 2 of 3 -
} 
Exclusion Criteria:Criteria of the New York Heart Association (NYHA), functional class I - without limitations and II - discreet limitation to the physical activity

\section{Contacts and Locations}

\section{Contacts}

Mauricio K Garcia, Phd

$55119903-7185$

mauriciokg@usp.br

Fabiola Jomar, MSc

Locations

Brazil, Sao Paulo

Clinical Hospital, School of Medicine, University of Sao Paulo Recruiting Sao Paulo, Sao Paulo, Brazil, 04116-040

Contact: Eduardo Massad, Doctor 551130617097 edmassad@usp.br

Contact: Fabiola Jomar, MSc 551155490111 Ext. 266 fabjomar@uol.com.br

Principal Investigator: Mauricio K Garcia, MSc

Investigators

Study Chair: $\quad$ Mauricio K Garcia, PhD

Shool of Medicine, University of São Paulo

\section{More Information}

Responsible Party: Instituto de Medicina Física e Reabilitação - HC - FMUSP (Mauricio Koprowski Garcia)

Study ID Numbers: CAPESq 0532/08

Health Authority: Brazil: National Committee of Ethics in Research 


\section{Hospital das ClíNICAS}

da Faculdade de Medicina da Universidade de São PaUlo

CAIXA Postal, 8091 - SÃo PaUlo - BRAsil

\section{TERMO DE CONSENTIMENTO LIVRE E ESCLARECIDO}

I - DADOS DE IDENTIFICAÇÃO DO SUJEITO DA PESQUISA OU RESPONSÁVEL LEGAL

1. NOME DO PACIENTE :

DOCUMENTO DE IDENTIDADE N ${ }^{\circ}$ : SEXO : .MŽ F Ž

DATA NASCIMENTO:

l..............

ENDEREÇO

APTO:

BAIRRO:

TELEFONE: DDD

CEP:

2.RESPONSÁVEL LEGAL

NATUREZA (grau de parentesco, tutor, curador etc.)

DOCUMENTO DE IDENTIDADE :

SEXO: M Ž FŽ

DATA NASCIMENTO.: ....................

ENDEREÇO:

BAIRRO:

CEP: $\mathrm{N}^{\circ}$

CIDADE

APTO:

TELEFONE: DDD ..).

II - DADOS SOBRE A PESQUISA CIENTÍFICA

2. TÍTULO DO PROTOCOLO DE PESQUISA

Estudo comparativo das respostas ergoespirométricas em esteira no solo versus subaquática.

PESQUISADOR: Mauricio Koprowski Garcia

CARGO/FUNÇÃO: Supervisor de Equipe Técnica. INSCRIÇÃO CONSELHO REGIONAL N 3275 SP.

UNIDADE DO HCFMUSP: Divisão de Medicina de Reabilitação HCFMUSP.

3. AVALIAÇÃO DO RISCO DA PESQUISA:

(probabilidade de que o indivíduo sofra algum dano como consequência imediata ou tardia do estudo)

4.DURAÇÃO DA PESQUISA : Dois anos após aprovação na Comissão de Ética.

III - REGISTRO DAS EXPLICAÇÕES DO PESQUISADOR AO PACIENTE OU SEU REPRESENTANTE LEGAL SOBRE A PESQUISA CONSIGNANDO:

INTRODUÇÃO

Você foi convidado (a) a participar voluntariamente de um estudo de pesquisa clínica. Este formulário de consentimento explicará a finalidade e detalhes deste estudo. Explicará também as suas responsabilidades e seus direitos como participante do 
estudo.

Você foi informado pelo seu médico que realizará um teste chamado ergoespirométrico realizado em uma esteira no solo e outros dois testes realizados em piscina aquecida numa esterira que ficará dentro da água.

\section{FINALIDADE DO ESTUDO}

Você recebeu uma proposta para participar de uma pesquisa para comparar o teste ergoespirométrico realizado em solo com o realizado em piscina aquecida a fim de se verificar quais as diferenças poderão ser observadas sobre o corpo levando-se em consideração os efeitos fisiológicos da imersão em água e sobretudo em água aquecida a $34^{\circ} \mathrm{C}$.

\section{PROCEDIMENTOS}

Você deverá visitar o Setor de Ergoespirometria da DMR do HC da FMUSP. Nessa visita você realizará um exame chamado de ergoespirometria que se desenvolverá uma vez fora da água e outras duas vezes dentro da piscina aquecida. Os dias e horários serão previamente agendados. Traga seu traje de banho e material de higiene pessoal.

\section{SALVAGUARDAS}

Você deverá informar ao seu médico sobre todas as doenças atuais e passadas e sobre todas as drogas e medicações que está utilizando no momento. Antes de ser aceito neste estudo você não poderá apresentar determinadas doenças e nem fazer usos de determinados medicamentos.

\section{BENEFÍCIOS}

O teste ergométrico é um procedimento não invasivo que pode conferir informações diagnósticas e prognósticas, além de avaliar a capacidade individual para exercícios dinâmicos. O benefício potencial desta pesquisa é a sua contribuição para a avaliação do teste e sua validação na aplicação em pessoas com problemas cardio respiratório circulatório.

\section{RISCOS E PRECAUÇÕES}

O teste ergométrico é um exame extremamente seguro quando respeitado o risco de eventos relacionado a esse exame Você pode, durante o exame apresentar algum destes sintomas:

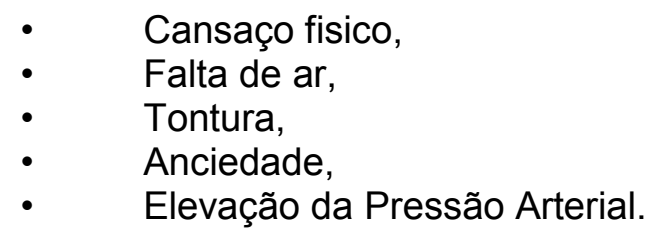

\section{RESPONSABILIDADES}

Você deverá comparecer ao setor no dia e horário agendado para a avaliação programada pelo responsável pelo estudo. Se você tiver qualquer dúvida entre em contato imediatamente com o seu médico. Se, antes, durante ou mesmo após a avaliação você tiver quaisquer reações anormais, informe imediatamente o seu médico, que decidirá o tratamento adequado ou se a avaliação será interrompida ou reagendada.

O estudo de pesquisa, o procedimento de estudo e todas as informações que devem ser dadas aos participantes, inclusive estas informações, foram revisadas e aprovadas por um Comitê de Ética. Este é um conselho independente de indivíduos, que inclui médicos, cuja responsabilidade é garantir os direitos, a segurança e o bem estar dos participantes de estudos clínicos. 


\section{PARTICIPAÇÃO VOLUNTÁRIA}

Sua participação no estudo é totalmente voluntária e você poderá interrompê-la a qualquer momento. Sua decisão de não participar ou de se retirar do estudo não prejudicará nem afetará seu atendimento médico atual ou futuro. Entretanto, se decidir se retirar do estudo, você deverá notificar imediatamente o seu médico. Isto é para sua própria segurança. Você compreende que, se seu médico entender que é de seu interesse que você se retire do estudo, você deverá fazê-lo imediatamente. Se sua condição piorar, seu médico descontinuará a te atender sempre que houver necessidade. Você compreende que sua participação no estudo poderá ser encerrada por seu médico a qualquer tempo, com ou sem o seu consentimento, se julgar isso ser o melhor para você. Essa interrupção, porém só acontecerá após a aprovação da razão pelo Comitê de Ética. Você também será informado de forma oportuna sobre todas as novas informações que possam influenciar a sua intenção de continuar a participar deste estudo.

\section{SEGURO}

Não esperamos que você possa ter problemas de saúde devido a participação neste estudo. Entretanto, esta pesquisa, garante tratamento para todos os problemas médicos que possam surgir em relação à sua participação neste estudo.

\section{CONFIDENCIALIDADE}

Seu médico e as pessoas que trabalham com ele saberão que você está participando deste estudo. Se você tiver um médico de família, este também poderá ser informado. Seus registros (fichas, prontuários e documentos relacionados a este estudo), serão mantidos por seu médico e sua confidencialidade será respeitada rigorosamente. Esses documentos poderão ser inspecionados por um representante do patrocinador ou por representantes de órgão governamentais locais, porém sua identidade será sempre protegida. O termo de consentimento para o manuseio e a divulgação de seus dados pessoais poderá ser revogado. Uma cópia desses dados também será retida no DMR HC. Os resultados finais do estudo serão comunicados aos órgãos responsáveis pelas aprovações poderão ser publicados em jornais científicos, mas seus dados pessoais nunca serão revelados.

Seu médico esclarecerá todas as suas dúvidas. Se tiver quaisquer problemas ou deseja mais informações sobre este estudo a qualquer momento, você poderá entrar em contato com:

Nome do investigador principal:

Prof. Mauricio Koprowski Garcia - Dr. Paulo Yasbek Júnior

Comitê de Ética e pesquisa: HCFMUSP 0532/08

\section{CONSENTIMENTO}

Li e compreendi estas informações, e todos os detalhes para este estudo me foram explicados por meu médico. Tive a oportunidade de fazer perguntas e elas foram respondidas. Tive tempo suficiente para analisar minha participação neste estudo.

Voluntariamente consinto em participar deste estudo e concordo em seguir as instruções de meu médico e em telefonar para ele imediatamente em caso de problemas.

Sei que posso desistir do estudo a qualquer momento sem que isso afete meu tratamento futuro.

Recebi uma cópia das informações e do termo de consentimento.

Fui informado e concordo que representantes do Comitê de Ética, bem como possivelmente autoridade locais do Ministério da Saúde e também de outros países possam verificar os dados registrados em meu arquivo sendo que todos os dados serão tratado confidencialmente e minha identidade será sempre protegida. Ao assinar 
este formulário, dou o meu consentimento para participar deste estudo clínico.

\begin{tabular}{lll}
\hline $\begin{array}{l}\text { Nome do Paciente } \\
\text { (LETRAS MAIÚSCULAS) }\end{array}$ & Assinatura do Paciente & Data
\end{tabular}

$\overline{\text { Nome do Investigador }}-\frac{\text { Assinatura do Investigador }}{\text { Data }}$

$\overline{\text { Nome de quem obteve o consentimento Assinatura }} \overline{\text { Data }}$

CONSENTIMENTO EM CASO DE PESSOA INCAPACITADA

(Em caso de pessoa incapacitada, o representante legal é a pessoa informada que, em nome do sujeito, fornece o consentimento para a participação do sujeito).

Como pai, mãe, guardião, responsável, parente ou outro representante legal responsável pelo sujeito acima determinado, li a Folha de Informação ao Sujeito e, até o limite da compreensão do sujeito, discuti este formulário de consentimento informado. Em nome do sujeito e em meu nome, concordo em assinar e submetê-lo aos termos deste termo de consentimento informado.

Relação com o sujeito: 